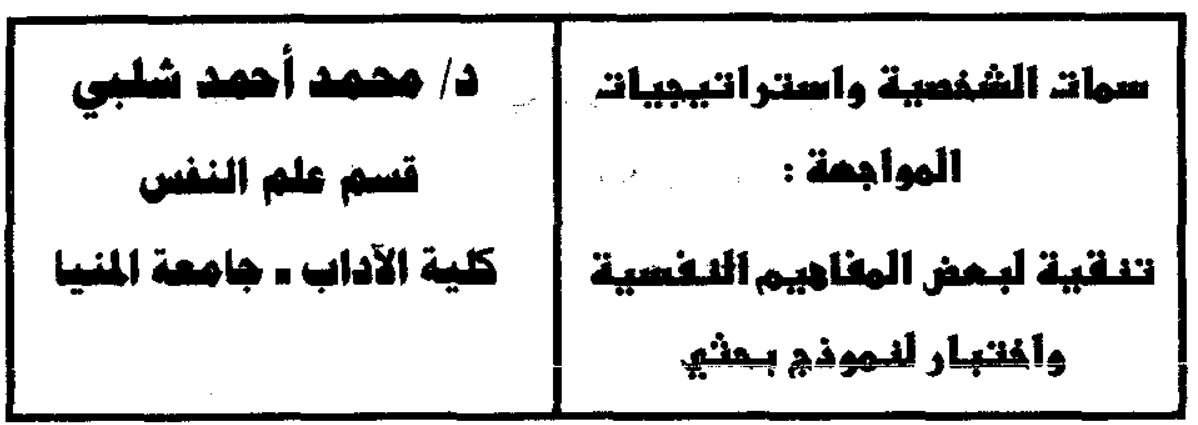

أجزيــث هذه الار اسة على عبينة عددها ـ ع ع من طلبة وطالبات

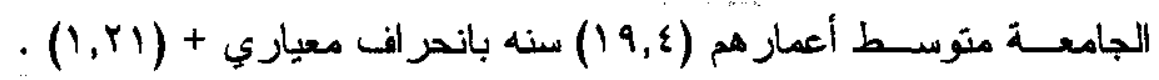
تهدف الار اسة الحالية إلمى وضع تعريفات دقيقة ومحددة (وضيقة) لكل من

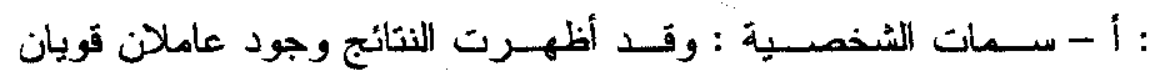
للإنفعالية (العصابية) و الإنبساط مقارنة بالدر اسيات العربية السابقة . ب- باسـتر اتيجيات المواجهة : وقد تم اقتراح فصل المفهوم الى أربعة مكونات

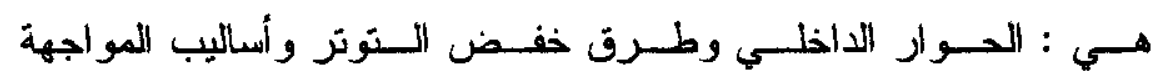
و اسـستر أتيجيات المو اجهــة ، وقسـد تم أيضلا اقتز اح نموذج بحثي لار اسة العلاقسات بين سمات الشخصية و استز اتيجيات المو اجهة مع التركيز على

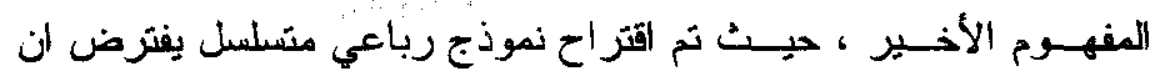
مكونسـات اســنز اتيجيات المواجهة متسلسلة وقد تم اقتراح الحوار الداخلي (الإيجابسـي و السـلبي) باعنـباره في مقدمة التسلسل بل لإن النتائج توهي بالــنظر إلــى هــا المكون باعنبازه أُحد المكونات المعرفية - الإنفعالية لمفهـوم الثخصــية ، وقد تم اقتر اخح طريقة جديدة للدرجات على مقياس الحو ار الداخلي ، وأظهرث النتائج وجود نلانثة أنماط للحو.ر ار الداخلي الأول ليجابي خالص (P I D) و الثاني السلبني المقاوم (M I D) والثالت السلبي

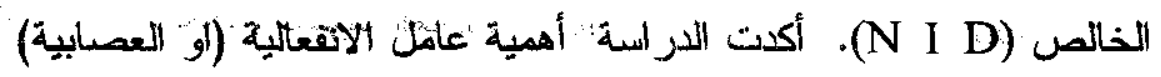




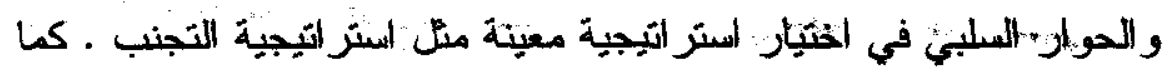

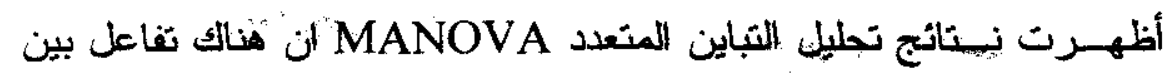

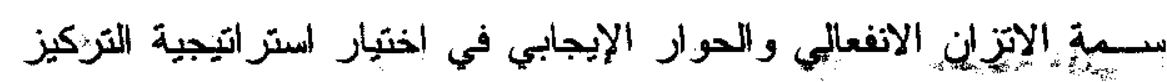

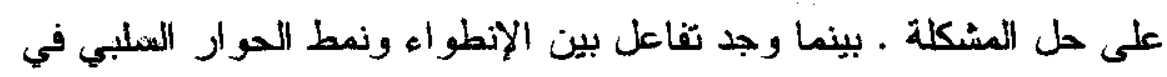
الغيتيّار أستر التيجية التجنب.

حظي موضوع سمات الشخصية واستر اتيجيات المواجهة باهنمام

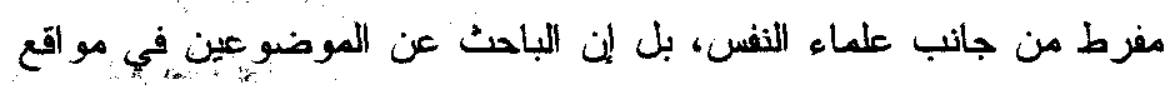

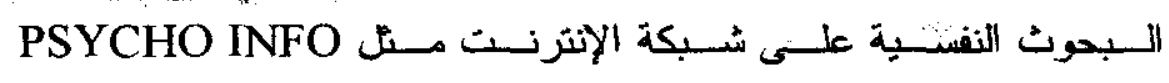

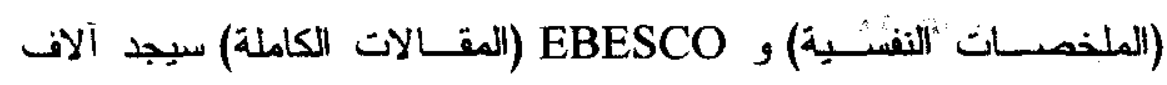

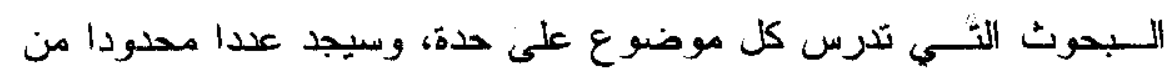
البحوث الثي تدرس العلاقة بين سمات الشخصية واستر اتيجيات المو اجهة.

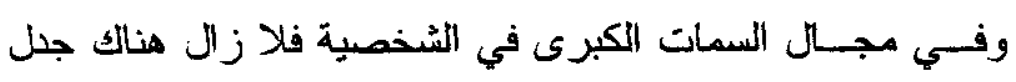

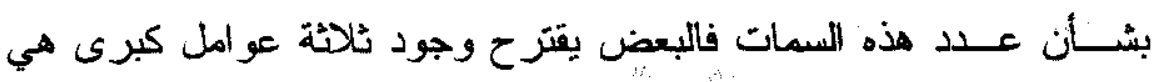

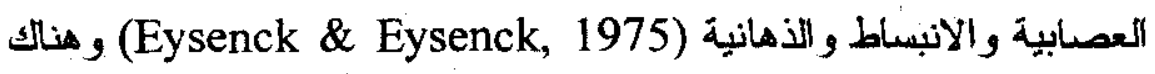

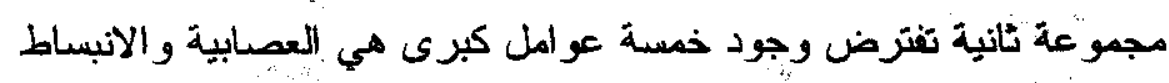
والالتزام Conscientiousness والعشرية (السماحة) Agreeableness (Norman, 1963; Costa \& McCrae, والتفـتح على الخبرة 1988; McCra \& Costa, 1985)

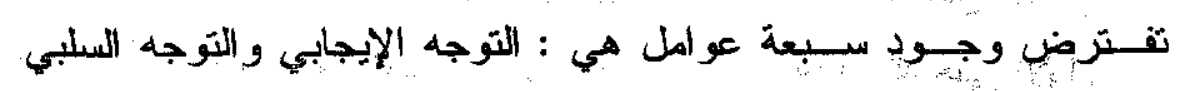

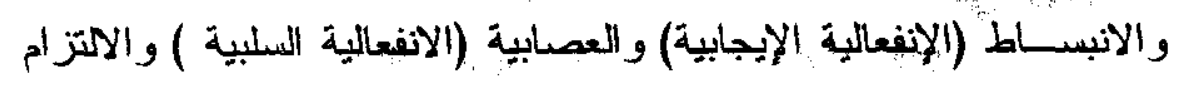

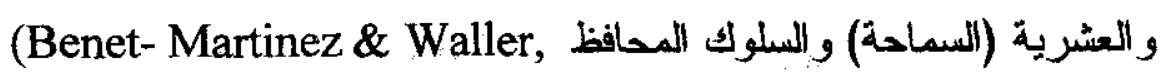


1995, Tellegen, et al., 1991)

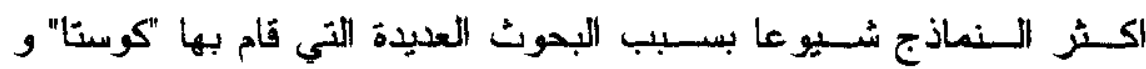

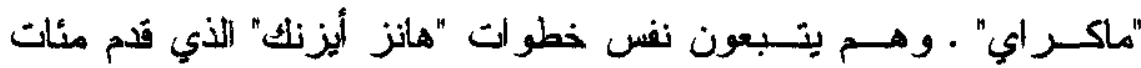

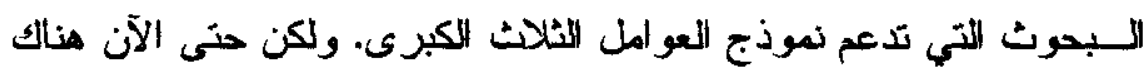

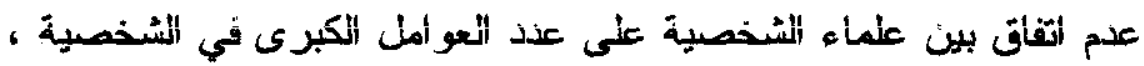

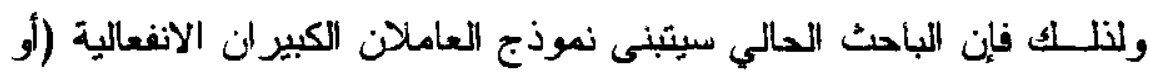

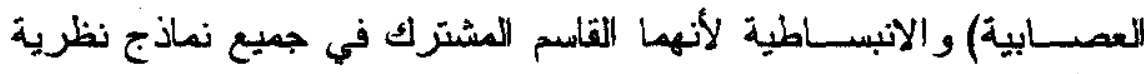

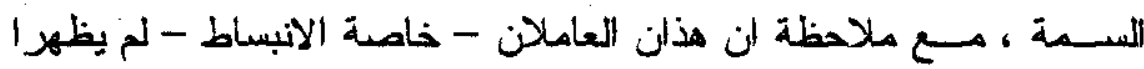

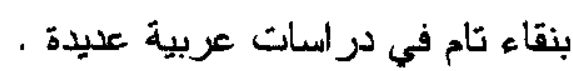

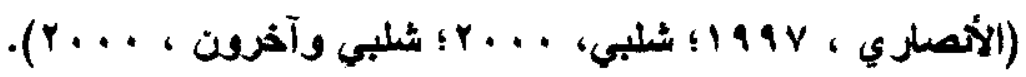
كما يوجد عدم اتفاق بشأن العوامل الكبرى في الشخصنية فهنالك -

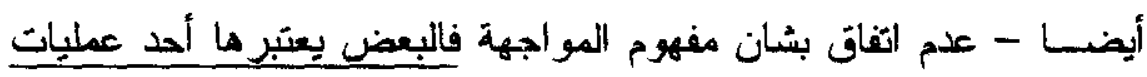

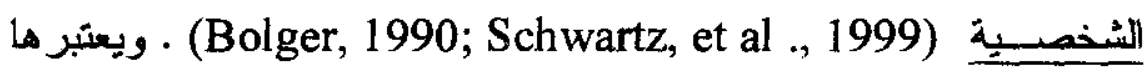
آخـرون أفكار وسلوكيات (Folkman \& Moskowrtz, 2004) بينما

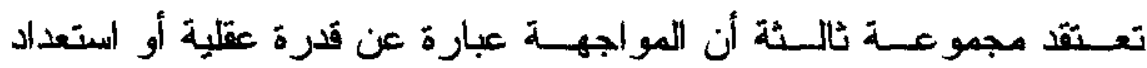
(Epstein \& katz, 1990; Carver, Scheier \& Weintraub,

بـلـل أن هـــاك عـدم اتفاق بشأن تعريف المفهوم فالبعض يضع

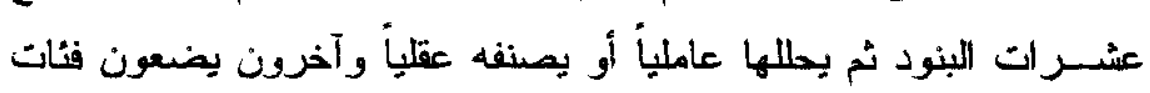

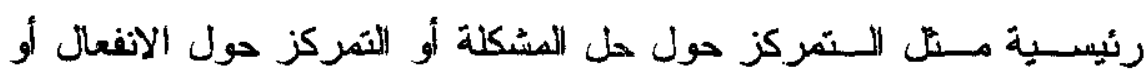
(Skinner et al ., 2003; Pearlin \& Billings, 1982; التجنـبـ 
Folkman \& Lazarus, 1980; 1984; Levneh \& Liveneh,

وهناك اختلافات بشأن مكونات استر التيجيات المو اجهة وذلك بسبب

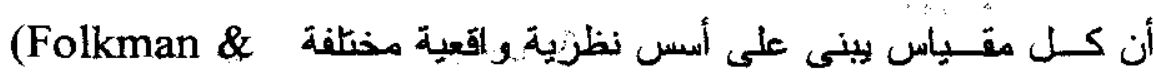
Lazarus, 1980; 1988; Moos, 1993 ; Amirkhan, 1990;

.Endler \& Parker, 1990)

و.فـــد أدت هذه الاختلافات حول المفهوم وطرق قياسه إلى عدم

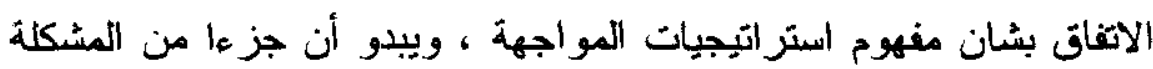

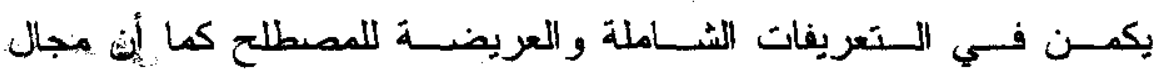

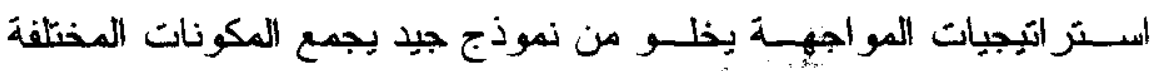

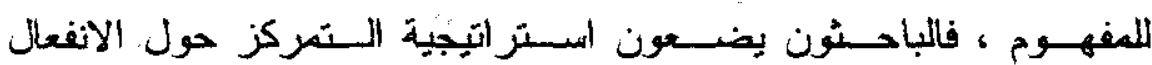
واستراتيجية التمركز حول الحل والتجنب والمساندة الاجتماعية في مقياس

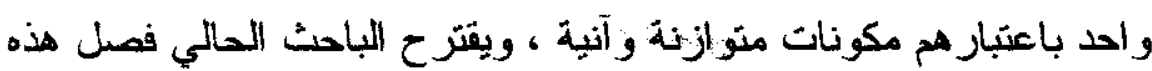

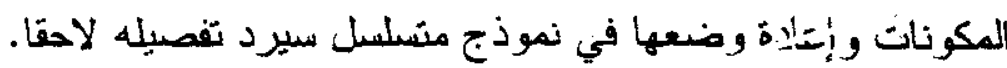

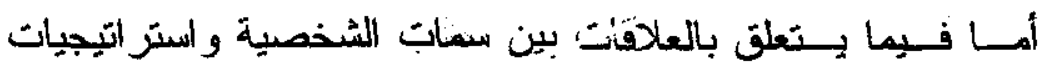

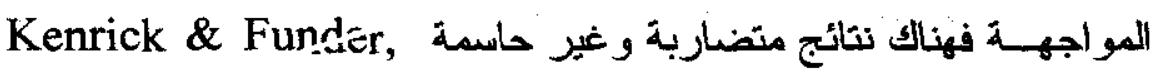
1988; Vickers, Kolar \& Hervig, 1989: Parkes, 1986; .Folkman \& Lazarus, 1980; 1985; Folkman, et al ., 1980 مما أدى البى ندرة البحوث حول العلاقة بين سمات الشخصية والمو اجهة . 


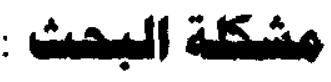

تكمن مشكلة البحث في النقِياط التالية :

1- أســتخدام علماء الشخصية لمفاهيم عريضة وشباملة لوصف سمات

الشخصسـية الكـبرى ، ويحاول الباحث في الدراسدة الحالية وضع تعسريفات ضسيقة ومحددة مع التركيز على العاملين الكبيزين في الشخصدية (الانفعالية والانبساط) في محاولة لاستعانته في الثقافة

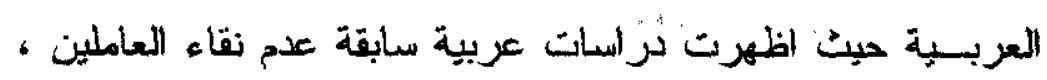

$$
\text { وبطر حللك تساؤ لات هامة هي : }
$$

أ- - هـل تحديـد (تضييق) مفهوم الانفعالية سيؤدي إلى زيادة

$$
\text { تشبعات البنود على عامل الانفعالية" }
$$

ب- - هـلـ تحديسد (تضييق) مفهوم الانبساط سيؤدي الى زيادة

$$
\text { تشبعات البنود على عامل الاثبساط؟ }
$$

Y- تثمستل المشـكلة الأنية في الاستخدام الأني (المنوازي) لمكونات

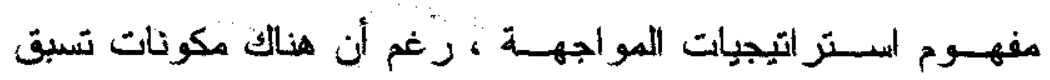
مكونات أخرى ، ويطرح ذللك ثناول هام و هو : هل سيؤدي فمل هل

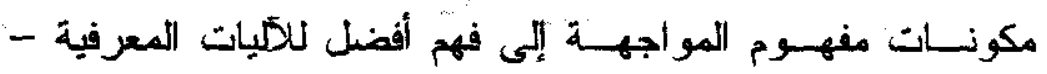
الاثفعالية للمفهوم ، كما اقترح الباحث نموذج بحثي متسلسل لذر اسة مفهوم استر التيجيات المو اجهة. 


\section{أهداف الدراسة :}

ويمكن تحيد أهداف البحث على النحو التالي :

1- إعادة تعريف وتحديد مفهوم العصابية.

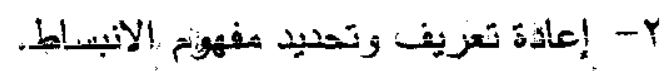

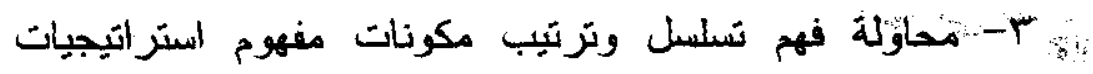

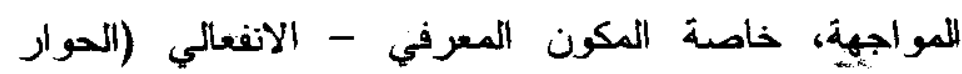

الداخلي)

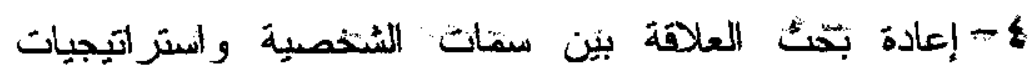

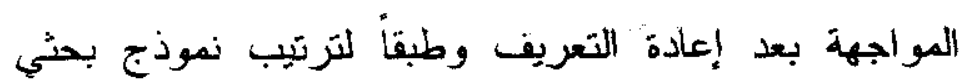

بقترحه الباحت الحالمي.

\section{أهمية البدراسة :}

بيتبر تثقية بعض مفاهيم علم النفس ومنها مفاهيم أبعاد الشخضية

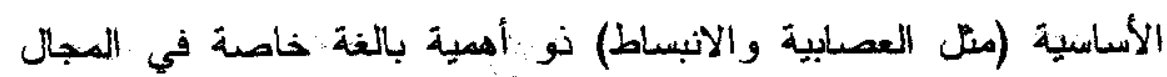

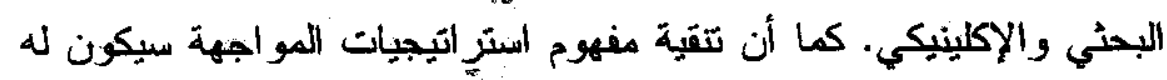

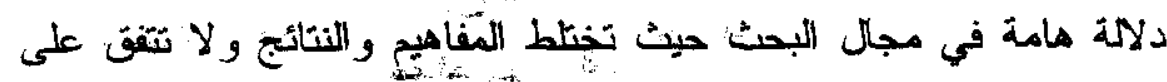

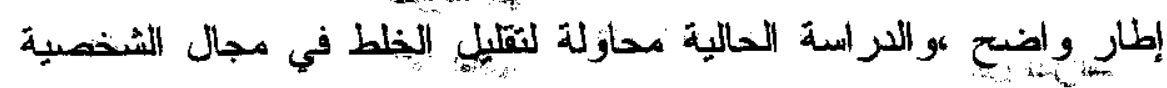
و استر التيجيات المو اجهة. 


\section{الفلهيم الأنساسية في الدراسة}

\section{السمات الكبرى في الشخصية}

هــاك عـدة نوجهـات فيما ينطلق بالسمات الكبرى في الشخصية وأهمه السمات الثلاثة الكبرى و السمات الخمسة الكبرى و السمات السبعة فئاك الكبرى.

\section{أولاً : السمات الثلاكة الكبرى :}

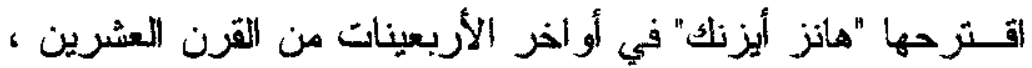

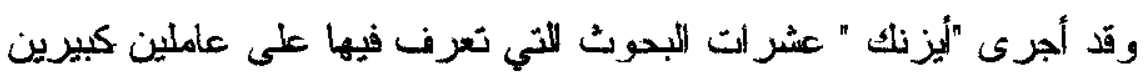

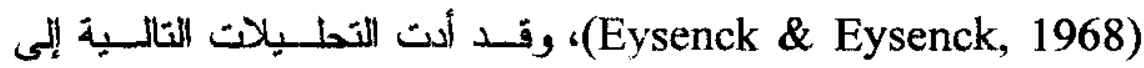

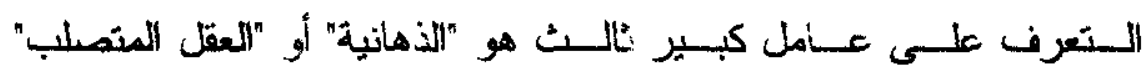
(Fysenck \& Eysenck, 1975)

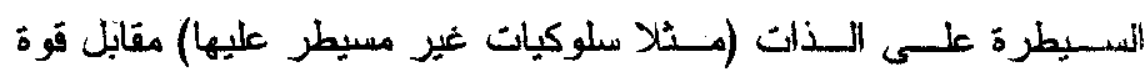
السيطرة على الذات (Digman, 1990; Watson \& Clark, 1993).

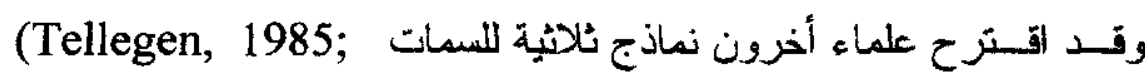
.Gough, 1987; Watson \& Clark, 1993) ورغــم الفـروق الجوهزية في المصطلحات و التفسيرات فإن هذه النماذج ثقتر حسات رئيسية هي : أ - العصابية (أو الانفعالية السلبية ) ب- الانبساط (أو الانفعالية الإيجابية ) 
ج- السـبطرة علسى الذات Tellegen, 1985; Watson \&

.Clark , 1993; Watson et al ., 1994) ثاتيا : السمات الخمسة الكبرى :

(Allport \& Odbert, "يرجع أساسها إلى "ألبورت" و "أودبرت

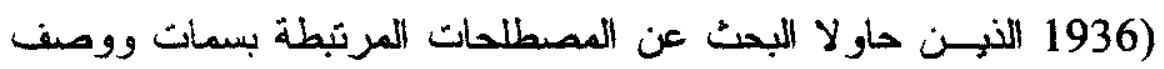

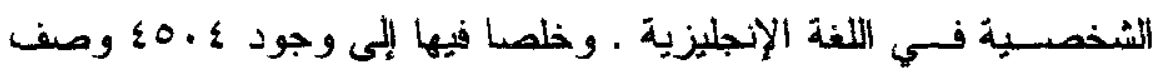

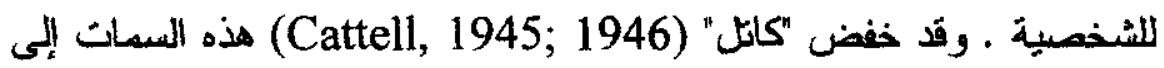

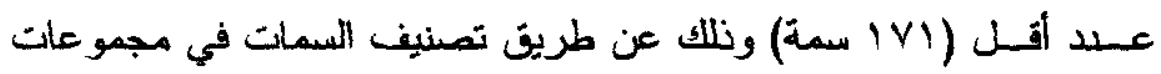

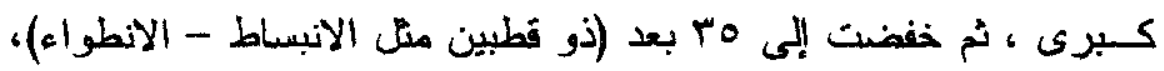

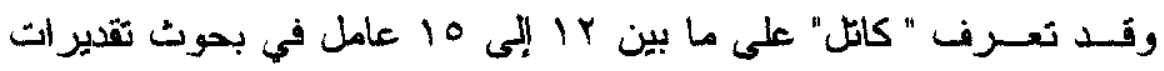

الأمران عند وصفه لثنصية من يعرفونهم.

وقد نبعت اللعو امل الخمسة من تحليلات تقديرات الأمران، وظهرت

(Digman \& Inouye, 1986; Norman, بقوة في العلبد من البحرث 1963; Norman \& Goldberg, 1966; Tupes \& Christal,

كما ظهرت العوامل الكبرى في دراسات حليثة استخدمت التقارير الذاتسية والاسـتخبارات \&crae \& McCrae, 1988; McCrae

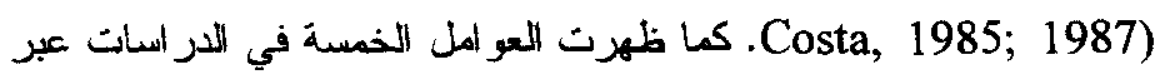
الثقافية) (John, Goldberg \& Angleitner, 1984)

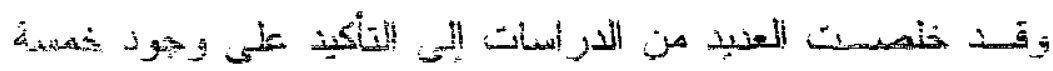


أ- المصـسابية (الإتزان الانفعلمي). ب- الانبساط (أو الصخب).

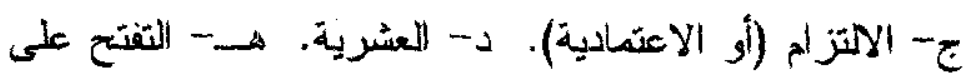
الخبرة (أو التخيل أو الذكاء أو الإقافة).

(Borgatta, 1964; Fisk, 1949; Norman, 1963; Tupes \& Christal, 1992)

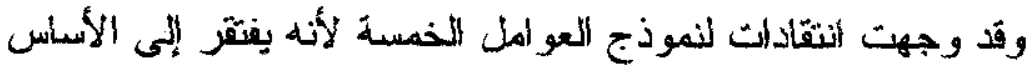

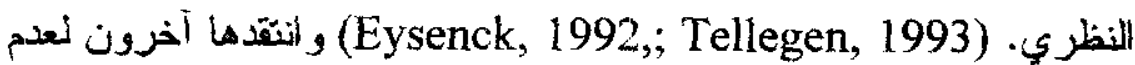

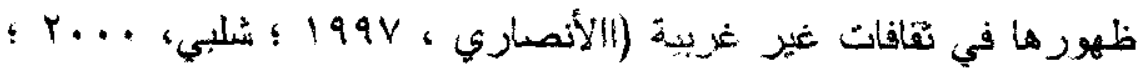
شنبي وآخرون ، ... (Y).

ثالثا : العوالمل السبعة الكبرىى :

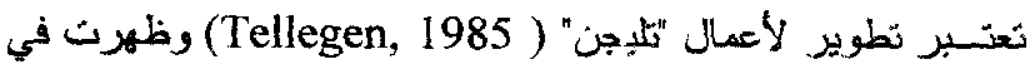

Benet-Martinez \& Waller, 1997; عـد مسن الأر اسات الحسيثة 1995 Tellegen, et al ., 1991)

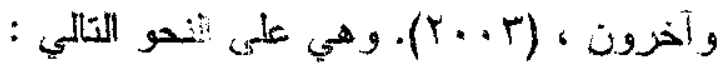

1- التوجه الإيجابي : ويشير اللتميز والتقوق. ب- التوجه السلبي

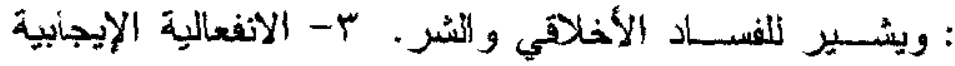

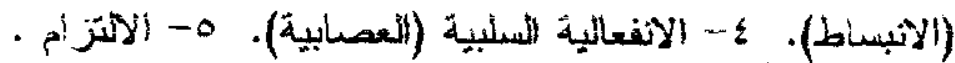

1- العشرية. V- السلوك المحافظ (التمسك بالثقاليد).

وبنظرة فلحمة لبعض الدراسات التي اهتمت بتحليد عدد العوامل

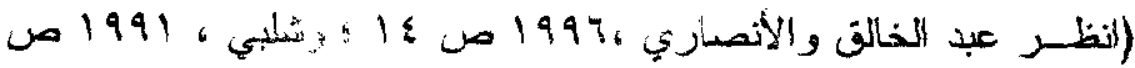




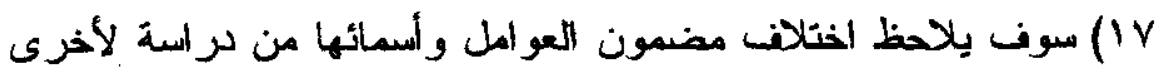
، مئلا هذاك عدد كبيز من التعريفات بشأن مفهوم العصابية والانبساط.

\section{أولا : تعريفات المصابية :}

يشير أيزنك إلى الثخص العصابي النموذجي بأنه :

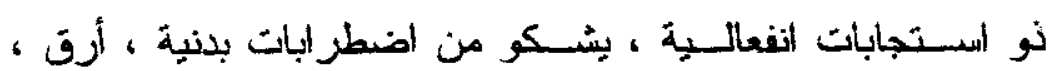

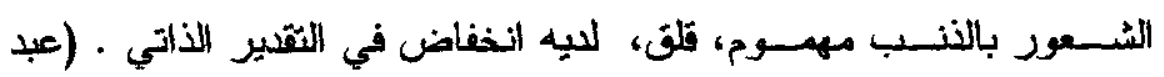

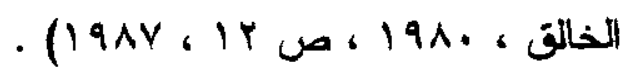

بينما يعرفه " كوستا" و "ماكر اي" ;Costa \& McCrae, 1978)

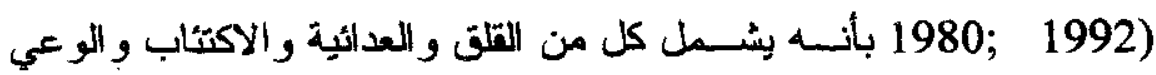
بالذات والاندفاعية والاستهداف وعدم القناعة.

كمــا يعـرف " بينت " و "و الر" العصابية (الانفعالي السلبي) بأنها

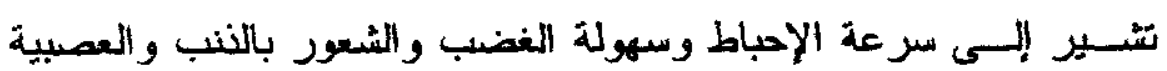

وسهولة التهيج (Benet \& Waller, 1995).

ولكسن هنالك ملاحظة هامة للغابة هي أن بنود المقاييس التي تقبس

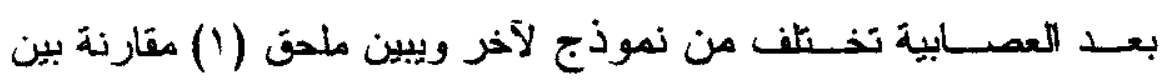

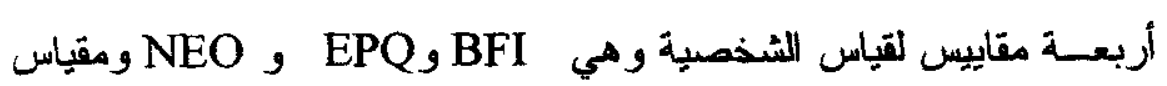

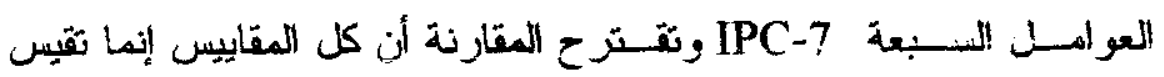

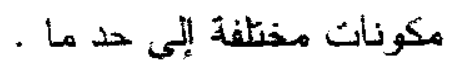




\section{ثاتبا : تعريفات الانبساط :}

ومسـا بنطــبق علـى العصابية بنطبق على مفهوم الانبساط(أنظر

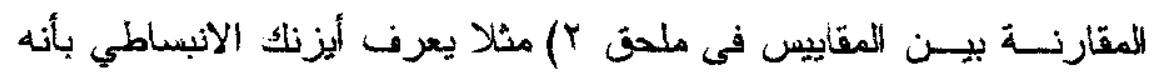

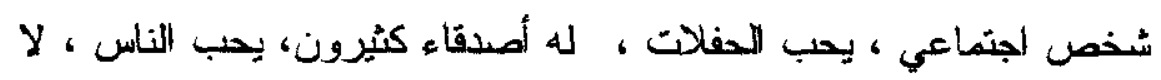

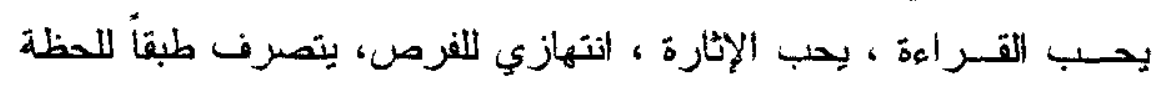

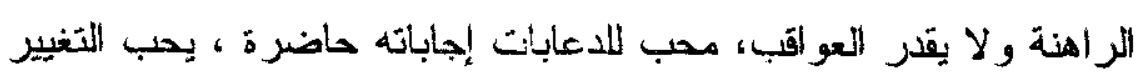

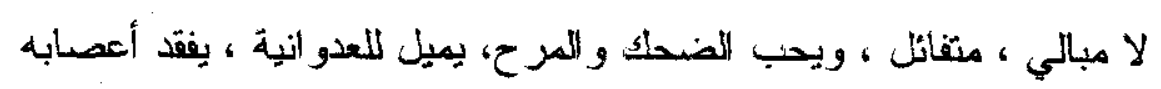

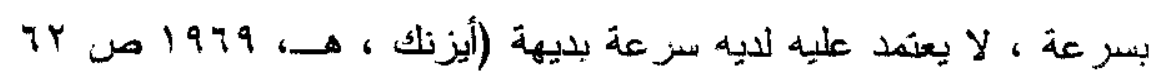

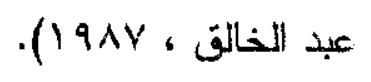

بينما يعرف " كوستا "و "ه اكر ابي" ;Costa \& McCrae, 1978)

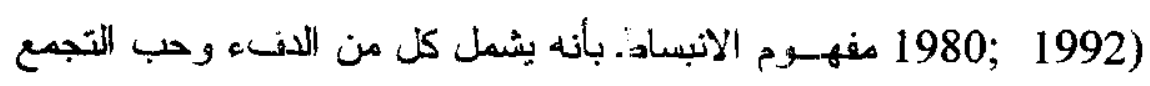

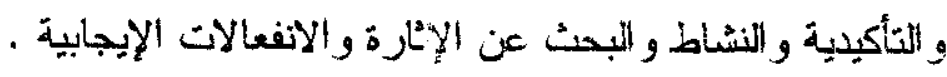

كـــا يعرف "بينت" و "و الر" الانبساط (الانفعال الإيجابي)

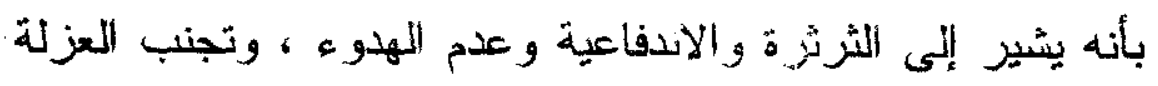
وعدم التحفظ (Benet \& waller, 1995).

ويذكــر "ماكر ائي" وآخرون (McCrae et al., 2004) أن سمة

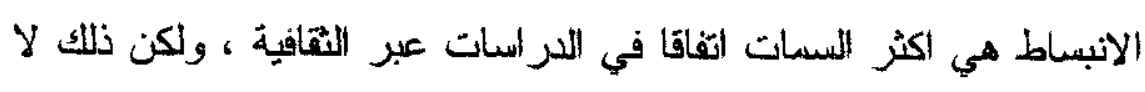

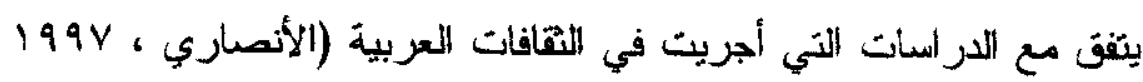

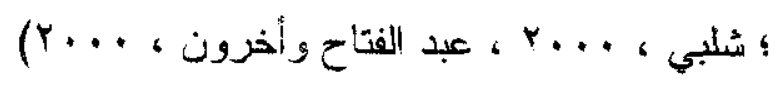




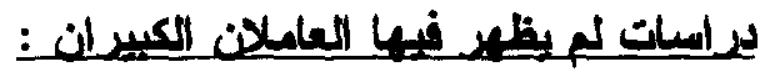

في دراسمة لــ "بلاس" و "فورزي" ظهرت لايهه ثلات عو امل كبرى

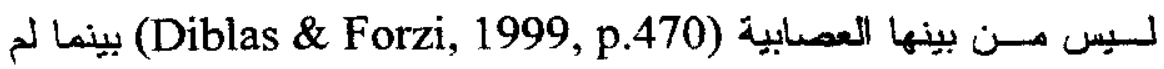

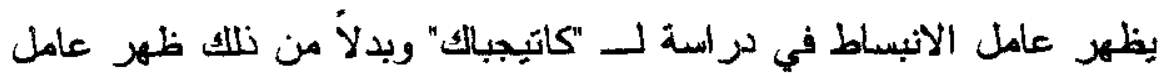

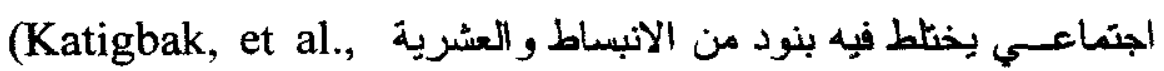
.1996, p. 104)

ولـــم يظهـر عامل الانبساط في دراسة لــ "شيونج" حيث ظهرت

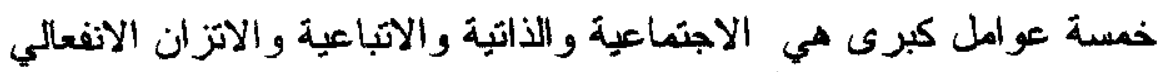
والعشرية (Cheung et al., 1992). وفــي دراسة أخرى لم بظهر العاملان الكبيران بصورة نقية وبدلاً من ذلك ظهر عاملان العامل الأول الشتمل على بنود من العشرية والالمتزام والاتــزان الانفعالي واشتصل العامل الثاني على بنود من الانبساط و التفنح

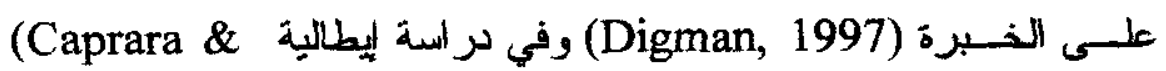
لـ لـ يظهـر عامل العصابية ـ وفي دراسة عربية لم يظهر عامل نفي للانبساط (الأنصاري، 1997) وفي دراستين مصريتين

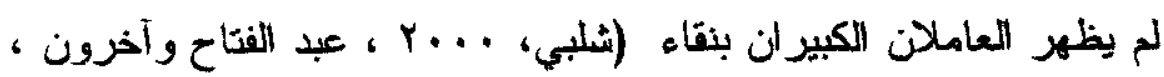
. (r...

وهسناك العديد من الدراسات الكلاسيكية الهامة لم يظهر فيها عامل (Fisk, 1949; Tupes \& Christal, 1961; Borgatta, الانبسـساط 1964 ; Noman 1963; Hogan, 1986; Pebody \& Goldberg, : 1989; Lor, 1986) 
1991) إلـى انخفاض تثتبعات اللبنود على عامل الانبساط حيث ظهر في

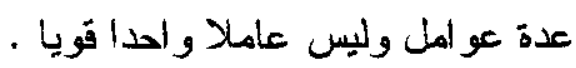

كمــا أن هناك دراسات أخرى كلاسيكية هامة لم يظهر فيها عامل (Cattlell \& Coan, 1957; Hogan, 1986; Pebody \& العصابية

.Goldberg, 1989; Botwin \& Buss, 1989)

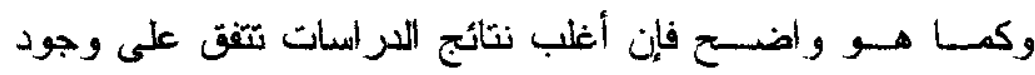

العامليـن الكبيزيسن إلا أن هناك دراسات لا تدعم هذه النتائج ، ويبدو أن أني

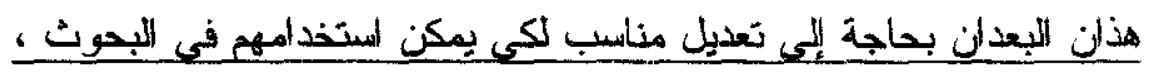

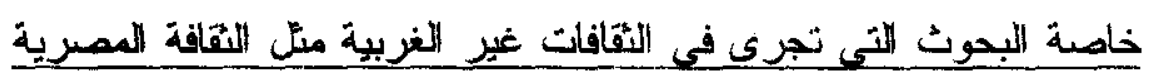

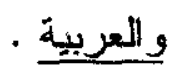

وهــا ما لقعنا نحو إعادة تعريف مفهومي العصابية (عدم الاتزان

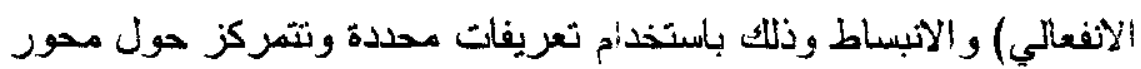

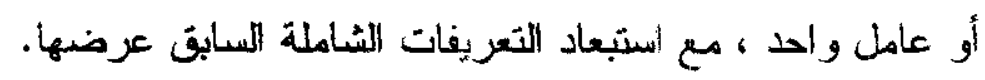

\section{هفوم استراتيجيات المواجهة}

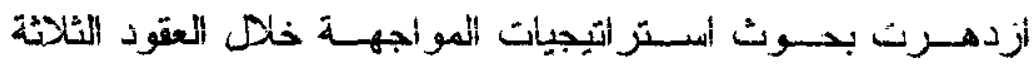

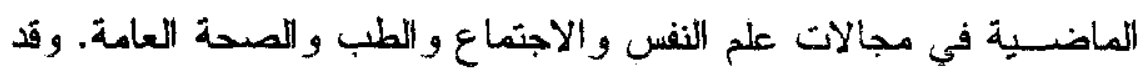

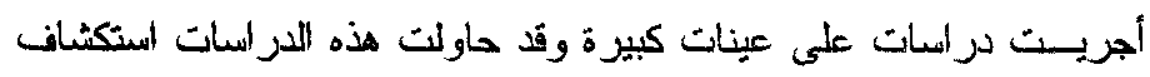

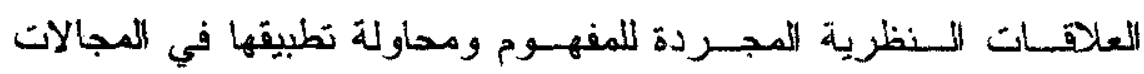

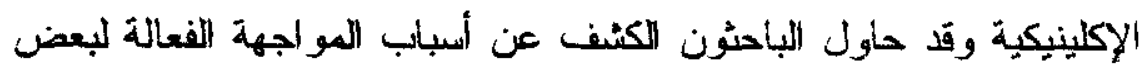

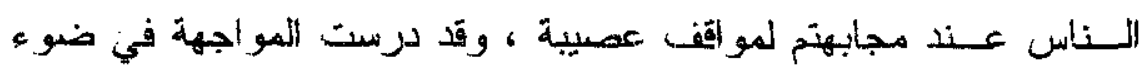
مفاهيخ أخرى مثل الثقافة والارئقاء و الثخصية. 
ويعـود المفهـوم الى بداية القرن العشرين حيث قدم "فرويد" إطار

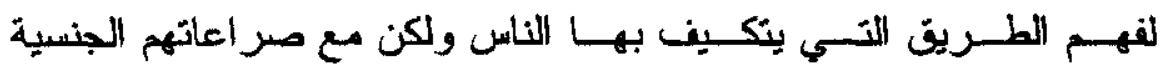

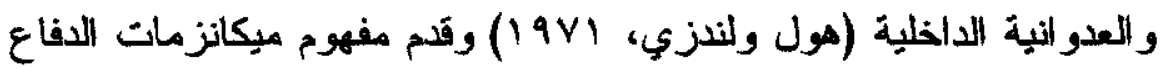

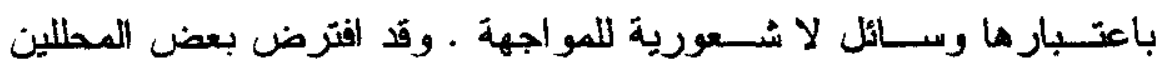
النفسيلين بعسد ذلــك التهيدات الخارجية باعنبار ما مضدر من مصار

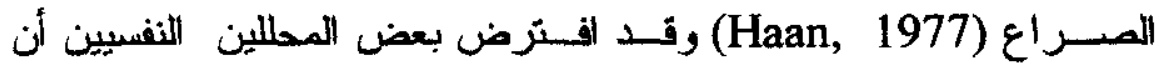

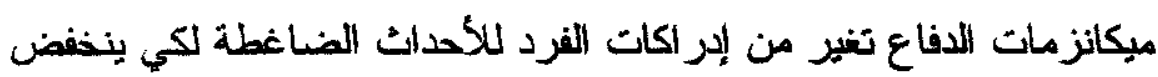
الكرب (Vaillant, 1994) وقد اتمزرح "فيلانت" (Vaillant, 1994) أن فيكان ميكانزمات الدفاع تنظم في ترتيب هرمي وأطلق على بعضها مبكانزمات

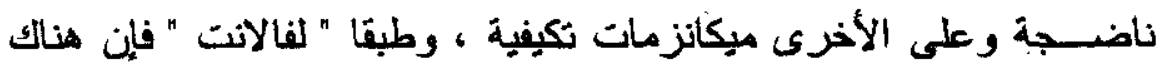
أربعة مستويات لدفاعات الأنا : الاخدي

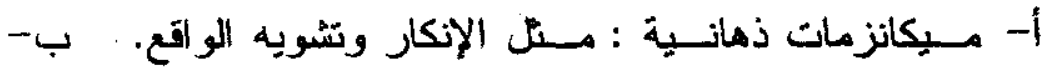

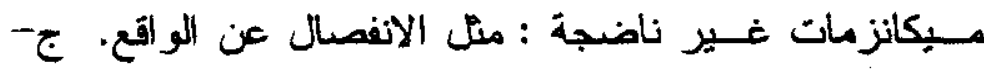

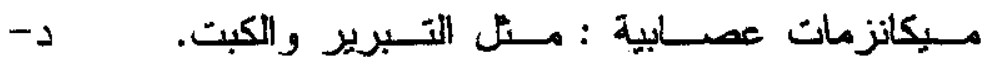
ميكانزمات ناضجة : مثل الضحك والتسامي.

ويعـتقد "فالانــت أن المسيكانزمات الناضجة هي فقط الواقعية .

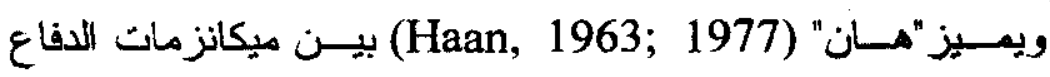

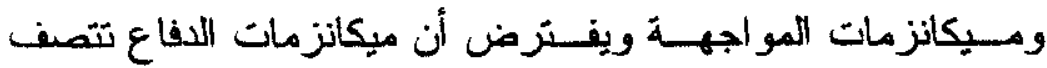

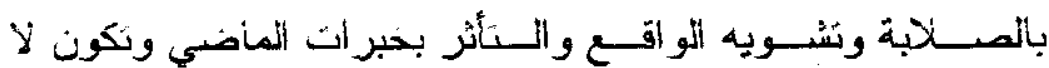

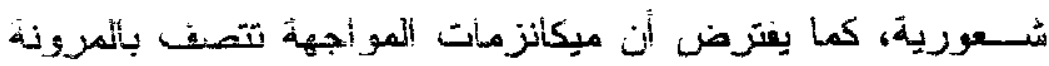

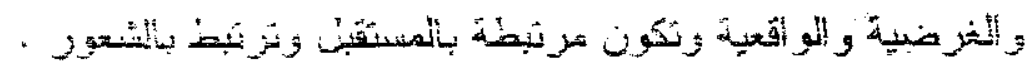


ويعتسبر "ريشــارد لازاروس" (Lazarus, 1966) أول مسن قدم

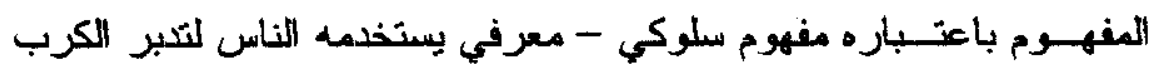
وتحديد المشكلات في حياتهم اليومية وتؤكد نظرية "لازاروس" على دور

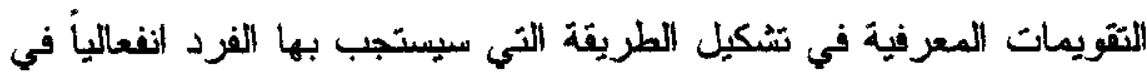

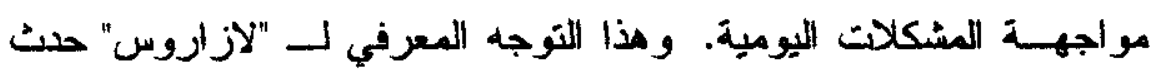

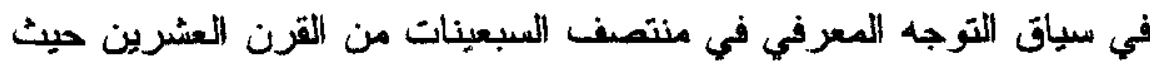

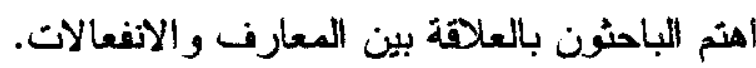

وكنلــك عندا ازداد اهنعام الباحثون بأثر أحداث الحياة فإنهم نقلوا

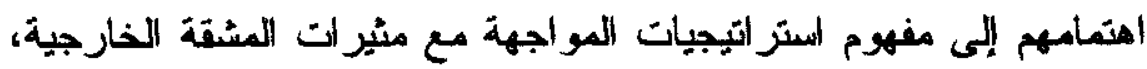

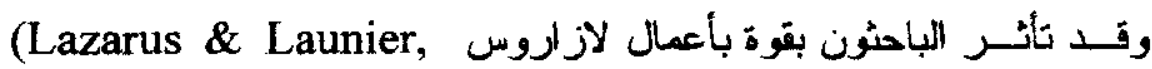
(1978 والـــي ركــز علــى دور التقويم المعرفي في تشكيل أستجابات

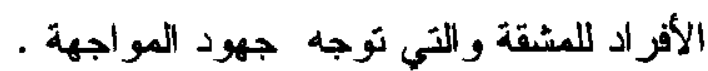

وتعـرف المو اجهة بأنها جهود سلوكية ومعرفية يفعلها الفرد لكي يسـبطر أو يستحمل أو يخفض الأعباء الثي ترهن أو تزيد عن إمكانيات (Pearlin \& Schooler, الفرد عند مو اجهته لمشكلات وضغوط نفسية . 1978; Cohen \& Lazarus, 1979)

وتعرف "فولكمان" و "موسكوفيتس" Folkman \& Moskowitz)

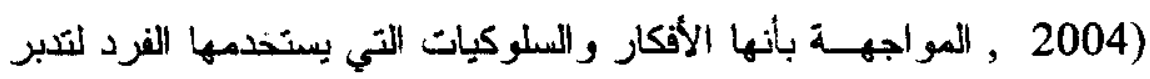
manage الاحنــيأجات الداخلية والخارجية للمواقف التي يقيمهن عنى انها

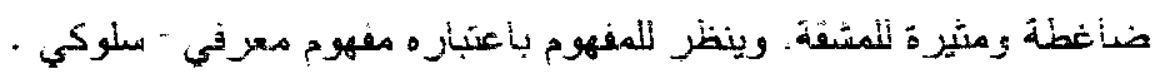

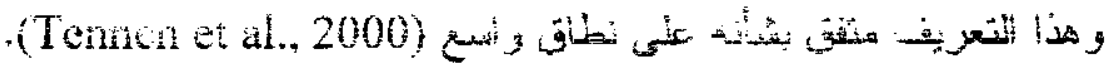


ويعتقد بعض الباحثين أن أستر اتيجيات المو اجهة هي إحدي عمليات الشُخصـية (Bolger, 1990; Schwartz, et al., 1999) بيـنما بنظر (ability) البعض (Epstein \& Katz, 1999) للمو اجهة باعنباز ها قلمرة يذكر سكنر و آخرون (Skinner, et al., 2003) أن هنالك منحيان رئيسان بيتخدما عند البحث عن مكوناث المواجهة هما : ا-منحنى القاع - القمة (استقرائي). - ب-منحنى القمة - القاع (استتاجي). في المنحي الأول يتم تجميع بنود كثيرة ثم بيتم تصنيفها عن طريق التحليل العاملي أو التصنيف العقلي المنطقي وفي المنحى التاني يتم وضع فئات عليا منل التجنب والتمركز حرل الانفعال و التكبف.

(Folkman \& Lazarus, "وقد افتزض "لاز اروس" و "فولكمان 1980; 1984; Lazarus, 1966) التمركز حول الانفعال. ب- التمركز حول المشكلة.

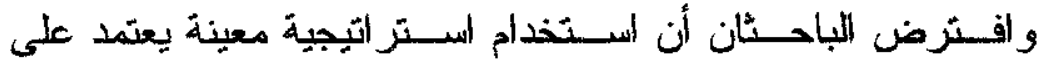
تقديسرات الفزد للموقف. وفي المو اقف التي يقلر ها المزرد بأنها قابلة للتغير فإنسه يســخدم السـتر اتيجيات التمركز حول المشكلة وبلمي النقيض فإنه يستخدم استراتيجيات التمركز حول الاتفعال في المو اقف الآي تكون صعبة التغيير · Folkman \& Lazarus, 1986; Lazarus, 1966: Lazarus) .\& Folkman, 1984; Schwartz \& Stone, 1993) ويفترض بعض الباحثين (Pearlin \& Billings, 1982) وجود

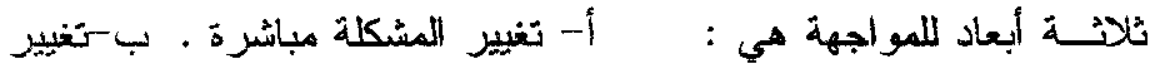
طريقة رؤية المشكلة . ج- تدبر الكرب الانفعالي 
(Parker \& Endler, 1992)

لاسـنز اتتجيات المواجهة باعتباره وسيطة بين المثذمات (أحداث المشقة )

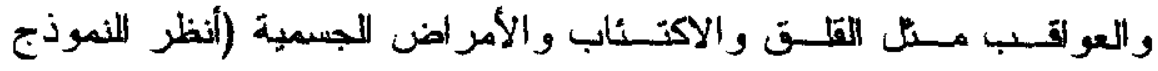

الرباعي المقترح في الدراسة الحالية).

ويفـترض "ليفنة "و "ليفنه" (Livneh \& Livneh, 1996) وجود ثلاثنة

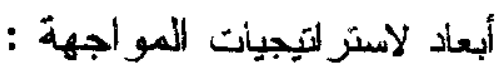
|- المواجهة الفعالة مقابل الإنكار و الهروب.

ب-البحث عن الدعم الاجتماعي مقابل للبحث عن الراحة في اللين. ت-عدم الانشغالل المعرفي مقابل الانشغال الوجداني.

(Tamres, k., وفـي براسسة موسعة أجر أها "تامرس" وآخرون

Denise, J. \& Helgeson, 2002)

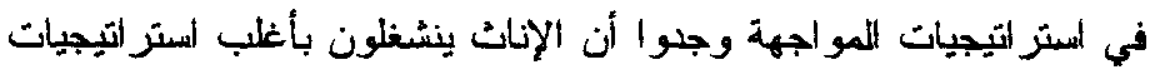

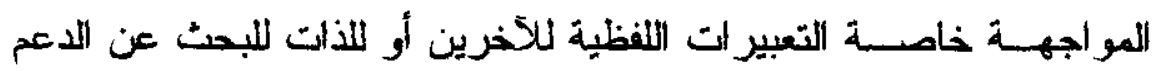

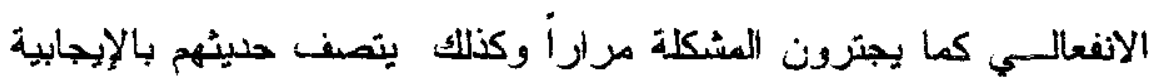
تجساه الـذات وتفــرض مهـذه النتيجة وجود استعداد داظلي لدى الإناث

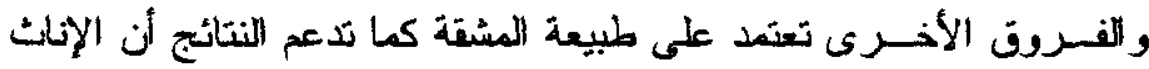

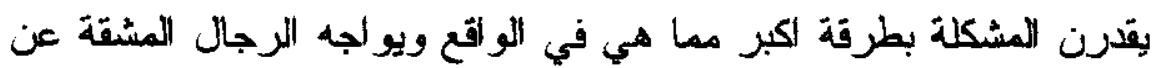

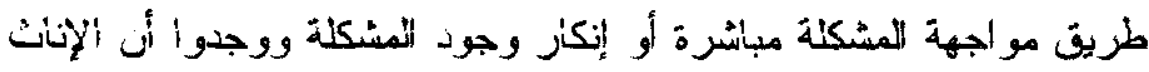

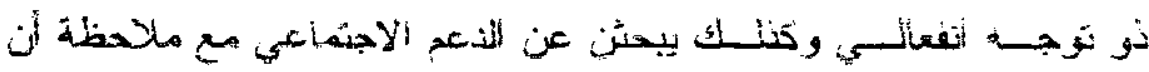

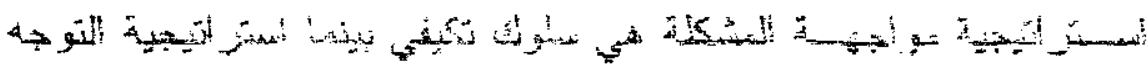

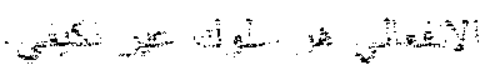


فـي مراسة "لبيرلين" و "تشولر" (Perlin \& Schooler, 1978)

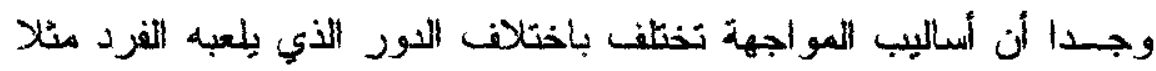

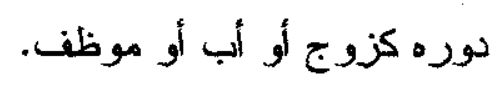

وتوصل "شانج" (Chang, 1996) إلى وجود عاملين الأول امتحان

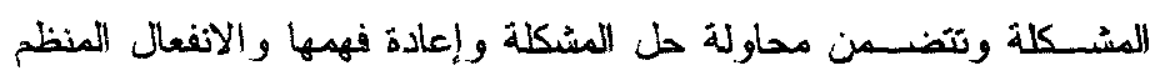

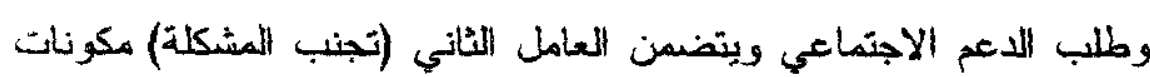

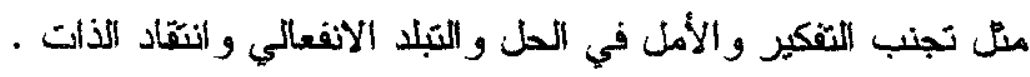

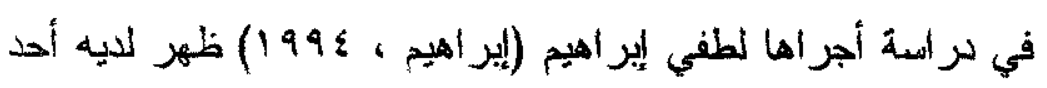

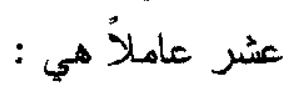

1- السلبية. ب - الانسحاب المعرفي. r- البحث عن المعلومات

$$
\text { والدعم الاجتماعي. }
$$

ع - إعادة التقسير . م- التفكير الإيجابي. Y- التحول إلى الدين. V V

- التنفيس.

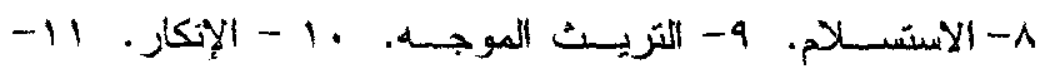

المواجهة النشطة.

(Tamres, Denise \& Hilgeson, ويستعرض "تامرز" و آخرون

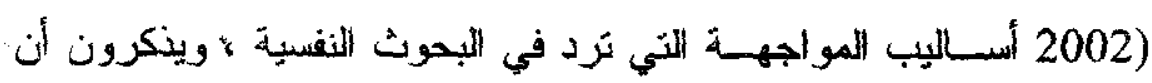
هنآك V ائزة تتضوي تحث هذا العنوان وهي كالآتي : 


\section{أولا : سئوكيت متيكزة حله المشيكية :}

وهي السلوكيات التي تهذف إلى إيدال مثيرات المشقة ولها مكونان:

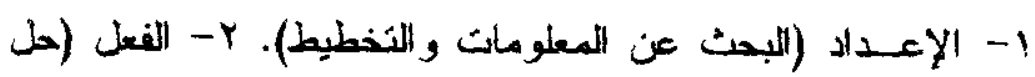

المشكلة و اللتعامل النشط).

الــتعامل النشط يشمل جهود الغرد التغيير أو إلزالة

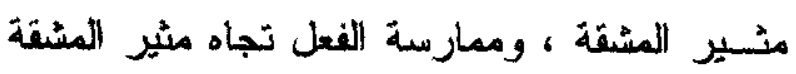

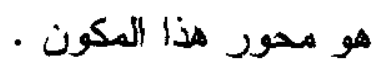

(ب) التخطيط: : تشمل جمع المعلومات ومراجعة الحلول

، وكنلك النية لاتخاذ عمل معين تجاه المشكلة .

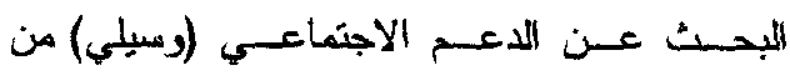

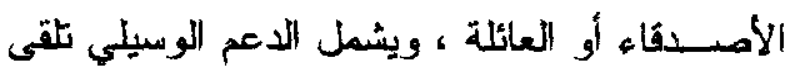

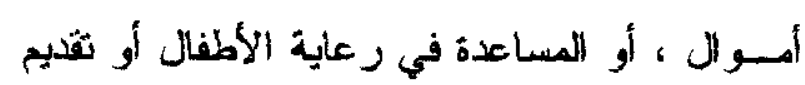

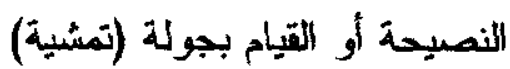

السـتر التيجية الستمركز هـول المشكلة (عام) :

السلوكيات السابقة تذكرها كثنبر من البحوث تحت

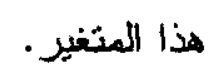

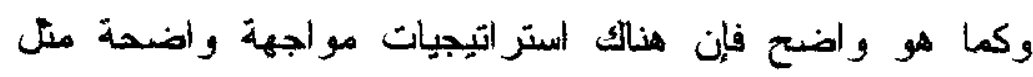

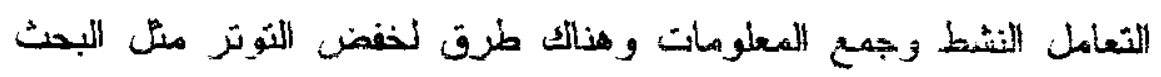

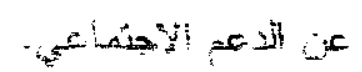




\section{ثُانيا : سيلوكيات متصركزة انفعلياُ :}

ثهـدف إلى تغيير استجابة الفرد نحو مثير ات المشقة و السلوكيات

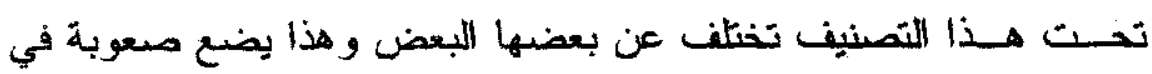

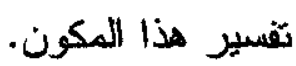

فالبعض يصنف استر اتيجية التمركز الانفعالي باعتبار ها نوليفة من البحسـث عسن الأدعيم والتتفيس Venting بينما تولف دراسة أخرى بين

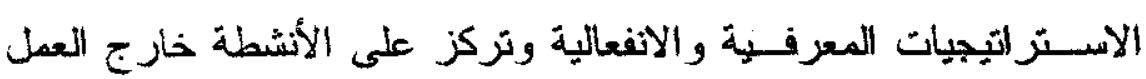

$$
\text { و الحصول على الأجاز ات و الراحات البحثي. }
$$

ب-التجنـب : جهـود الفرد للتشتيت وتجنب المشقة ويشمل نلك

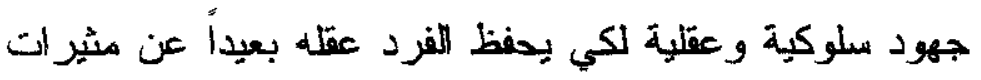

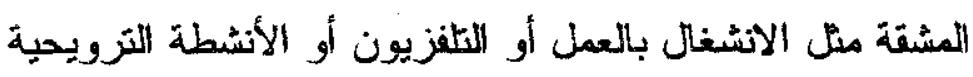

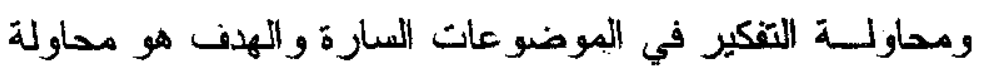
لعدم التفكير في المشقة وتجنب مثير المشقة نفسه. ت- الإنكار : إنكار وجود مثير ات المشقة والابتعاد معرفياً عن

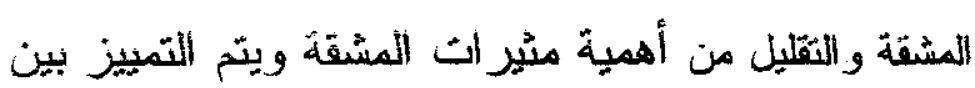

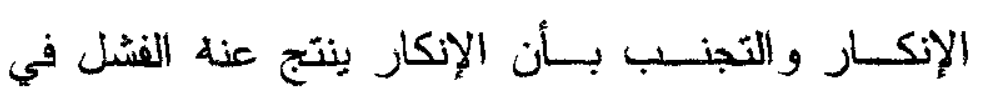
الاعتر اف بوجود المشكلة بينما التجنب بنتج عنه تجنب مشكلة معروفة 
ث-إعـادة الــنقدير الإيجابي : Positive reappraisal : يشمل

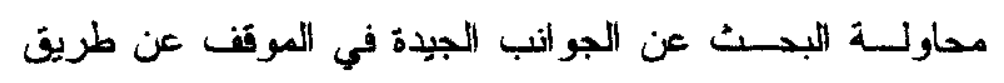

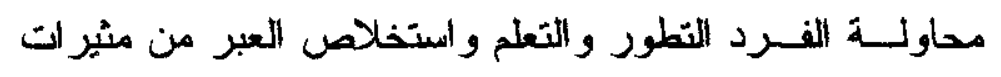
المشقة. ومصطلحات مل إعادة البناء المعرفي و إعادة التشكيل

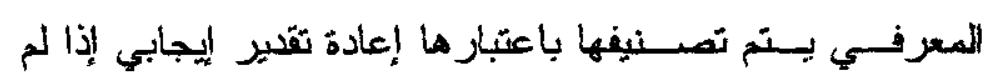
يتضمن نلك إنكار للمشقة. ج- العـزلة Isolation : وتتــير إلـى عدم الحنيث عن المشتقة وتجنب الناس بصفة عامة.

ح- التتفـبس Venting: إطلاق الانفعالات والتهور وكذلك البكاء

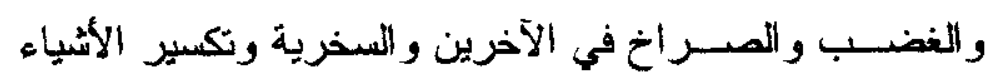
· وتعاطى العقاقير ولفن

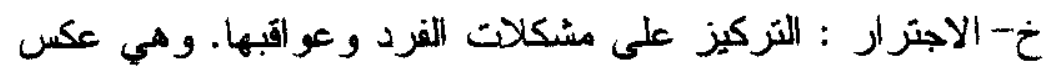

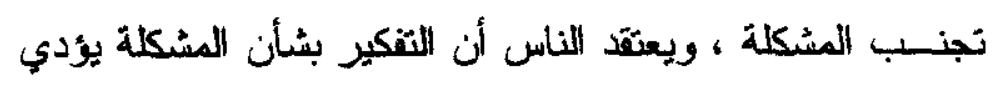

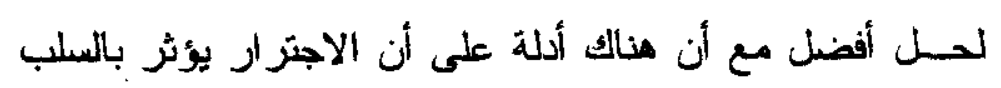
على حل المشكلة.

د- التفكير التفاؤلي Wishful : الرغبة في اختفاء مثير المشقة أو

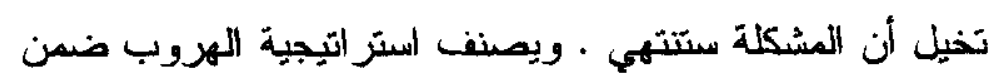

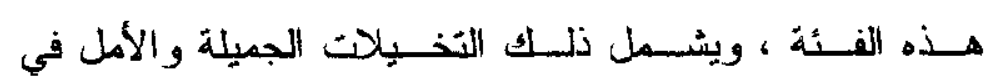
المعبزات. 
ذ- لــوم الأذات : هو التزكز على مسئولية الفرد في حسوث المشقة

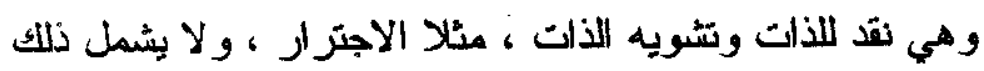

$$
\text { التزجه لحل المشكلة. }
$$

ر- الحليث الذاتي الإيجابي : حولرات داخلية تَّجع الفرد اللشعور

بأنسه أفضـل (مثلا يذكر نفسه بالجو اثب المشرقة في الحياة)

وطمانة الذات بأنه قار على المعامل مع المشقة.

ز - التماريــن الرياضــية : التتفـيس outlet الجسمي (التمارين

الرياضلية) للتشتيت بعيدا عن المشقة وهو نشاط انفعالي .

وكمـ هـــو واضـع فإن المكونات السابقة ششمل خلط لمكونات لا

علاقــة بينها، فالبعض يمل حوار داخلي (اجترار ولوم الذات و الحيث الإيجابــي) و البعض بمثل طرق لخفض التوتز من التمارين الرياضية او

البكاء و هناك مجمو عة ثالثة تشبير لاستر اتيجية مو اجهة مثل التجنب.

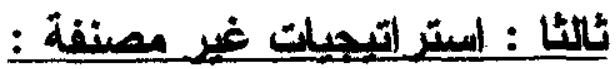

أ- البحث عن دعم اجتماعي (غير محدد) :

هـناك درلسات عديدة تؤلف بنود تحت فئة واحدة هي البحث عن

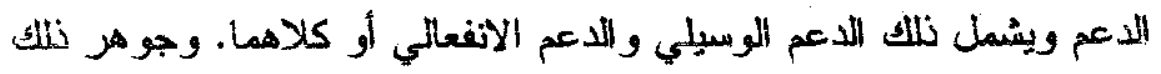
هو بذل الجهد للبحث عن المساعدة والراحة لدى الآخرين · وتتضمن هذه الفئة كلا من التمركز حول المشكلة و التمركز الانفعالي . 
ب- الديـن : المـلاة والأنشطة الدينية و الحليث مع رجال الدين و التعبير

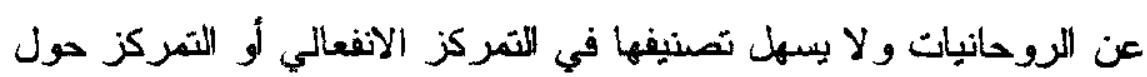
المشكلة .

ويسرى الناس هذه الطريقة في التعامل باعتبار ها بحث عن الحل

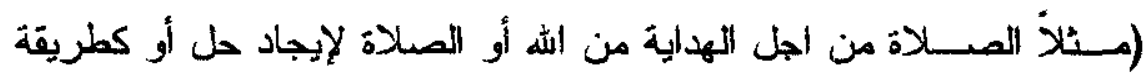

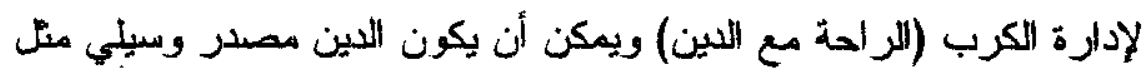

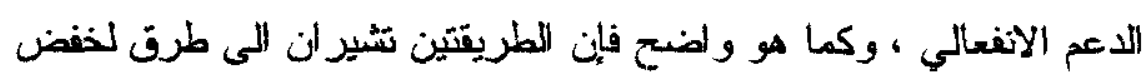

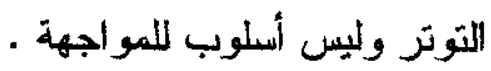

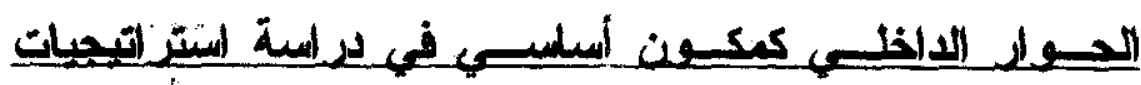
: لمبولجية

يستخدم مصطلح الحوار الذاخلي Internal dialogue والأفكار الآلــية automatic thoughts وأحاديسـث الــات Self-Statement

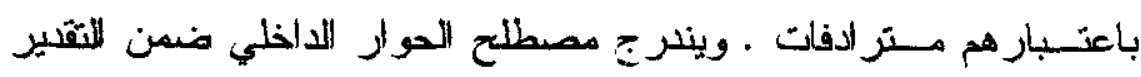

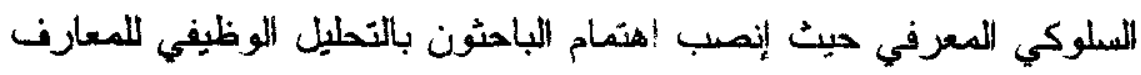

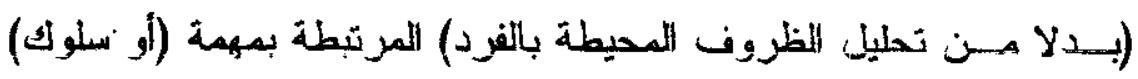

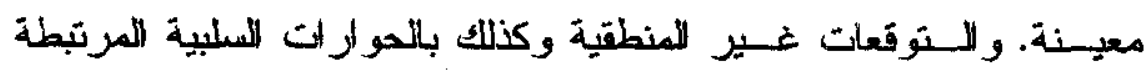
بالشخص أو الموقف أو الاضطر اب (Kendall, 1982) وقد صمست عدة مقاييس تعبر عن مفهوم الحوار الاخلي. ومــال ذلــ استخبار الأفكار الآلية Automatic Thoughts (Hollon \& " الذي طوره "هولون" و "كندال" Questionnaire (ATQ)

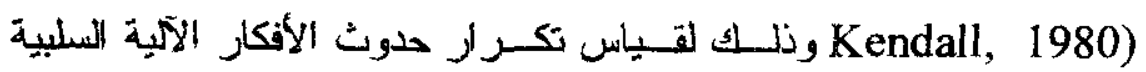


المرتبطة بالاكتئب، و هذا مبني على المعارف المرتبطة بالخبرات المقلقة،

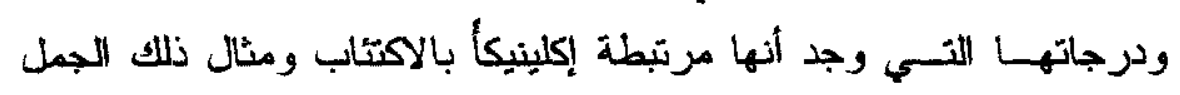
التالية التي ثزد كحوار داخلي (أو حديث الفرد لنفسه) : - أشعر أنني ضد العالم بأسره. ب- أرغب من أن أكون شخص كويس

r- حياتي ملخبطة. ع- مستقبلي كئيب. 0- لا أسنطيع إنجاز أي

$$
\text { شيء (المرجع الاسبق) - ن }
$$

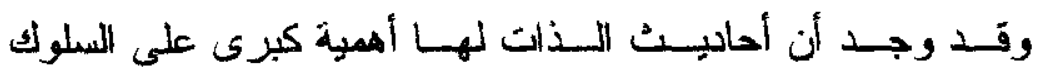
(Sshwartz\& Gottman, "الاجنماعي ، منلا حلل "توارتز" و "جوتمان (1976 جوانب السلوك النوكيدي ووجدا أن الثخص منخفض التوكيد يقول لنفسه جمل سلبية اكثر عن ذاته إذا قورن بمرتفعي التوكيد. كما وجد أن الحوار ات الداخلية الإيجابية و المبلبية لها لاور هام في (Mandel \& Sharauger, تســهل ارتشباط النكور بعلاقة مع الالاثاث (1980 حيــد أن الحوار ات الداخلية يمكن أن تسهل أو تعوق سلوكيات الفرد في مواقف أو مهام معينة. ويفسرق الباحنين بين الحوار ات الداخلية المرتبطة بكل من القلت

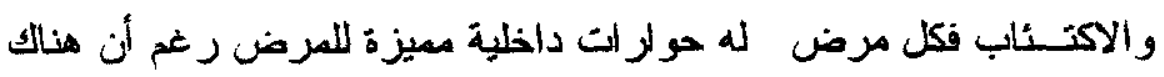
تداخل بينهما (Safren et al., 2000).

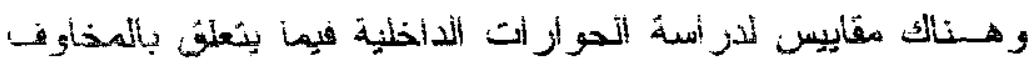

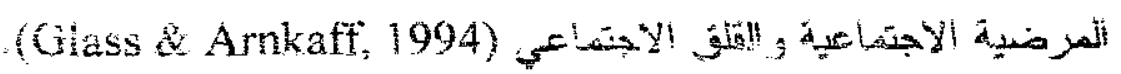


والار اســات اللتـي ابسـتخدمت مفهوم الحوار الذاتي قليلة للغاية وترتبط بالاكتثاب و العدوان والسلوك التوكيدي والعلاقة مع الجنس الآخر و القلق واضطر ابات الأكل والألم.

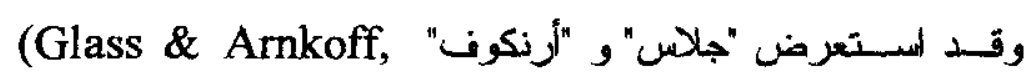

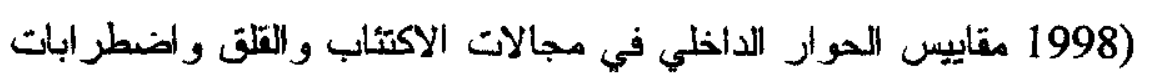

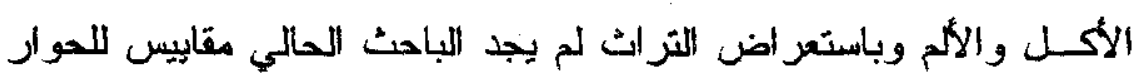

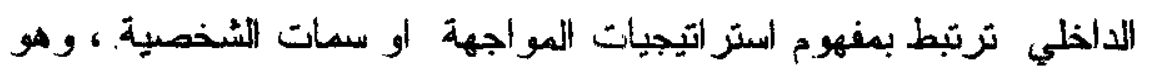
ما سيحاول الباحث الحالمي تكوينه في الدراسة الحالية . ويسـتخدم علماء النفس مفهم الحوار الذاتي باعتباره أحد مكونات

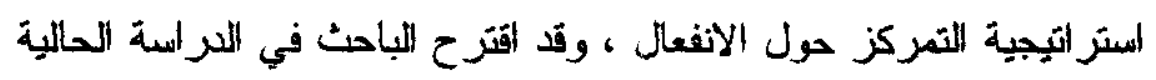

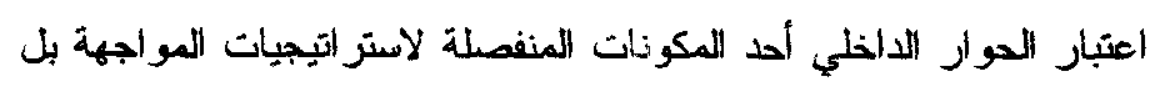
ير اعتباره في مقدمة تسلسل مكوناتي المفهوم.

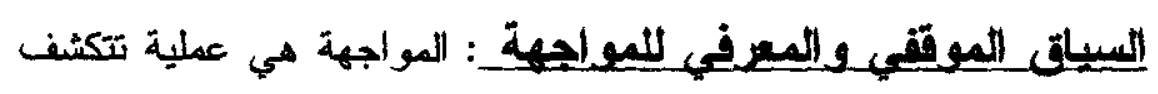

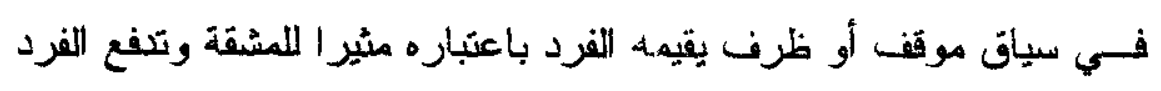

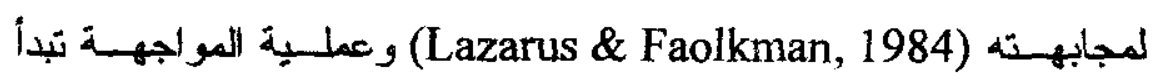

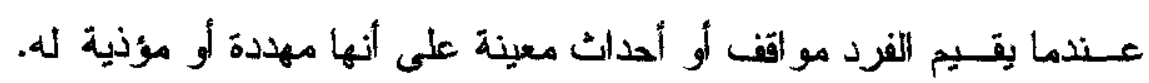
وتتصـف هـذه التقسيمات بالانفعالات النسبية التي غالبا ما تكون شديدة.

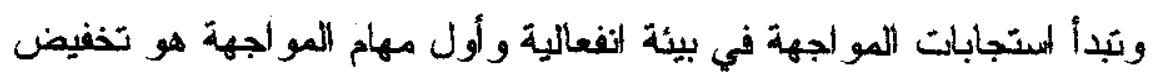

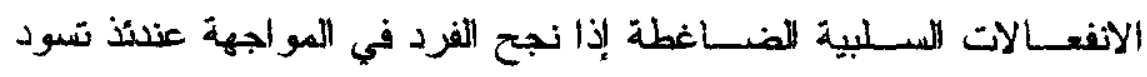
الانفعالات الإبجابية وإذا فنل الفرد عندئذ تسود الاثفعاللات السلبية. 
يعتبر مفهوم استراتججيات المواجهة من المفاهيم المعقدة ومتعددة

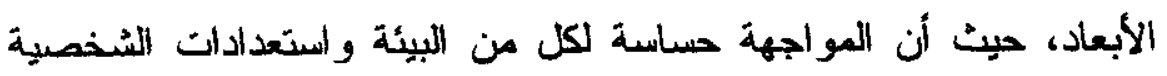

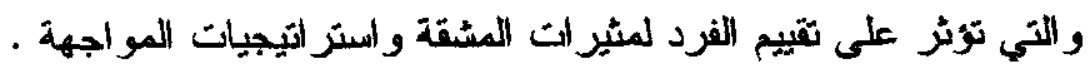

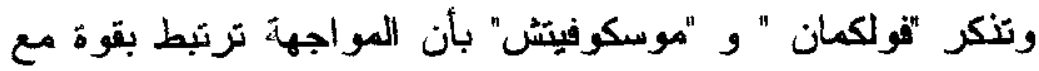

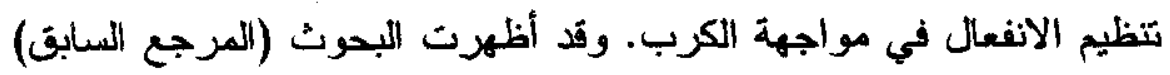

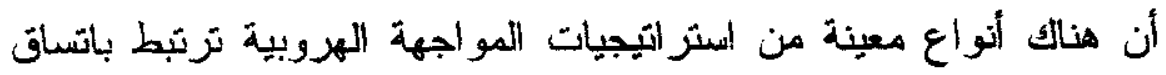

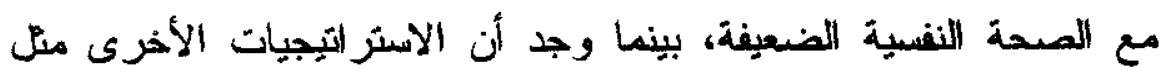

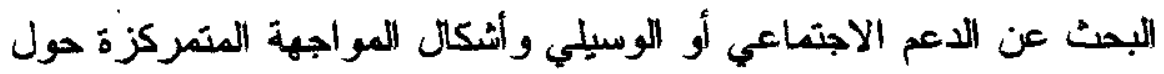

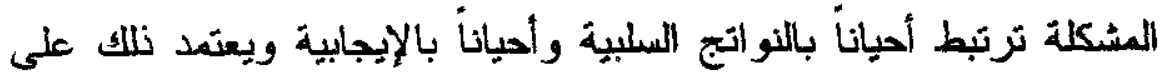
الخصائص التي يقيم بها الفرد المو اقف الضناغطة. فالمو اجهة ظاهزة معقدة ودينامية تشمل الفرد و البيئة العلاقة بينهما. ويذكر "بيرلين" و "شولر" (Pearlin \& Schooler, 1978) أن

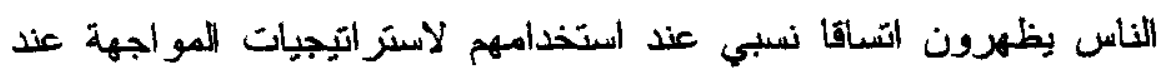
مجابهنه لنفس المشكلة.

وتنكر "فولكمان" ولازاروس" أن هناك اتساق ضئيل طبغأ لاختلاف المواقف (Folkman \& Lazarus, 1980) وكنك بكون الاتساق

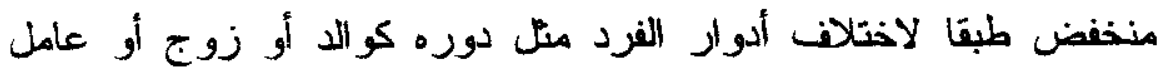
. (Pearlin \& Schooler, 1978) يبلو أن أستراتيجيات المواجهة تختلف من ظرف لآخر : ثقد

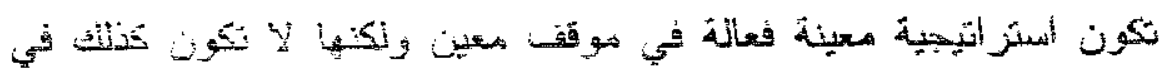

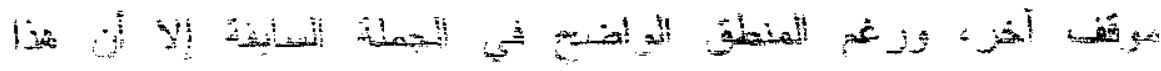


الموضوع (فعالية استراتيجيات المواجهة) لا يزال من أكبر المشكلات

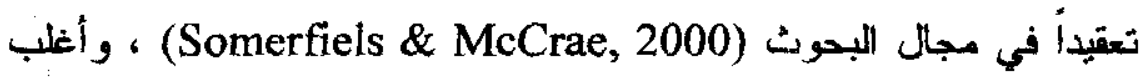

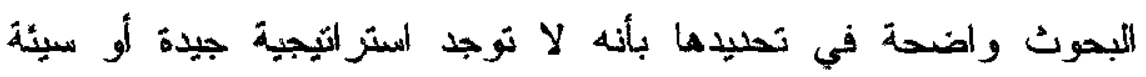
وبدلاً من ذللك فإن عملية المواجهة (Lazarus \& Folkman, 1984)

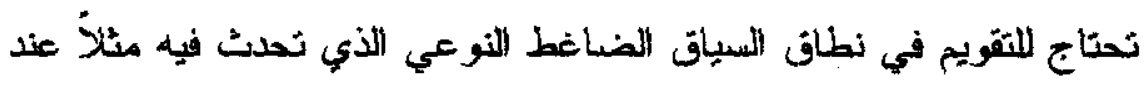

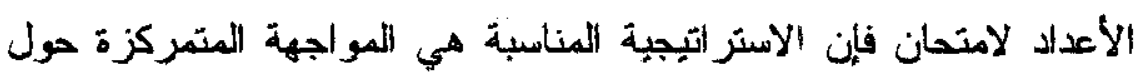

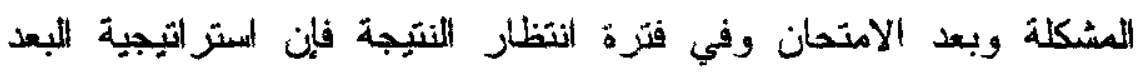

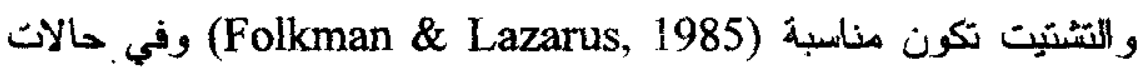

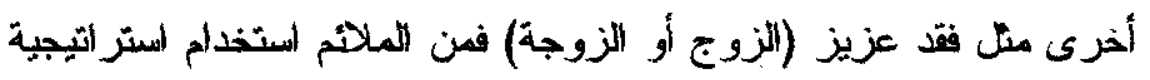

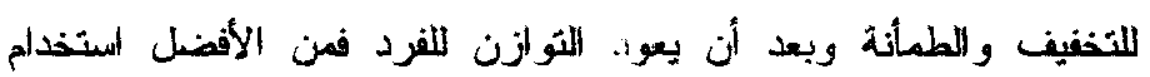

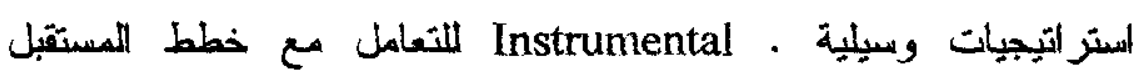
(Zeidnex \& ويعنقد بعض الباحثين (Stroebe \& Schut, 2001) Saklofske, 1996, p.158)

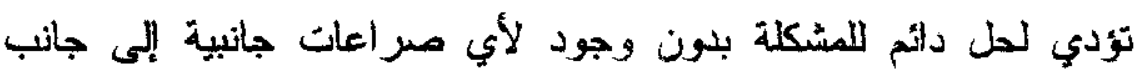
احتفاظ الفرد بحالة اتفعالية إيجابية.

(Aldwin \& Revenson, 1987; وقد طرح بعض الباحثين

Gignac \& Gottlieb, 1996, Natoumanis \& Biddle, 1998)

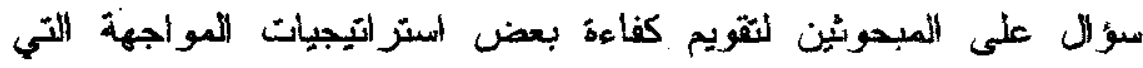

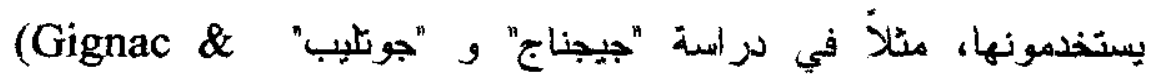
Gottlieb, 1996) تم قياس نقويم المبحوثين لاستر اتيجيات المو اجهة التئي

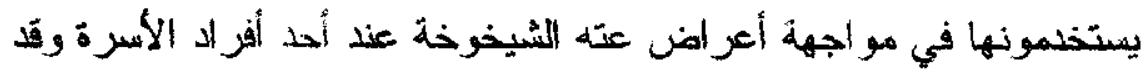

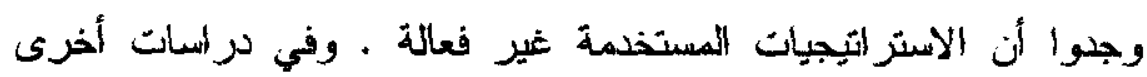


تمث براسة فعالية استراتيجيات المواجهة في مواثف أدائية مثلا (Carver \& Scheier, 1994; Folkman \& Lazarus, الامتحانات

ألثز المواقف المثيرة للمشقة على المواجهة : تفترض العديد من

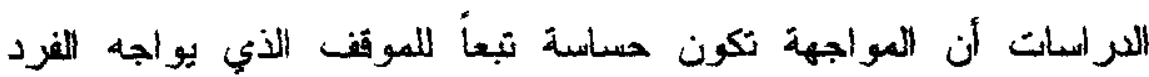
(Eckenrode, 1991; Lazarus \& Folkman, 1984; Wethington .\& Kessler, 1991)

وقد وجد أن المواقف المتشابهة تميل لاستثارة أنماطا متشابهة من

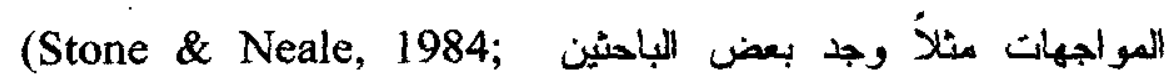
Compas, Forsythe, \& Wagner, 1988) مستريات من الاتساق عندما يواجهرن نفس المشكلة عدة مرات وبالمتل

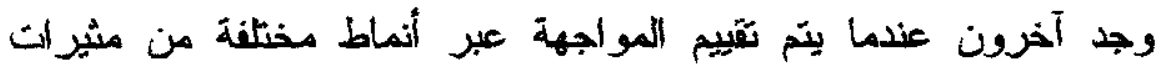

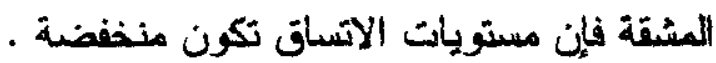
وهناك عدة طرث اللتميز بين المواقف الشاقة حيث بتم تجميعها

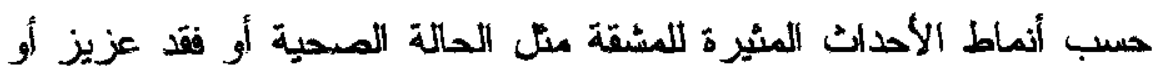
وجود مشكلة مالية أو مشكلة اجتماعية \& Maitlin, Wethington \&

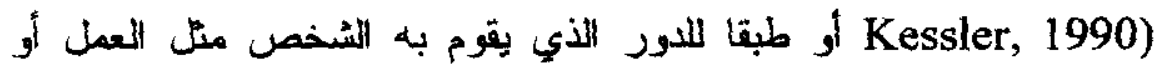

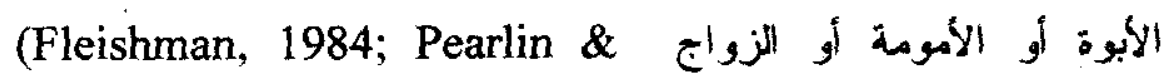

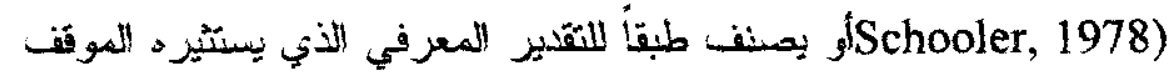

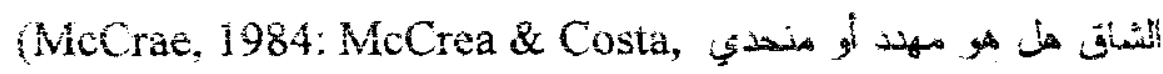


وقد ميز بعض العلماء بين نوعين من مثيرات المشقة (المواقف (الشاقة) :

(Bakan, 1966; Helgeson, 1994; الأول : خاص الثاني : عام

.Wiggins \& Trapnell, 1996)

وتتميز المواقف الخاصة بأنها ترتبط باحتياجات مثل التفوق

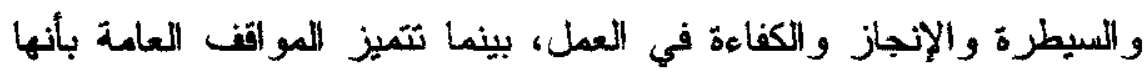

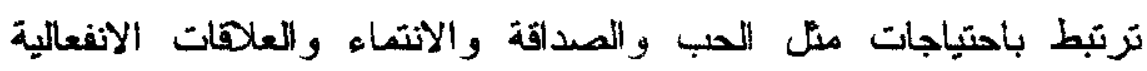

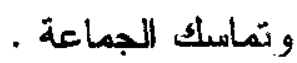

ويبدو أن المواتف الخاصة تتميز باستراتيجيات منمركزة حول

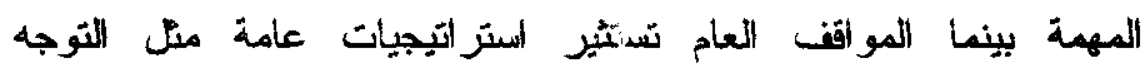
الاجنماعي.

وقد أظهرت دراسات عديدة أن الاستراتيجيات المتمركزة حول

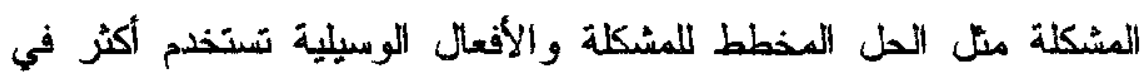

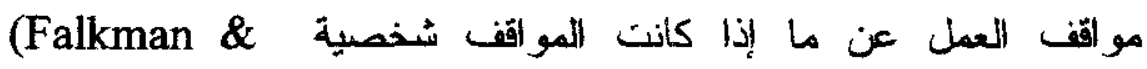
. Lazarus, 1986; Folkman et al., 1986; Terry, 1994) وقد وجد في إحدى الدراسات أن التحكم في الأات يستخدم بفعالية

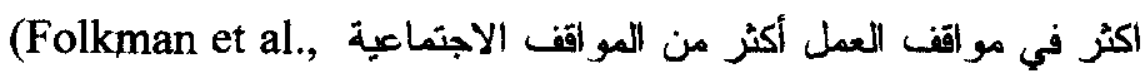
.1986)

وعلى النقيض من ذلك فإن هناك نراسات سابقة أثشارت إلى أن

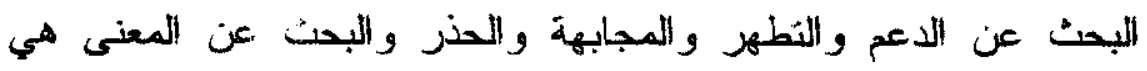


(compass et al., 1988; الاستر اتيجيات السائدة في المواقت الاجتماعية Folkman et al., 1986; Terry, 1994)

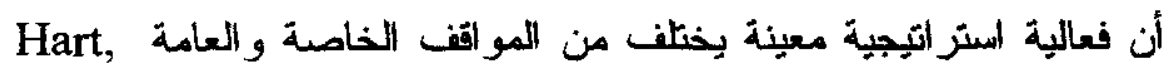
1991; Maitlin et al., 1990; Pearlin \& Pearlin \& Schooler, 1978)

و هناك دليل متزايد على أن المواقف الخاصة و العامة لها أثز

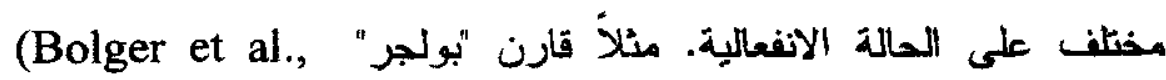

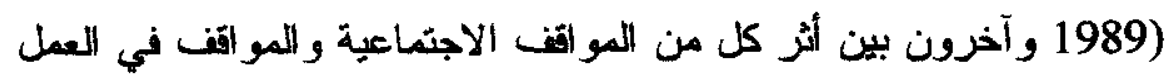

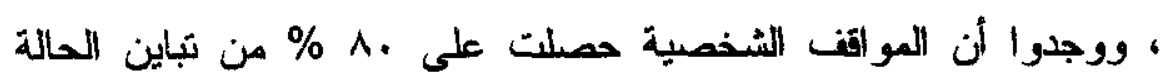

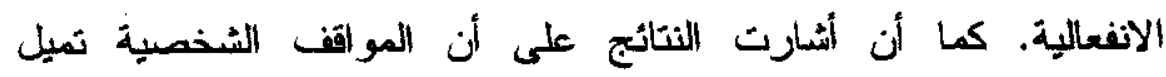
لكاستمرار في عدة أليام. بحث "أوبرين" و "دولوجيس" (O'brien \& Delongis, 1996)

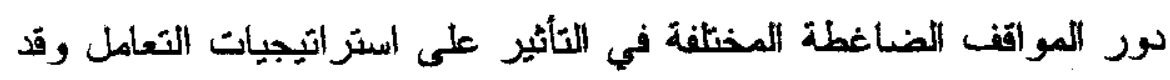
حدد أنماط المواتف الضساغطة بأنها:

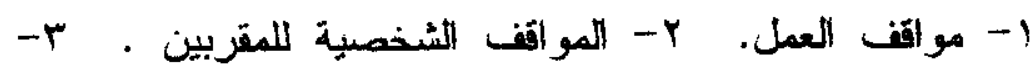
المواتف العامة Communal مثل الغرباء .

وأظهرت الانتائج أن المواقف الضماغطة منبئ قوى عن الطريقة

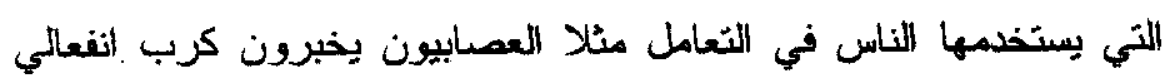
اكتر وتظهير الدراسات للسابقة وجود علقة بين الانبساط وانستراتيجية التمركز حول المنّكية 
وفي الادراسة الحالية بنصب الاهتمام بالمواقف الضناغطة ألمنعلقة

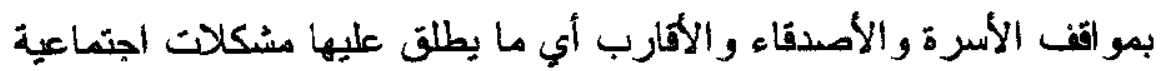

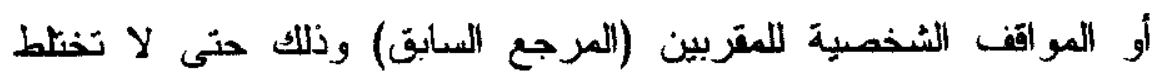

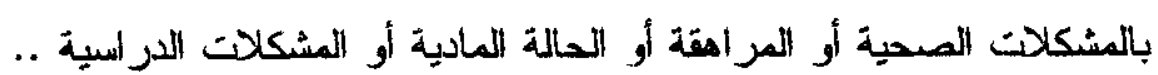

\section{النتائح المتضارية في يحوث المولجهة :}

ورغم مرور سنوات عديدة على ظهور مفهوم ونظريات المواجهة وتطوير مقاييس لبحثها فإن الباحشين ليس لديهم فهم شامل لبناء مفهوم

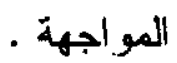

وتظهر الدراسات نتائج منضاربة مثلأ أظهرت دراسة لـ

"فولكمان" و "لازاروس" (Folkman \& Lazarus, 1980) استخدما فيها طريقتي المواجهة (حول المشكلة وحول الانفعال) أن هناك عالن عاملين

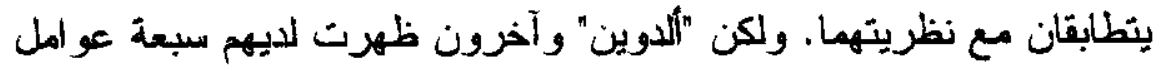
عند بحنهم النفس نتائج "فولكمان" و "لاز اروس" (Aldwin et al., 1980)

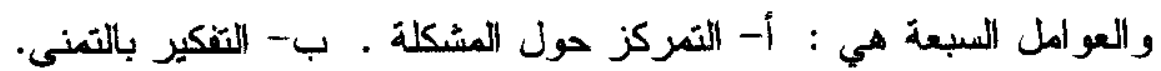
ج- النمو. د د- النمو.

هـ تقليل التهليد. و - البحث عن الدعم الاجتماعي. س- لوم الذات. صر- خليط من التجنب و البحث عن المساعدة.

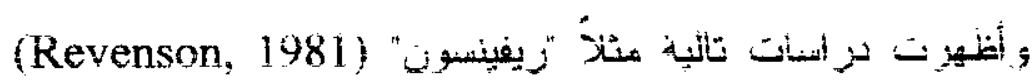

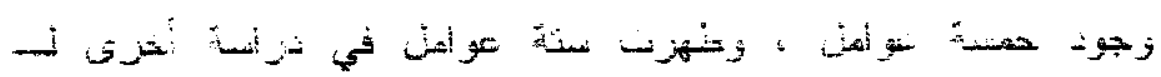

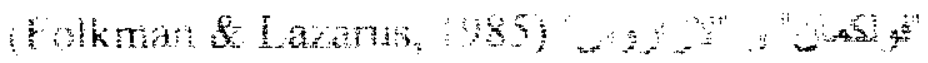


و أظهرت نتائج " فيتالينو" و آخرون (Veitaliano et al., 1985)

باستخدام نفس المقياس وجود خمسة عوأمل هي : أل- التمركز حول

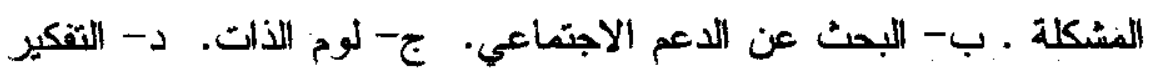

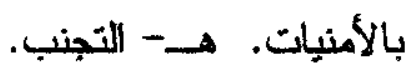

(Parker, Endler \& Bagby, ولم يستطع باحثون آخرون (1993 من استعادة عاملي المواجهة ( التمركز حول المشكلة والتمركز

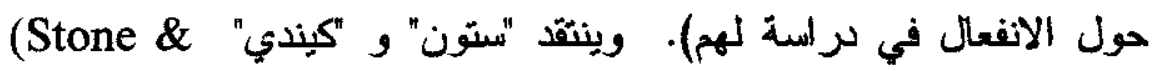
Kennedy - Moore, 1992) مقاييس المواجهة.

يذكر "إلين سكنر" وآخرون (Skinner, et al., 2003) أن

النموذج التقليدي (التمركز حول المشكلة مقابل التمركز حول الانفعالات والاقتزاب مقابل التجنب - والمعرفي مقابل السلوكي) لم يعد مناسبا

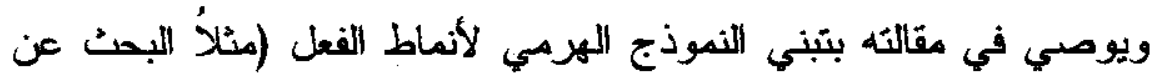

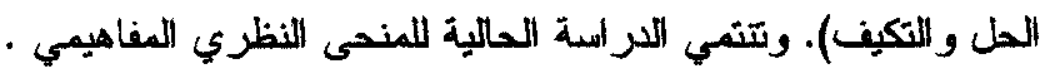

\section{قياس استر اتييجيات الميواجية :}

تم تطوير العديد من المقاييس لقياس المواجهة ، وكل مقياس به

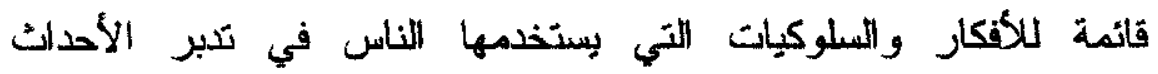

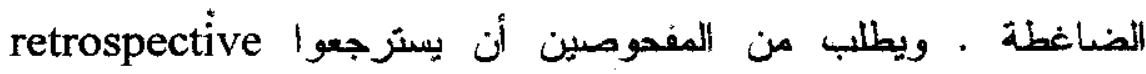

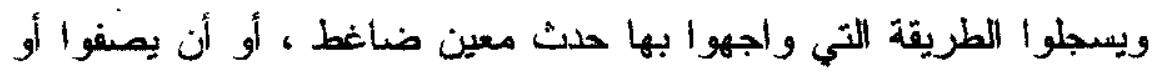

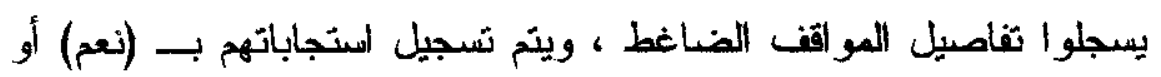
(لا) أو بطريقة "ليكرت" Likert وهناك العديد من المقاييس التي طبقت. 
Folkman \& Lazarus, في دراسات عليدة مثل مقياس طرق المواجهة

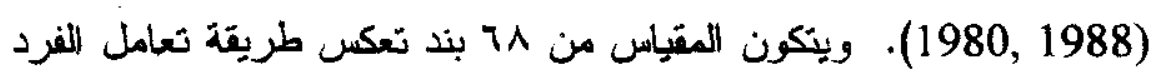

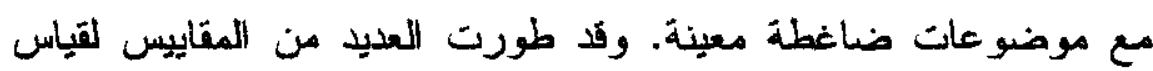

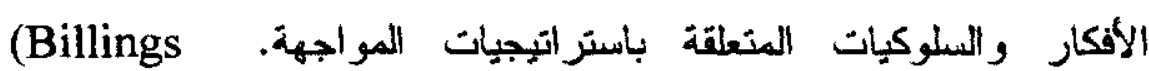
\&Moos, 1981; Folkman \& Lazarus, 1980, Pearlin \& .Schooler, 1978)

ومن أهم المقاييس المتكيدية مقياس Carver et al., COPE

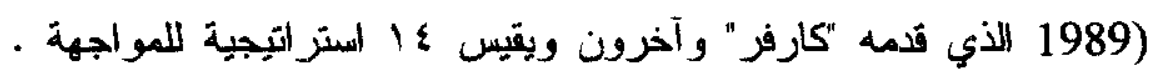

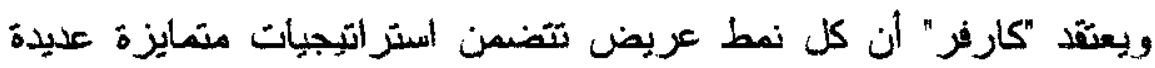

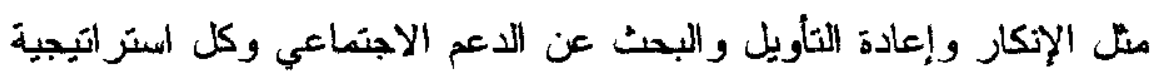

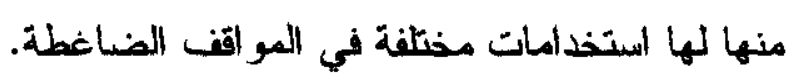

كما توجد مفاييس أخرى هامة منل مقياس الأساليب العامة

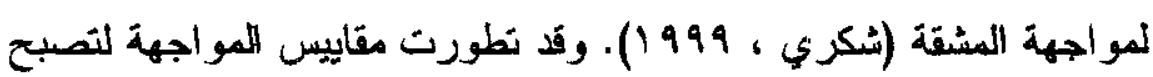

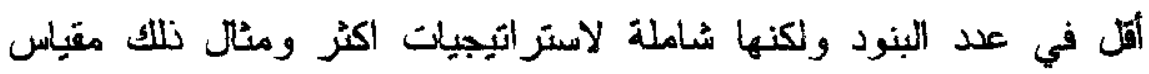
المواجهة متعدد الأبعاد . (Endler \& Parker, 1990) ويقيس استراتيجيات المواجهة المتمركزة : أ- حول المهمة ـ ب- حول

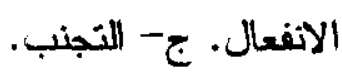

وهناك مقياس آخر بسمى مؤشر الستراتيجيات المواجهة (Amirkhan, 1990)

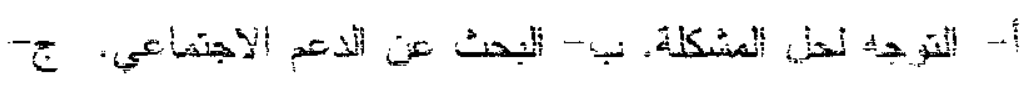


و هناتك جرانب تشابه بين المقياسين السابقين ·

وقذ اقترح "ستون و "ثيل" (Stone \& Neale, 1984) مقياساً

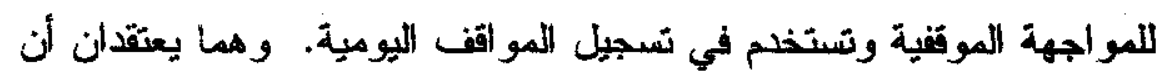
سلوك معين قد يستخمه فرد باعنباره استراتيجية تشتيث بينما يستخلمه آخر باعتباره استراتيجية استرخاء . ويتكون المقياس هن م بنود فقط (الشتيث وإعادة تعريف الموقف، و الفعل المباشر ، واللتطهير و المو افقة و الدعم الاجتماعي والاستزخاء والتين) . . ويصف الأفراد الأحداث المزعجة في كل يوم ويؤشروا على الاستز لتيجية التي لستخمو ها وهذا

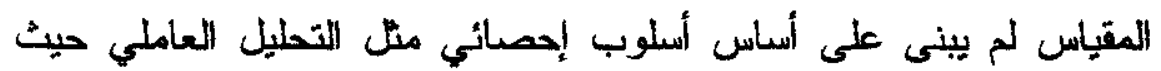
ينتقده بعض الباحشين. (Stone \& Kennedy - Moore, 1992) ولا زال بناء مفهوم المواجهة والمقاييس المستخدم ققياسه موضع استفهام لم يحل حتى الآن (Suls, David, \& Harvey , 1996 p. 723 (ب). ويذكر "اليفنة" و "ليفة" (Livneh \& Livneh, 1996) أن مقاييس استراتيجيات التعامل المثباينة قد أدت إلى تجزأة المعرفة وكذلك أدث لنتائج منضاربة ويذكر أن البعض يسنخلم استر أتيجيات التعامل على أنها

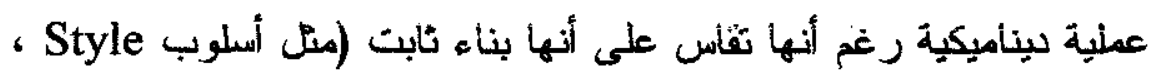
و أستعداد وميل) ، والبعض بِيتخدمها باعنبار ها حالة يسيثير ها المو اقف البيئية (هالة مؤقتة) ويعتر ها البعض سمة شخصية أو معتقد بام.

\section{مشكلات قياس مفهوم استر اتبحيلت المولجمة :}

تواجه بحوث أستز اتيجيات المواجهة بنقد شديد خاصة ما بيتعلق Costa, Sojerfield, \& McCrae, 1996; بالمفهوم و التعريف 
(Parker \& وكنلك عن طرث القياس (Tennen \& Affleck, 1996) و هل من المفيد تياسه باعتباره استعداد أو استجابة للمواتف (Schwarzer \& Schwarzer, 1996; - Moore, 1992) Stone \& Kennedy لمقاييس التعامل والمواجهة (Samerfield, 1997) \& (Racioppo, 2000

ويستخدم بعض الباحثين مفهوم المواجهة باعتباره استعداد أو (Pearlin \& Schooler, تفضيل نمطي لمواجهة المشكلات منل الإنكار (1978 وهذا يجعله مكون معرفي في بناء الشخصية. وأحد أهم مشكلات مقاييس استراتيجيات المواجهة هو انخفاض

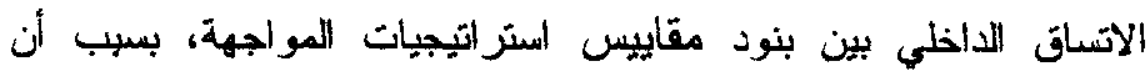
استخدام الفرد لاستر اتيجية واحدة قد تغنيه عن استخدام الاستراتيجيات

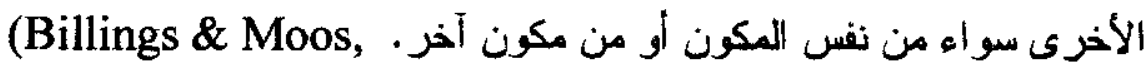

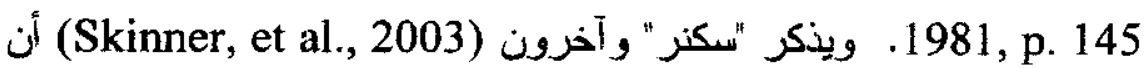
هناك إجماع قليل حول النظريات و النماذج المقترحة وكنلك طرق قياس

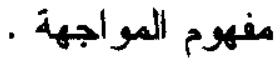

(Folkman \& Moskowitz, وقد ذكرت فولكمان وموسكوفيتس (2004 أن هناك عدة عيوب في المقاييس المتاحة حاليا وهي : أ- الطول وملكون المرهق. ب-- البنود غير الملائمة حيث تكون صعبة في في تفسيرها.

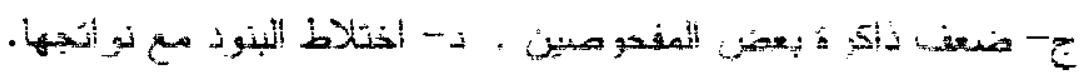


وهناك أتجاه حاليا لنطوير مقاييس موجزة في مجالات الشخصية

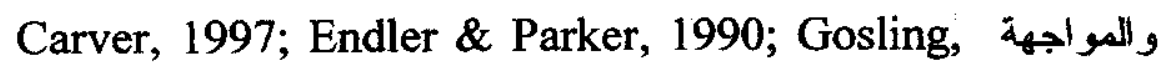

Rentfrow \& Swann, 2003; Stone \& Neal, 1984

وهاك عدة مشاكل تتعلق بالأسس النظرية و السيكومترية :

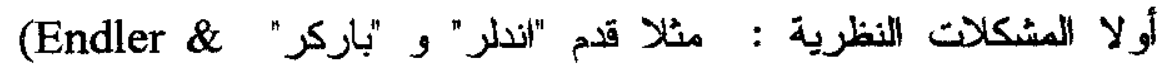
مقياس للمواجهة على أساس نظري ويتضمن ثنلاث

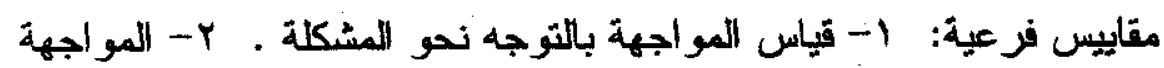

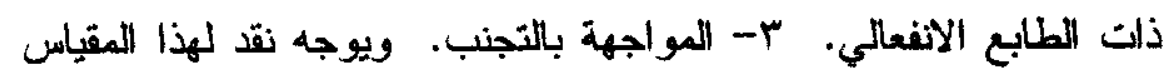

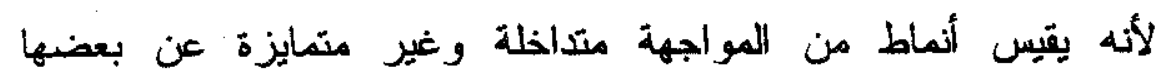
(Stanton, Danoff- Burg, Cameron, \& Ellis, 1994) ويطور بعض الباحثين مقاييس تبعاُ لنموذج نظري أو منطقي،

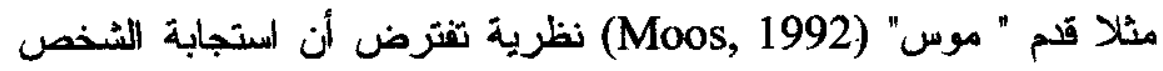

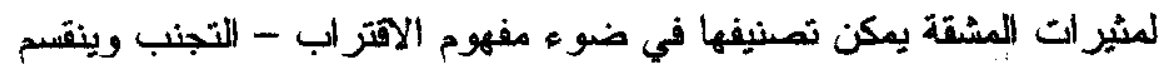
كل منهم إلى أربعة أنماط.

وقدم "كارفر" وآخرون (Carver, et al., 1989) مقياس يشمل

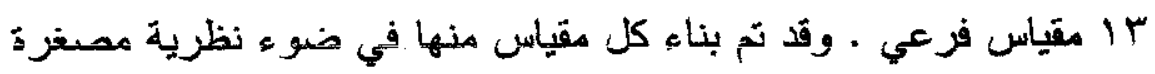
. mini-theory

وفي المقاييس ذات الأساس النظري ربما بهمل الإحث بعض

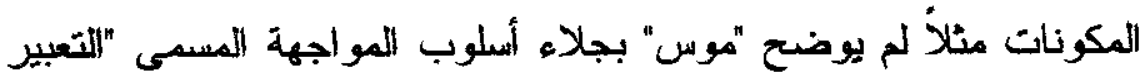
الانفعالي" وهل ينتمي إلى الاقتر اب أو إلى التجنب . 
ثانيا : المشكلاث السيكومترية : لا تغطى مقاييس المواجهة كل المجالات

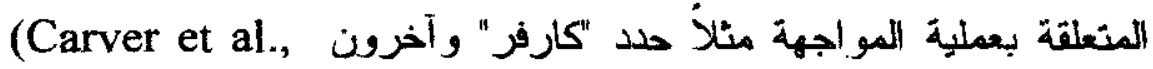

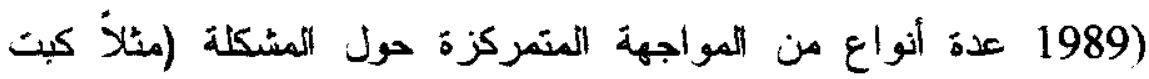

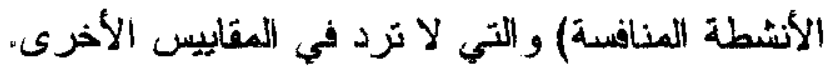

(Stanton, et al., 1994 , Stanton, وتشير "ستانتون" وآخرون

Kirk, Cameron, \& Donoff- Burge, 2000) المتمركزة حول المواجهة بالانفعال تفشل في قياس الانفعال (تحديده وفهمه والتعبيز عنه).

كما ينتقد استخدام التحليل العاملي في تكوين المقاييس Aldwin \& Revenson, 1987; Endler \& Parker, 1990 : Folkman \& حيث بنم كتابة عدد كبيز من استجابات المواجهة ثن

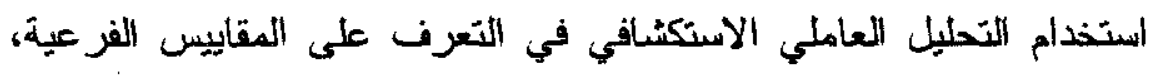

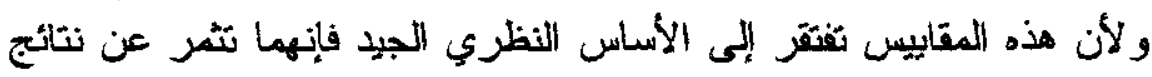
منضاربة (أنظر (Folkman et al., 1986 Vitaliana, et al., 1985) وهناك عدد من اللباحثين رفضوا أسلوب التحليل العاملي لتكرار

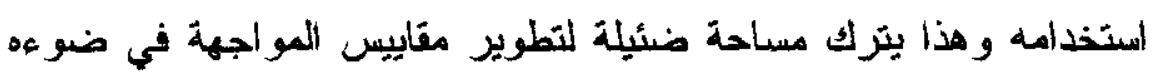
. (Zuckerman \& Gagne, 2003 p. 171)

كما تنتقد المقاييس لنكرار استخدام نفس المعنى في عدة جمل

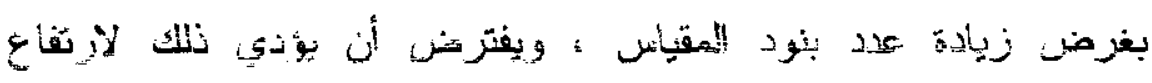

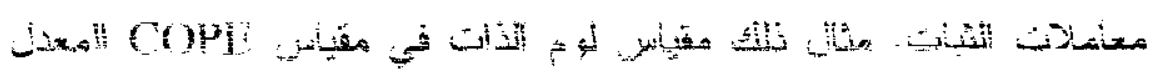
; Mnt 
1- ألوم نفسي . ب- جلبت لنفسي المشكلة . r- أنققد نفسي. ؛

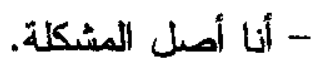
وكل بنود المقياس تتبع نفس النمط من تشابه البنود .

وينتقد بعض الباحشين طرق قياس المواجهة Coyne \&

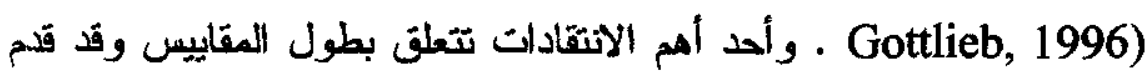

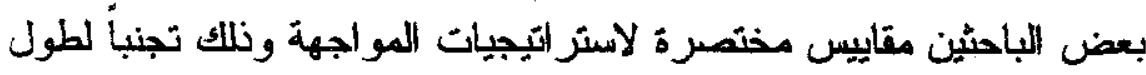
المقاييس المتاحة (Carver, 1997). ولا يوجد معنى لاستعر اض كل

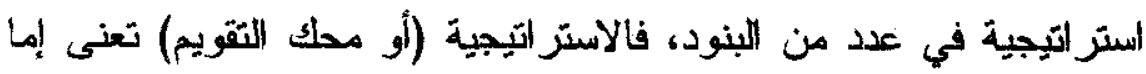

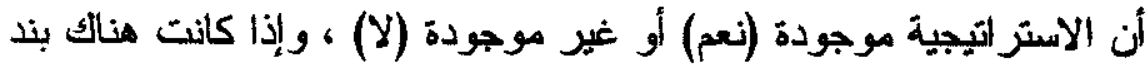

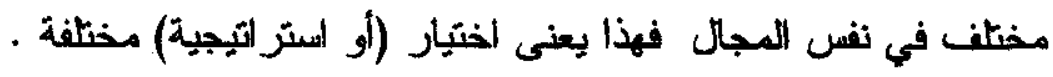
ولنلك فإن كل بند يمثل استراتيجية مختلفة ولا يجوز تجميع هذه الاستر التيجيات تصت فئة عامة نوعية أو عامة وكذلك لا بفضل الستخدام

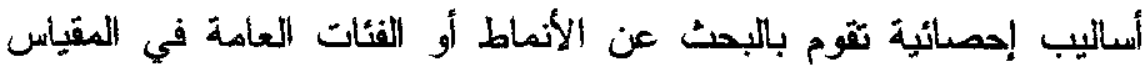
مثل الأسلوب الإحصائي المسمى التحليل العاملي. ويظهر استعر اض التزاث السابق أن مفهوم أستراتيجيات المواجهة

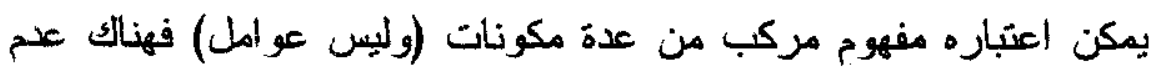
اتفاق بشأن طبيعة ومكونات المفهوم ومقايِيسه. و الدراسة الحالية محاولة لطرح نموذج جليد حول طبيعة ومكونات المفهوم. 
اختلاف مكونات مقاييس استر اتيجيات المواجهة بين الباحثين :

سنعرض لاختلاف مكونات ثلاثة مقاييس للمواجهة لكي نبرز الاختلاف الشاسع بين مكونات هذه المقاييس رغم أنها تقيس نفس المفهوم.

1 : متراس COPE

يتضمن المقياس المكونات التالية :

1- لوم الذات : ونتشير لنقد الذات باعثبار الفرد أساس المشكلة.

r- اجنرار المشكلة : وتتير إلى التقكير مرارا في المشكلة.

r- التعبيز عن الانفعال : وتشير إلى إظهار المشاعر بلن كبتها.

ع- فهم المساعر : وتشير لمحاولة الفرد توضبح مشاعره وإيعاد

الخلط.

0- الاحتفاظ بالثفاول : وتشّير لمحاولة الفرد لاحتفاظ بالتفاول

$$
\text { رغم المشكلات. }
$$

ד- إيدال اللهدف : البحث عن هدف بديل.

V- لوم الآخرين : وبتشير الاتهام الآخرين بأنهم السبب في

المشكلة . لوم الاترين

1- عدم الانشغال بالمشكلة : محاولة الفرد تشتيث أفكاره بعيداً

عن المشكلة (Zuckerman \& Gagne, 2003). 


\section{ب- متياس الأبعاد المتعدة للمواجهة :}

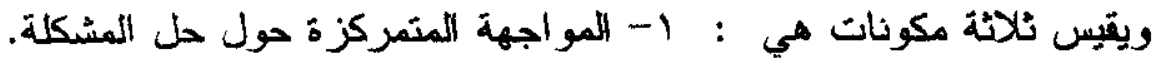

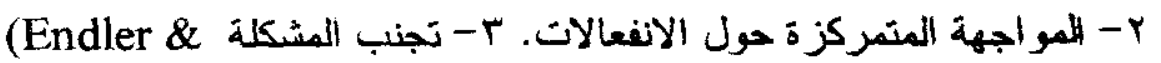
Parker, 1990)

ج- متياس استراتجيليت المواجهة : ويتكون المقياس من : 1- أنماط مواجهة المشكلة (المو اجهة النشطة و التخطيط لحها).

$$
\text { r- البحث عن الدعم (الوسيلي والانفعالي). }
$$

ب- المواجهة الاثفعالية . (Carver et al., 1989)

وكما هو وافنح فإن مشكلة عدم اتفاق اللباحئن على تعريفات

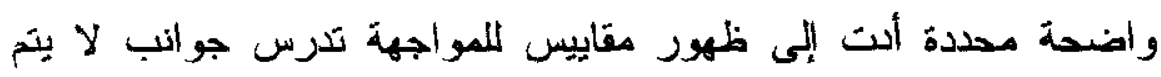

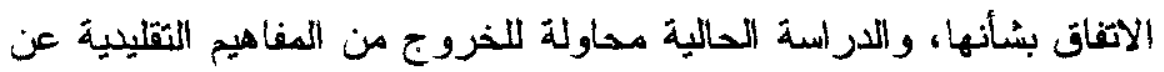
طريق اقتر اح نموذج بحثي يستو عب مغاهيم استر اتيجيات المو اجهة.

الإراسيت البيابتة لبحث العلاقة بين سيمت الشيخيبة

\section{والميولجهة:}

هناك أدلة حليثة تفترض أن كل من المواقف وسمات الثخصية

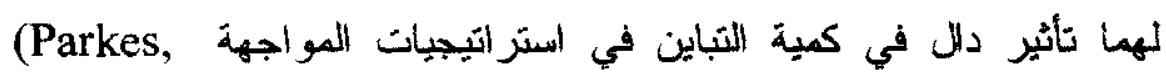

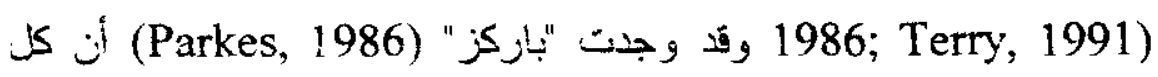

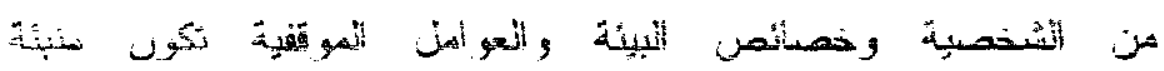

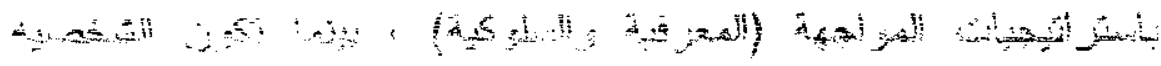


وعو امل الموقف منبئة بالمحارولات المباشرة لتغيير الظرون الضاغطة أو

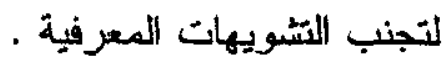

ويذكر " واطسون " و "هوبارد" Watson \& Hubbard,

(1996 أن سمات الشخصية مهمة للغايية في تحديد تكيف الفرد للفيغون

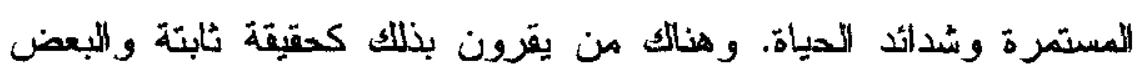

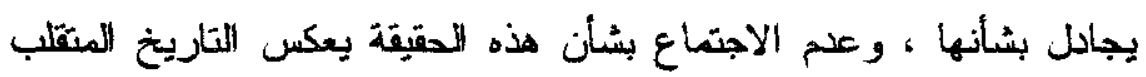

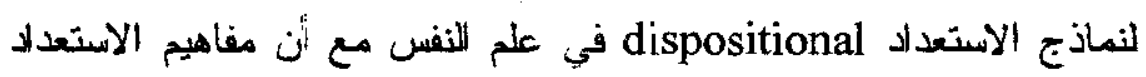

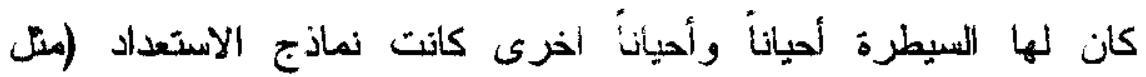

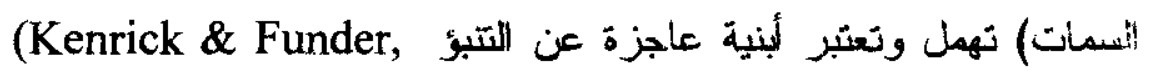
1988; Vickers, kolar \& Hervig, 1989)

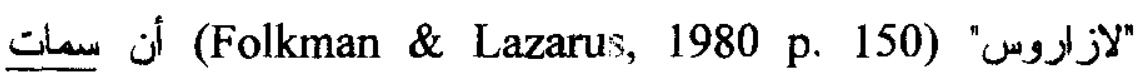
الشخصية لها تأثير ضئيل على المواجهة لأن مفاهيم الشخصية ثابتة

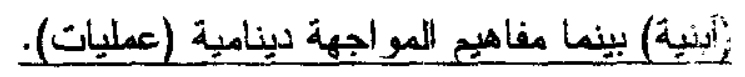

وقد أجريت العديد من الدزاسات التي تدعم وجهة للنظر .السابقة وقد أنت (Folkman \& Lazarus, 1985: Folkman, et al., 1980)

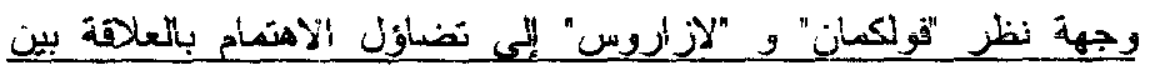
سمات الشخصية و المو اجهة.

(Suls, David, \& Harvey, وقد نكرت " سولس" وآخرون 1996, P. 720) المواجهة المتبعة . - المان 
وقد ذكر "كوهن" و "لازاروس" (Cohen \& lazarus, 1979)

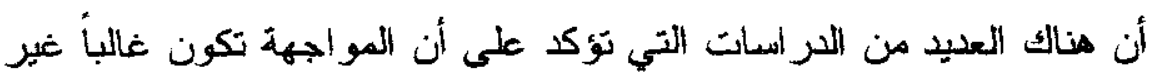
متسقة من موتف لآخر ، وأن المواقف لها تأثير على عملية المواجهة وأن الني

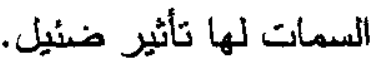

ويذكر "واطسون" و "هويارد" .Watson \& Hubbard, 1996)

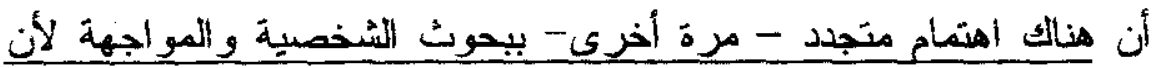

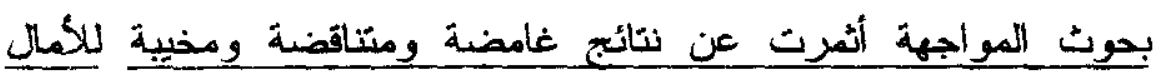
.(Aldwin \& Revenson, 1987; Costa \& McCrae, 1989)

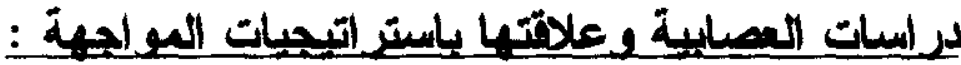

رغم النتائج المتناقضة واللغامضة للعلاقة بين سمات الشخصية Aldwin \& Revenson, 1987; Costa \& واسترائجيات المواجهة McCrae, 1989; Kenrick \& Funder, 1988; Vickers, kolor \& إلا أن هناك عدد من البحوث التي أظهرث وجود علاقة قوية بين العصابية وبين استر اتتيجيات المو اجهة غير التكيفية. وفيما يلي عرض لأهم الدراسات التي اهتمت ببحث العلاقة بين سمات الشخصية (العاملان الكبيران) واستز اتيجيات المو اجهة.

تلعب العصابية دور هام في عملية الضغوط- المواجهة وقد أشارت البحوث اللسابقة إلى روابط دالة بين سمة المصابية و المو اجهة

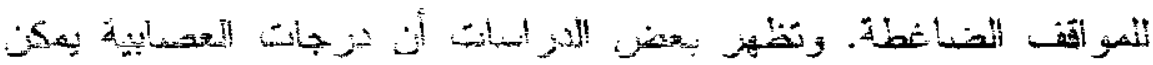

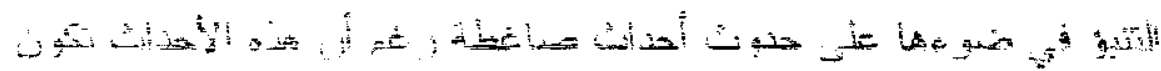

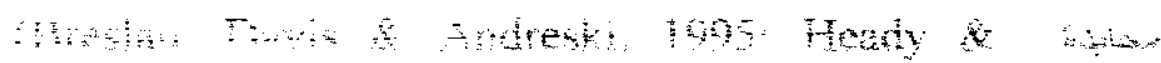


Wearing, 1989; Ormel \& wohlfarth, 1991) يخلقون المشكلات لأنفسهم (Watson, et al., 1994).

ويبدو أن العصابيين يميلون إلى التقليرات السلبية للأحداث البيئية ويركون المنبهات المحايدة بطريقة سلبية أكثر مما يفعل الآخرون. . (Costa \& McCrae, 1990; Watson \& Clark, 1984)

كما أن العصابيين من السهل إغضابهج ومن ثم بسلكون لطريقة

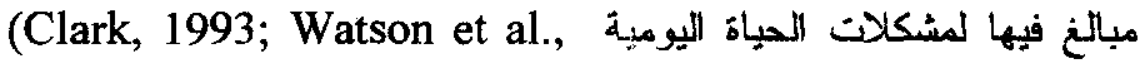
(1994) وترتبط العصابية بدلالة مع استراتيجيات المواجهة غير الفعالة وقد (Costa \& McCrae, 1989; Endler \& Parker, 1990) ارنبطت العصابية باستراتيجيات التمني وتوبيخ الذات و الهروب و التمركز Bolger, 1990; Hooker, Frazier, \& Monahan, حول الانفعال 1994; Rim, 1986; smith et al., 1989; Vickers et al., 1989) • وفي دراسة أخرى وباستخدام مقياس COPE وجد "كارفر" و "شيير" أن العصابية ترتبط (Carver et al., 1989; Scheier et al., 1994) بدلالة مع عدم الآثغال السلوكي و عدم الانثغل العقلي والإنكار والتفيس

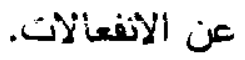

وقد أشار "هاكر اي" و "كوستا" (McCrae \& Costa, 1986) في

دراستين لهما أن العصابيية ترتبط بعدم الحسم و العدائية و التمني و الهروب بالتخييل ولوم الألات و الاتسحاب و السلبية والسكون. كا أن نتائج التحليل العاملي أظهر عاملين أحدهما بسمى "المواجهة العدمابية" وتشير الى ولى

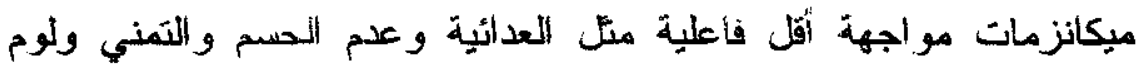
الذات و السلبية. وقد طبق "راتسب" وآخرون (Ratsep., et al., 2000) 
مقياس NEO للعوامل الخمسة ووجد أن بعض العصابية هو الذي يرتبط

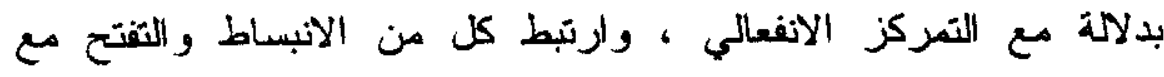
استراتيجية التمركز حول المشكلة لدى العينة الضسابطة من الأسوياء.

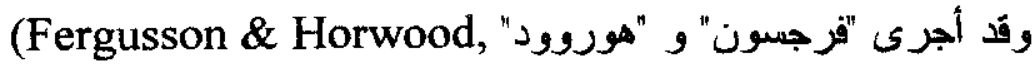

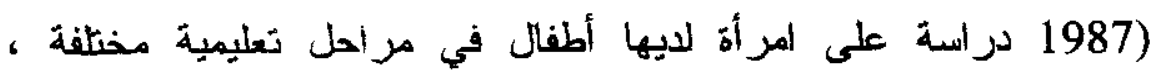
وأظهرت متابعتها أن العصابية هي أقوى منبأ عند لنعرض لأحداث العيات العياة الكبرى. وفي دراسة أخرى (Buss et al., 1987) وجد أن العصابية منبأ جيد عن دخول الفرد في صر اعات الجتماعية.

أجرى "بولجز" و "شيلنج" (Bolger \& Schilling, 1991) دراسة على عينة من وبم شخص لقياس أثر العصابية على استر اتيجيات

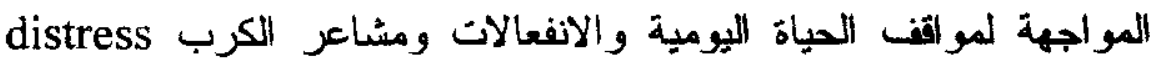

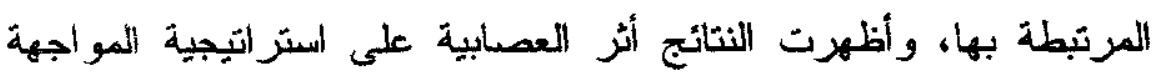
التي بِتخدمها الفرد خاصة الاستر اتيجيات المتمركزة حول الانفعال. ويتميز العصابيون بالميل إلى الوجدان (والمشاعر) السلبية مثل

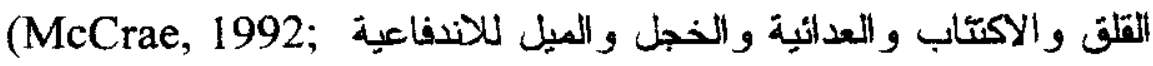
.McCrae \& Costa, 1987)

وتفترض نتائج عدة دراسات أن مرتفعي العصابية يكونوا أقل

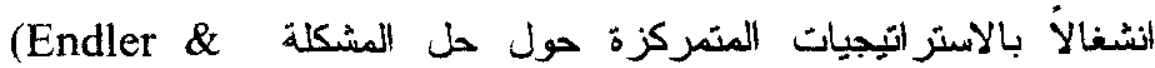
Parker, 1990; Hooker, Frazier, \& Monahan, 1999: Parkes,

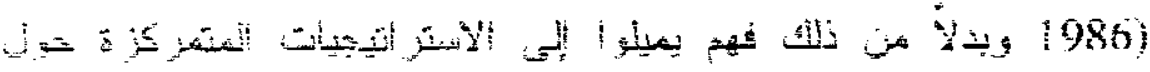

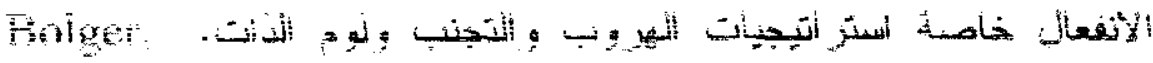


1990; Endler \& Parker, 1990; Hooker et al., 1994;

.McCrae \& Costa, 1986; Terry, 1994)

وعلى أساس من البيانات السابقة فهناك علم جزم بان العصابية

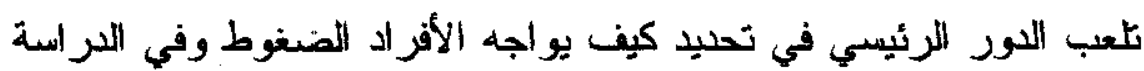

الحالية سيتم بحث العلاهة بين مفهوم عدم الاتزان الانفعالمي (بعد تنقية مفهوم العصابية وتحديده) وأساليب المواجهة (بعد بتقيتها أبضاً).

دراسيت الآبيسط وعلاتتها ياستراتيحيات المولحهة : يتصف الشخص المنبسط بالمتعة والنشاط والاهتمام والحماس اكثر من الشخص

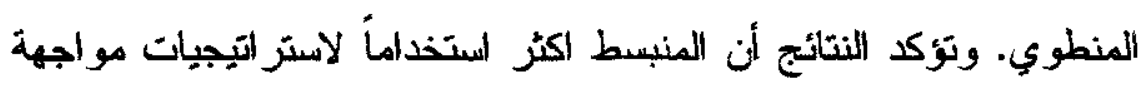
فعالة (McCrae \& Costa, 1986) فهو يستخلم اكثر استرانيجيات الفعلي المنطقي والتفكير الإيجابي وإيدال المكان المزعج كما أظهرت :تائج التحيل العاملي عامل يسمى "المو اجهة الناضجة" يرتبط بالانبساط. وقد أظهرت نتائج بحوث أخرى علاقات ارتباط إيجابية مع

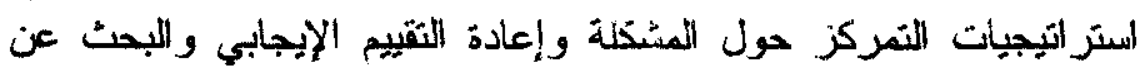

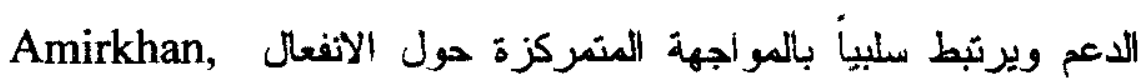
Risinger \& Swickert, 1995; Hooker et al., 1994; Rim, .1987; Vickers et al., 1989.

وتظهر نتائج "أميرخان" وآخرون \&isinger \& ارتباط الانبساطية ببعض استراتيجيات المواجهة Swickert, 1995) الفعالة متل البحث عن اللدعم الاجتماعي و اللثفاؤل. 
ويميل المرتفعون في سمة الاثبساط إلى المشاعر الإيجابية مثل

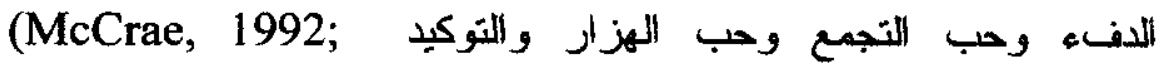
McCrae \& Costa 1987)

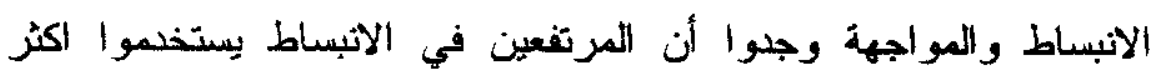

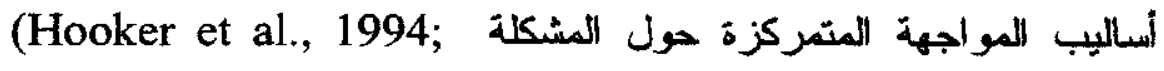
كما بنشغل المرتفعين McCrae \& Costa, 1986; Parkes, 1986) في الانبساط بصورة أقل بالاستراتيجيات السلبية منل التجنب ويستخدمون استر اتيجيات انفعالية إيجابية \&ooker ct al., 1994; McCrae \& (Hooker et al., منل التحث عن الدعم الاجتماعي Costa, 1986) (1994 ويستخدمون استراتيجيات لوم الأات والتجنب بصورة ألتل من التئن الانطو ائيين (Hooker et al., 1994) وفي دراسة أخرى \& Ender لم تظهر علاقات دالة بين الانبساط والاستر اتيجيات

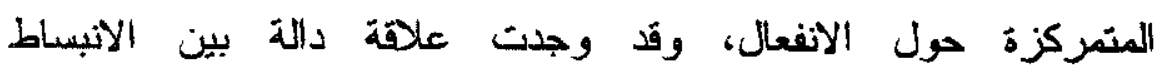
والاستر اثتيجية المتمركزة حول المهمة لاى الإناث.

ويشير نلك إلى أن النتائج متسقة فيما بتعلق بالعلاقة بين الانبساط

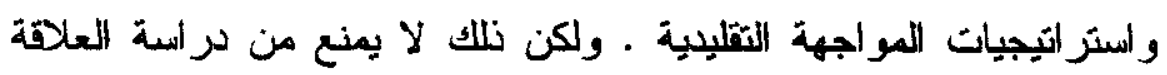

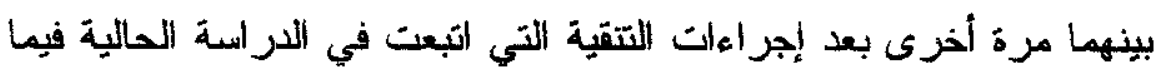
يتعلق بالسمات الكبرى و استر اتيجيات المو اجهة. 


\section{تعريف المفاهيب الأسيسية للتر اسية :}

تم تقميم عدد من النعريفات المقترحة للعاملين الكبيزين في

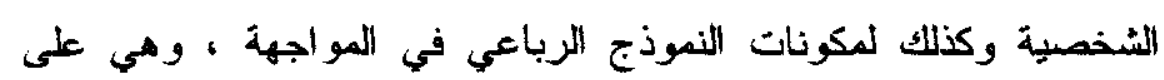
النحو التالي :

\section{أرلا : مغهوم الشخصية}

أ- الانفعالية : تشير إلى حالة من عدم الاتزان الوجداني ويشمل ذلك نقلب

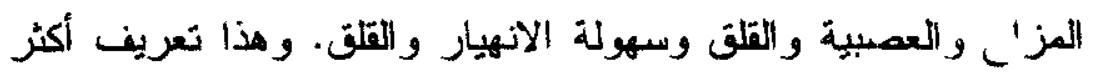

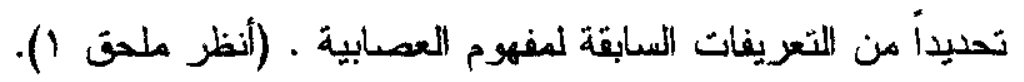

ب-الانبساط : يُّير إلى حب التواصل مع الناس والاستمتاع بذلك مثل الاستمتاع بلقاء أشخاص جدد وبتفضيل التعامل مع الناس وتكوين

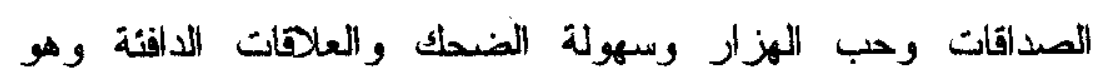

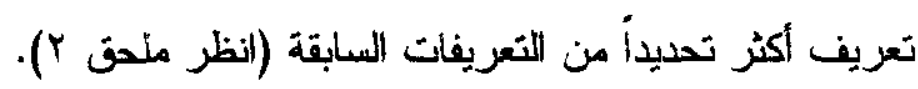

ثانيا : مفهوم المواجهة :

تم تصنيف مفهوم استر اتيجيات المو اجهة في أربعة فئات منسلسلة:

$$
\text { أ- المكون المعرفي الإفعالتي (الحوار الداظلي) : }
$$

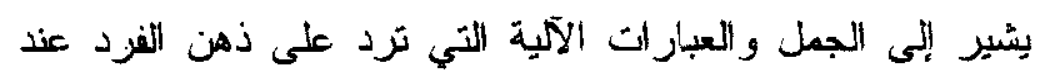

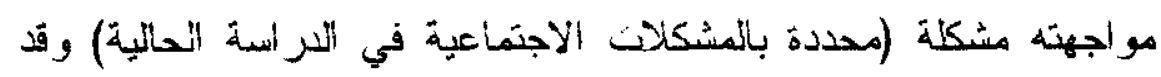

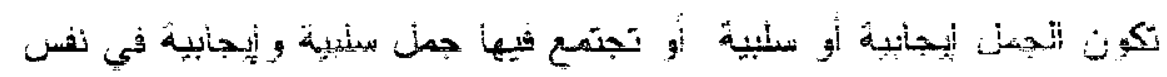




\section{ب- - بلوب المواجهة :}

يشير إلى الهوء والثأني (في مقابل الاندفاعية) عند مواجهة

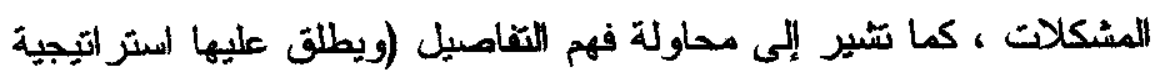
إعادة التثويم المعرفي في الدراسات السابقة).

ج- استر اتيجيات (أو عمليات) المواجهة :

تُشير إلى الطريقة التي يستخدها الفرد عند مواجهة لمشكلة، وقد تم تحيد

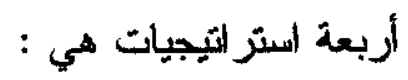

1- وضع خطة منظمة للأفعال (التخطيط العقلاني)

r- التمركز حول حل المشكلة (التفكير الموجه لحل المشكلة)

$$
\text { ع- ـ- التجنب (خشية التصرف فيزداد الأمر سوء). }
$$

وقد تم الستبعاد استراتيجية التمركز حول الاتفعال، حيث أنها لا

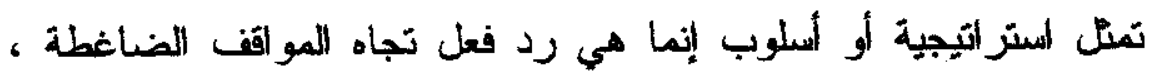

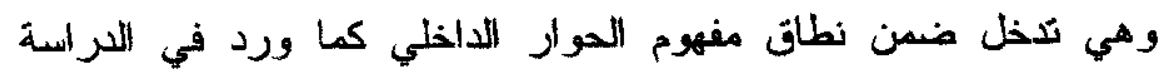

الحالية .

د- طرق خفض التوتز :

تشير إلى أي وسيلة يستخدمها الفرد إما : 
لكي ينفس عن انفعالاته منل (السب أو الشتيمة) (وتعتبر أحد أساليب التمركز حول الانفعال في البحوث التقليدية) أو لكي الكي يشتت ذهنه عن الانشغال بالمشكلة مثل مشاهدة التلفزيون أو اللجوء للمساندة الاجتماعية منل الجلوس مع صديق أو اللجوء للادين مثل الصلاة وقر اءة الكتب الدينية.

\section{س - المواجهة ميع المشكلات الاجتماتية :}

وقد تم تحديد نوعية المشكلات في الدراسة الحالية بانها المشكلات

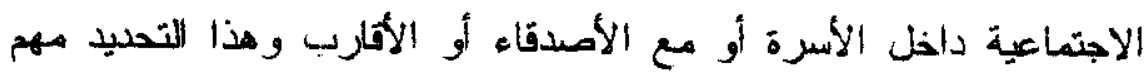

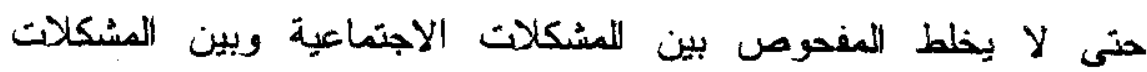

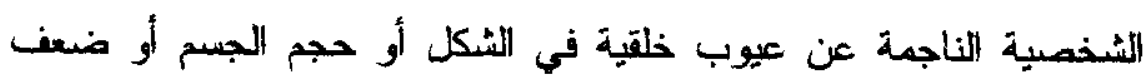

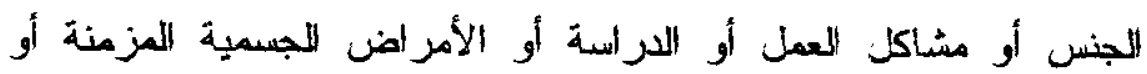

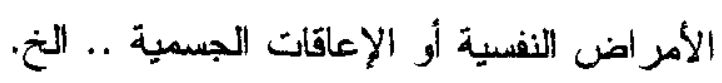

\section{فروض الدواسة :}

1- استخدام تعريفات محذدة (وضيقة) للعاملين الكبيرين في

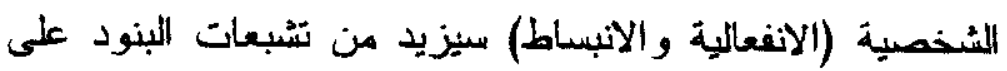
كل عامل في البيئة العربية خاص المصرية.

r- المتزنون انفعالياً والاثبساطيون يستخدمون طرث استرخاء تكيفية

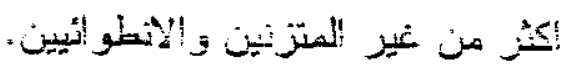


ب- لا توجد فروق بين المرتفعين و المنففضين في المتغيرين

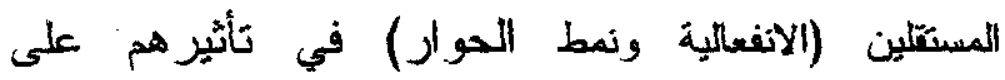

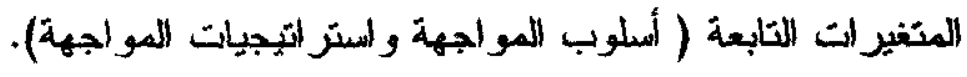
ع- لا توجد فروق بين المرتفعين والمنفضين في المتغيرين

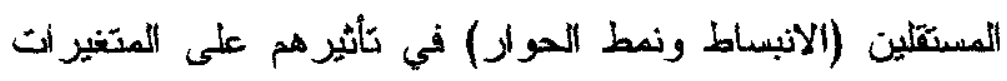

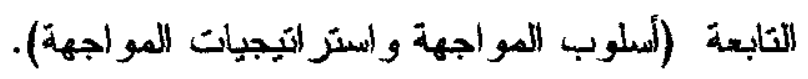

0- لا يوجد تفاعل بين المتغيرين المعنقلين الانبسطاط ونمط الحوار

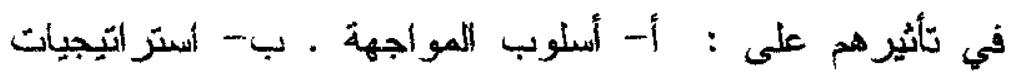

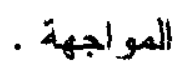

צ- لا يوجد تفاعل بين المتغيرين المستقلين الاتفعالية ونمط الحوار

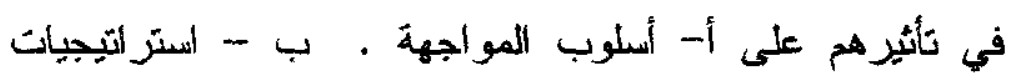

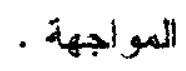

V- يفترض أن البندان المذكوران في مقياس التأني - الاندفاعية لهما

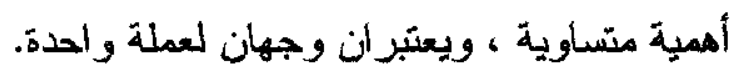

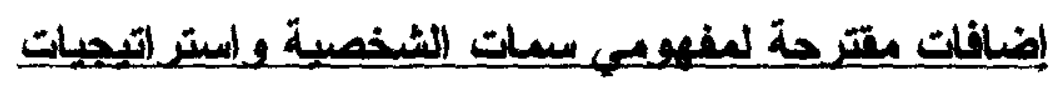

\section{ataly}

اقسترح الباحسـث الحالـــي إضــافات واقثراحات لمفهومي سمات

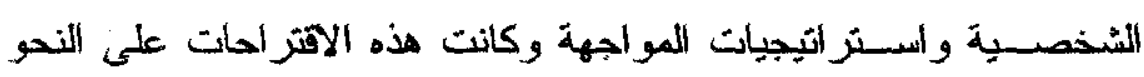
التاليه : 
أو لا : العاملان الكبيز ان ثم التركيز على عاملين كبيرين فقط من عو امل الثخصية و هما الانفعالية (عدم الالتزام الانفعالمي أو العمابية) والانبساط. وكانت الخطوة الأولى هي تصنيف بنود أهم أربعة مقاييس لدراسة

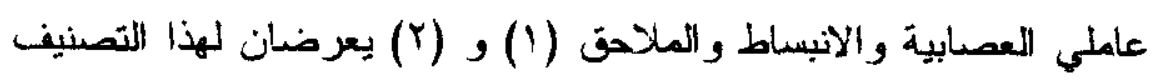

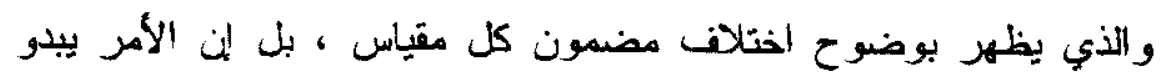
وكأن كل مقياس بقيس مفهوم مختلف عن الأخر .

و هناك عدة ملاحظات هامة يمكن استتاجها من الملحق (1) .

Y- أن مقياس EPQ يثمل أكبر عدد من السمات بمكن تصنيفها في

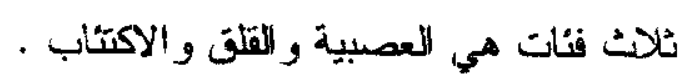

r- أما مقياس BFI فإنه يعرض لعدد محدود من البنود ثقيس العصبية

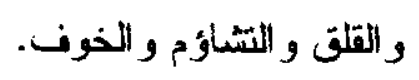

؟- أما مقياس NEO-FFI-R فإنه يقيس سمات مخثلفة عن ما سبق فهناك بنود عن الخجل والتميز والانهيار والغضب والهبل وقلة الحيلة بالإضافة إلى العصبية. - أما مقياس العو امل السبعة IPC-7 فإنه يقيس العصبية والاكتثاب-

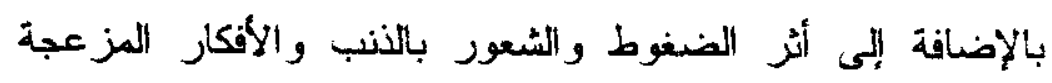

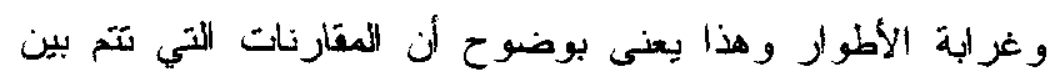

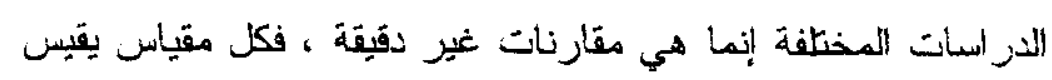

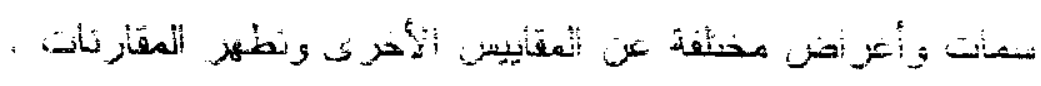
" lem 


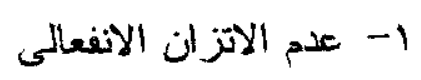

r- الاضطراب النفسي مثل العلق والاكتئاب والضعف النفسي

$$
\text { والوسواس القهري. }
$$

ويقترح الباحث أن يحل مفهوم عدم الاتزان الانفعالي (الانفعالية)

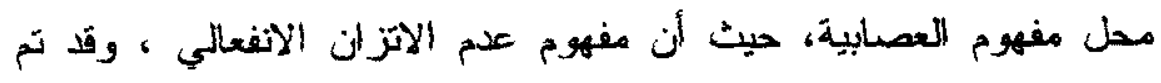

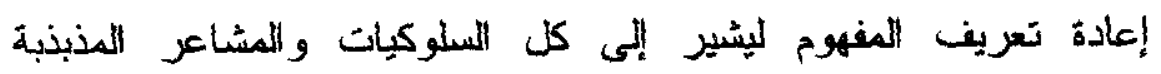

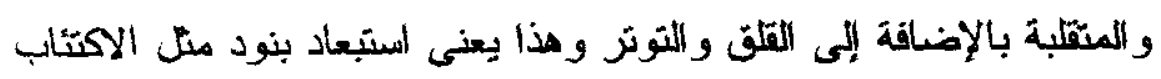

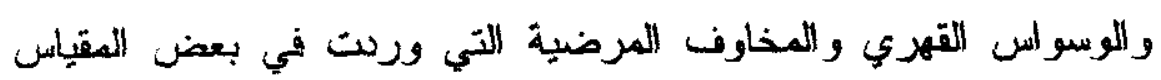

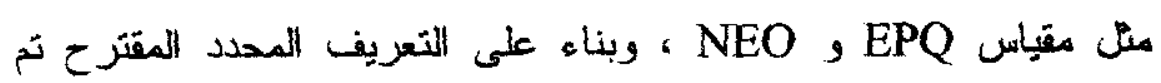
EPQ, اختبار البئود التي تتاسب هذا التعريف وذللك من المقاييس الأربعة وبناه . BFI, NEO, IPC-7

وبالنسبة لمفهوم الانبساط فإن الباحشين يستخذمون تعريفات

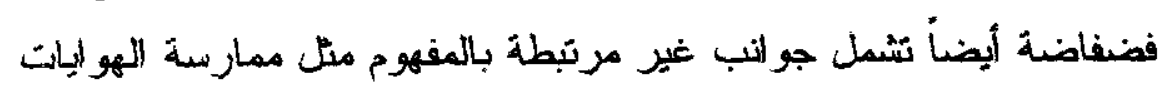

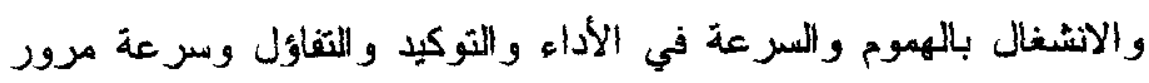

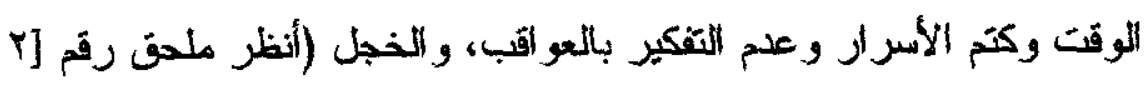

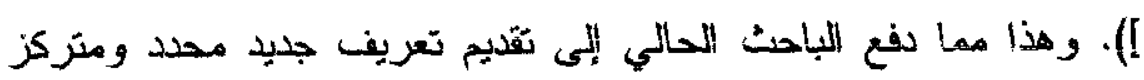

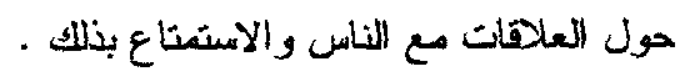
ويتيح التعريف الجليد لمفهومي الاتزان الوجداني والانببسط دقة

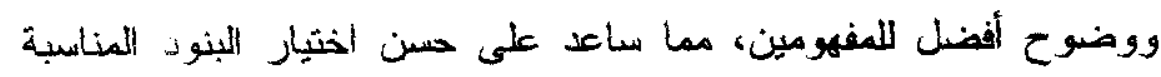
للتعريفين الجديدين. 


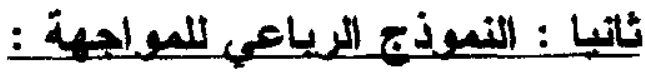

بعد الستعر اضر التزاث وبيان جوانب الثناقض والاختلاف في

مفهوم أستراتيجيات المواجهة فإن الباحث الحالي بقترح نموذجا رباعين

يسنو عب مكونات المفهوم · هذا النموذج يفترض فيه ورجود تسلسل لهذه

المكونات فهناك مكونات تسبق مكونات أخرى ، كما أن أستراتيجية

المو اجهة المتمركزة حول الانفعالات لا تمثل في الحقيقة أي استراتيجية إنما هي خليط من الحوار الاخلي للفرد (إيجابي أو سلبي) وكذلك لطرق خفض المتوتز وكلاهما بيستر عبه النموذج الرباعي.

مثلخً يفترض ان مكون الجوار الاخلي يسبث كل مكرنات مفهوم

استراتيجيات المو اجهة بل أنه يمل مكون أساسي ومحوري ملت مفهوم

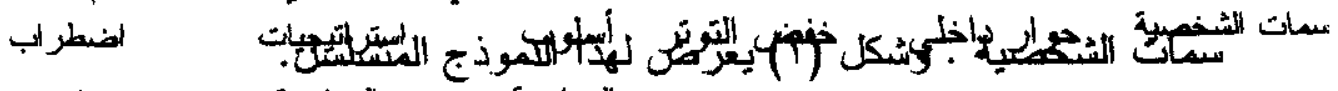

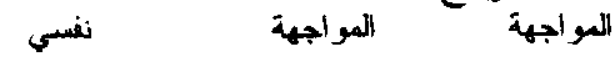

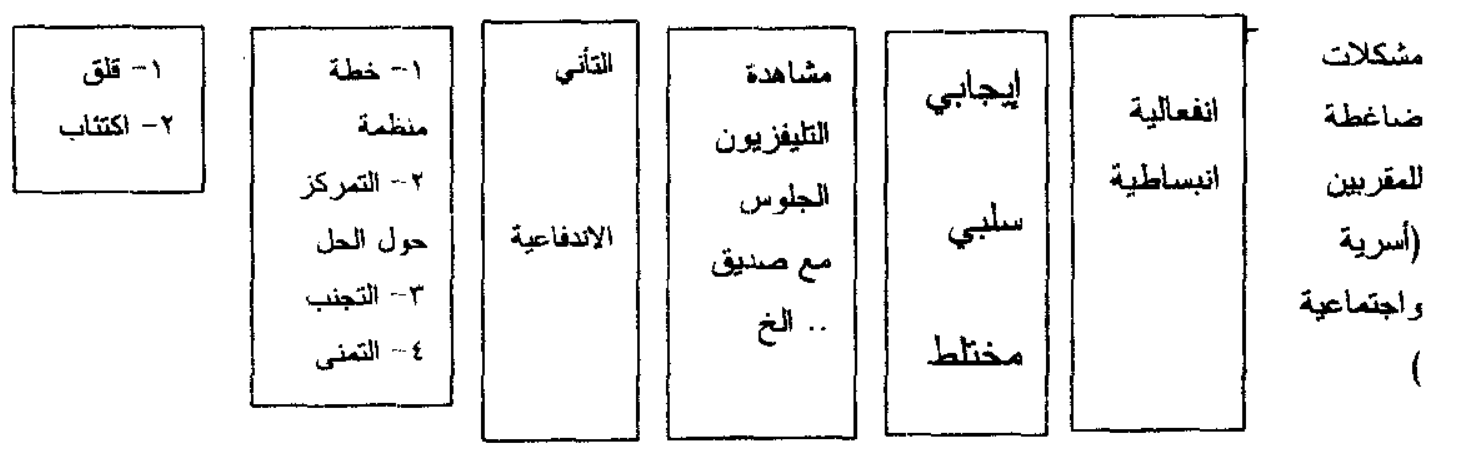

شُكل تخطيطي (1) يعرض لنسلعل منطقي لمكونات مفهوم

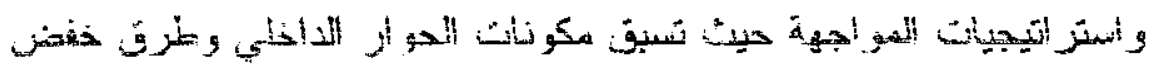

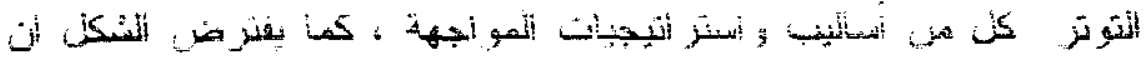


اتجاه البحث يبدأ من مكونات النشخية والحوار اللداخلي وينتهي باستر التيجيات المواجهة.

يعرض النموذج لأربعة مكونات متسلسلة في مفهوم استر اتيجيات

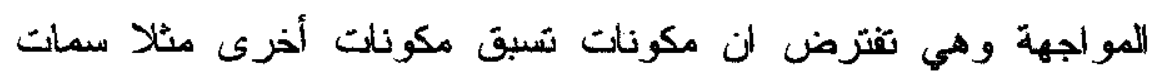

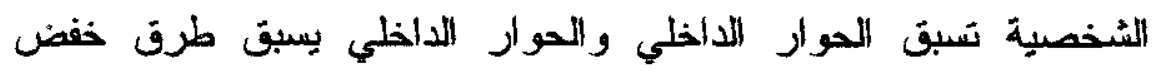

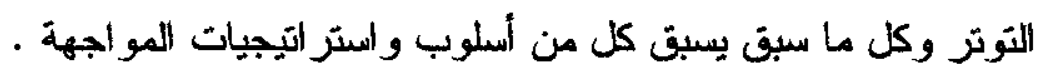
أولا : الحولر الداخلي : ويشير إلى الحوار الداظلي وينقسم إلى ثلانة أنماط: 1- النمط الإيجابي : الذي يغلب على حواره الأخلي جمل وعبارات

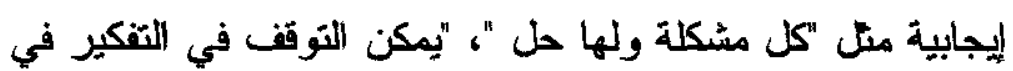
المشكلة عندما أريد".

Y- النمط السلبي : الأي يغلب على حواره الداخلي جمل وعبار ات

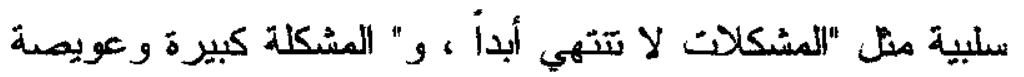
ولا أسنطيع تحملها "..

r- النمط المختط: ويشمل جمل إيجابية وسلبية في نفس الوقت . وسيرد تفصيل ذلك في الجزء الخاص بإجر اءات اللر اسة . كانيا : طرى الاسترخاء :

أي طريقة أو وسيلة بيتخمها الفرد في محاولة منه لتشّتيت ذهنه

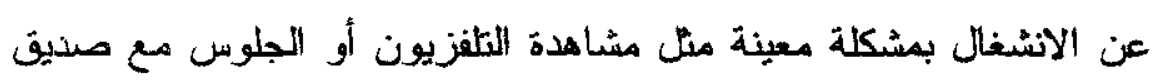
أو ربما التشاجر مع الآخرين أو قراهة الكتب الدينية. 


\section{ئلثا : أسلوب المواجهة :}

ويشير إلى أسلوب وخصائص المواجهة وهو ما يطلق عليه التأني

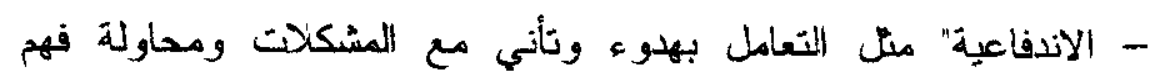
تفاصيل المشكلة (المقويم المعرفي) قبل بدء حل المشكلة.

رابعا : استراتيجيات المواجهة :

وبتير إلى طرف مواجهة الفرد للمشكلة ، وقد تم تحديدها في أربعة

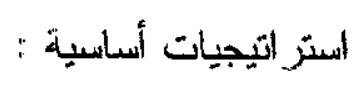

1- خطة منظمة للأفعال (التخطيط) لحل المشكلة : أضع خطة

$$
\text { منظمة لما سوف أفعله. }
$$

r- التمركز حرل حل المدّكلة (أو الإنشغال المفرط) : أركز على

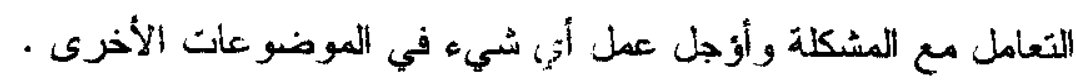

$$
\text { r- التجنب : أخشى أن أتصرف فيزداد الأمر سوءا. }
$$

؟- التمني : لا افعل شيء فقد تحل المشكلة بدون تكخل منى.

\section{إجراءات الدراسة}

تحدد إجراءات الدراسة في الخطوات التالية :

وبالآضافة اللفروض السابقة فسيتم اختبار طريقة جليدة مقترحة "طريقة البنود المسيطرة" حيث 


\section{$r \Delta \wedge$}

بختبر اللباحث طريقة جديدة لإعطاء اللارجات في نوعية معينة من مقاييس الشخصية، ويبدو أن الطريقة المقترحة تناسب مقياس الحوار الداخلئي.

\section{إجزاءات الدراسة :}

تحست إجر اءات الدر اسة الحالية في كل من :

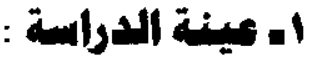

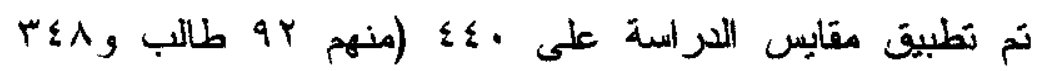

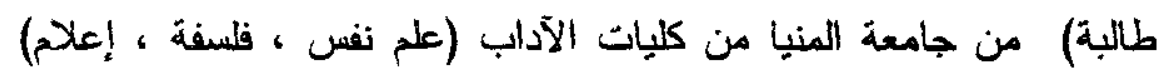

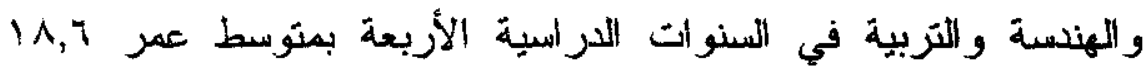
وانحراف معياري 1, ا للطلبة ومتوسط عمر r, 19, وانحراف معياري

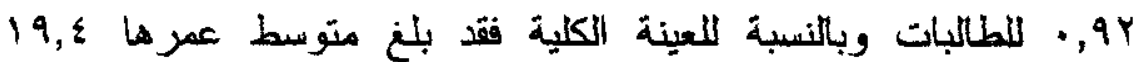

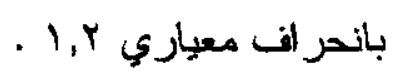

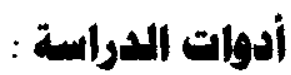

تكونت أثوات المراسة من سنة مقاييس ( جميعها من اقتراح الباحث) ، ايثان منهما لقياس السمات الكبرى في الشخصبة (العاملان

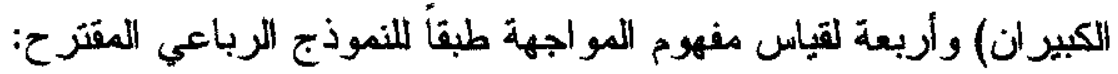

: الثباث

تم حساب ثبات المقاييس المستخدمة بعدة أسباليب ونلاك للتحقق من لمعايير السيكومترية وجنول (1) يبين معاملات ثبات المقاييس المستخدمة. 
جدول (1) معاملات الثبات كما تظهرها طرق إعادة التطبيق و "جوتطان" و"

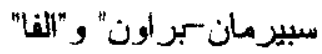

\begin{tabular}{|c|c|c|c|c|}
\hline ألفا & سبراون & جوتمان & إعادة الثططبيق & \\
\hline$\cdot, V Y$ & $\cdot, \lambda r$ & $\cdot, v r$ & $\cdot, \mathrm{YA}$ & عدم الاتزان \\
\hline זה, & $\cdot, \wedge \varepsilon$ & $\cdot, \wedge \varepsilon$ & •, & انبساط \\
\hline$\cdots, v r$ & $\cdot, v_{1}$ & $\cdot, v_{1}$ & 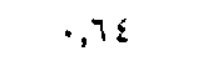 & حوار ايجابي \\
\hline$\cdot, 79$ & $\cdot, V V$ & $\cdot, V Y$ & $\cdot, 7$ & حوار سلبي \\
\hline - & - & - &,$r$ & أدفاعية \\
\hline - & - & - & .0 & أسلوبب \\
\hline ع 1, & $\cdot, 0 \varepsilon$ & $,, 0\}$ & - is & خفض التوتز \\
\hline & & & $\cdot, 91$ & نمط الحوار \\
\hline
\end{tabular}

أولا : مقايسيس السيمات الكبرىى :

\section{أ- مقياس الاتفعلية :}

(عدم الاتزان الانفعالي) : ويتكون من Y ا بند ، وقد أعده الباحث

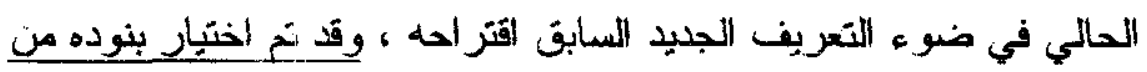

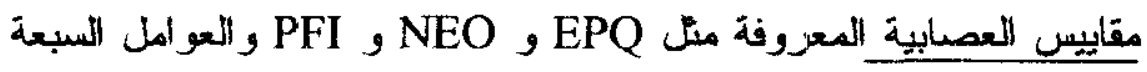


IPC-7 العامل (أكون قلق على أمور لا يصح فعلها).

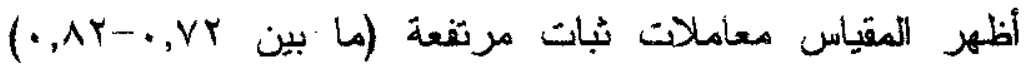
ونلك باستخدام معاملات ثبات إعادة التطبيق و "جوتمان" و "سبيرمان -

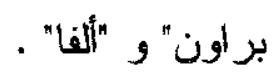

وبالنسبة لصدق المقياس الاداخلي فقد تم حساب ارتباط كل بند

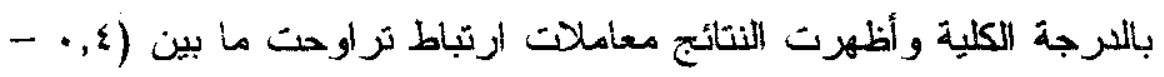

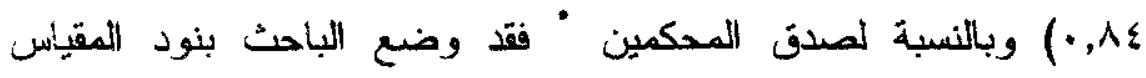

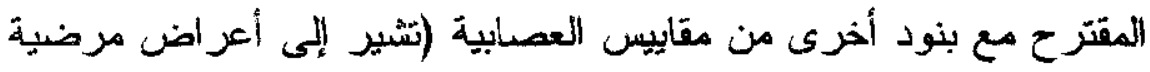

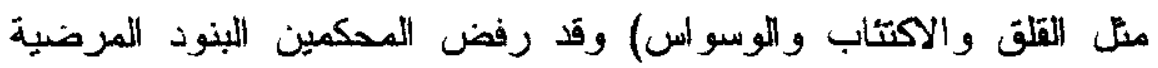

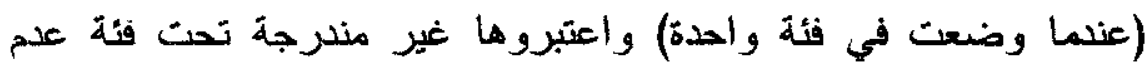

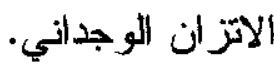

وفيما بتعلق بالصدق اللعاملي فقد أظهرت نتائج التحليل المعاملي

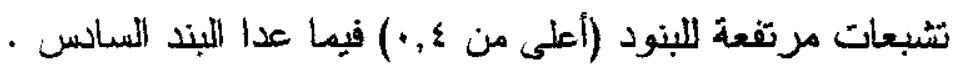

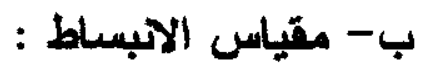

ويتكون المقياس من 10 بند ، واختيرت عبار اته من مقاييي الانبساط السابقة خاصة المقاييس الأربعة السابق نكرها.

"يشكر الباحث الزملاء المشاركون في التحكيم وهم : د. هبة إبراهيم و د. إيمان

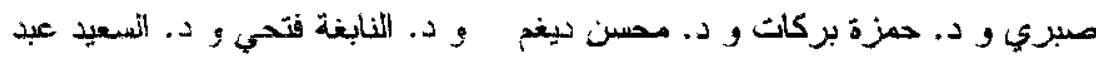

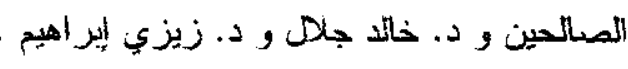




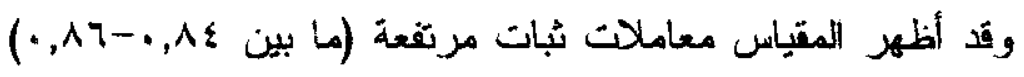

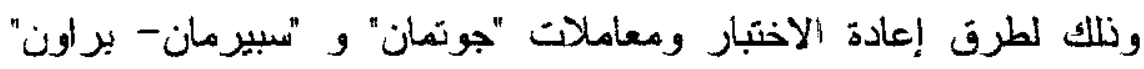
وألفا. ولم يتم اسنبعاد أي بند.

وبالنسبة للصدق فقد تم حساب معاملات الصدق الداخلي (ارتباط

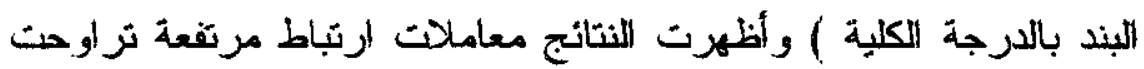

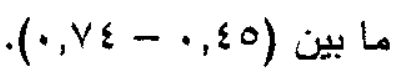

وبالنسبة للصدق العاملي، فقد ظهرت تشّبعات مرثفعة للبنود على العامل (وجميعها أعلى من ع, •.)

\section{ثاتبا : مقاييس المواحهة :}

أ- مقياس التأثي - الأدواعية : وقد نكون من بندين فتط الأول

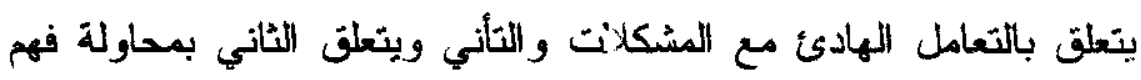

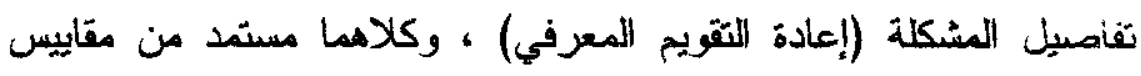
المو اجهة الثقيدية.

الثبات : أظهرث النتائج معاملات نبات منخفضة وهي نتيجة

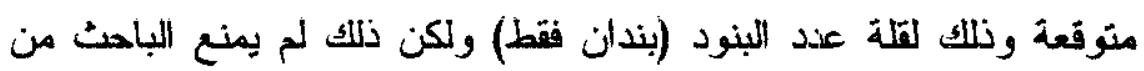
الاعتماد على نتائجه .

الصدق : تم الاعتماد على صدق المضمون والبندان منكرر

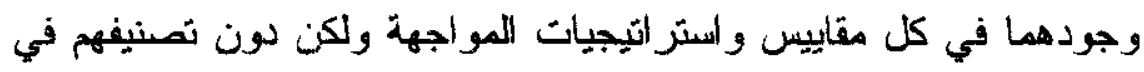

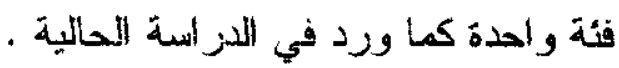




\section{ب- مقياس استراتيجيات المواجهة :}

وبيكون من أربعة بنود فقط تقيس اللتعريفات السبابقة لمفهوم

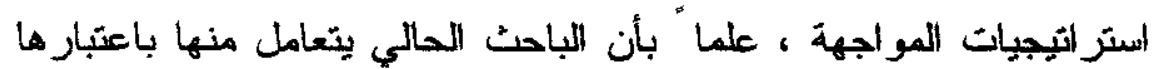
بنود منفصلة فهي لا تكون وحدة واحدة ، ولا يصلح معها المعالجات الإحصائية التي تفترض أحابية أو ثنائية القطب (مثل أبعاد الشخصية). وقد أظهرت معاملات ثبات إعادة التطبيف معاملات ثبات منخفضة نسبيا (0, +) ويجب الإثارة إلى أن إعادة التطبيق قد تم بعد ثلاثة أسابيع ويبلو أن المو اقف الاجتماعية الضاغطة تكون متغيرة في الفتز ات القحيرة (خلص الأسابيع الثلاثنة) ويعنى نلك أن هذا المقياس حساس لمنغير الزمن ويبدون أن إعادة النطبين سيزيد من عامل اللبات إذا تم إعادة التطبيق خلا أمبوع إلا أن ذلك الإجراء سيكون غير سليم بسبب تذخل متغير

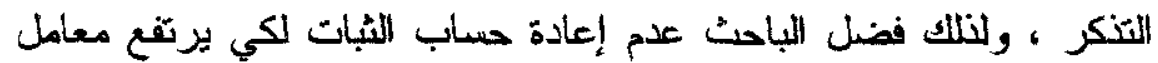
الثبات . ويبدو أن مفهوم الثبات نفسه بحاجة للمراجعة لعدم مناسبة استخدامه مع بعض المكونأت النفسية وكذلك لعدم مناسبئه للاستخدام مع ه المقاييس قليلة البنود. ويجب الإشارة إلى أن استراتيجيات المواجهة الأريعة تزد في أغلب المناذج و المقاييس التي تدرس المفهوم . والبنود كنها تشير إلىى أسترانتيجيات متفق بشأنها بين علماء النفس المهنمين بالمقياس ، و هذا مؤشر لصدق المضمون. 
ج - مقياس طرق خفض التوتر :

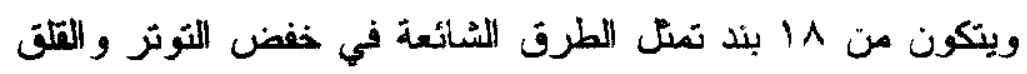

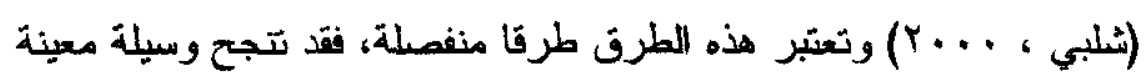

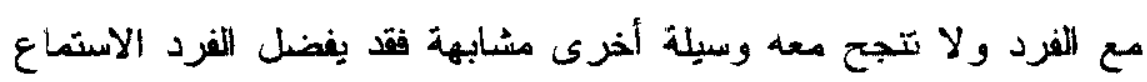
للأغاني كطريقة لخفض التونز ولا يفضل مشاهدة الأفلام ، ويمكن تصنيف طرق خفض التوتز إلى طرق نكيفية مثل الجلوس مع الأمدقداء وطرق غير تكيفية منل تتاول المو اد المخدرة.

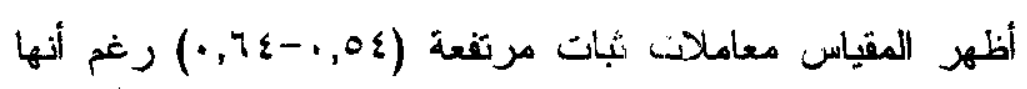

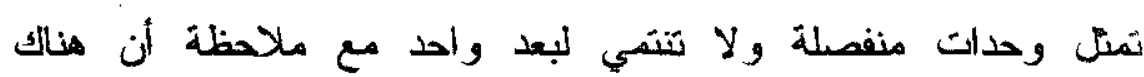

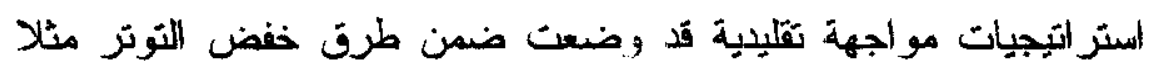

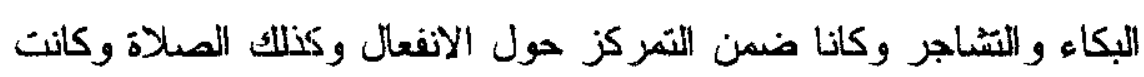

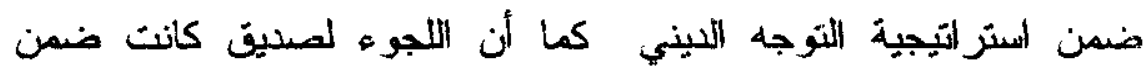
السنز التيجية المساندة الاجنماعية.

$$
\text { د - مقيلس الحوار الداخلي : }
$$

تكون اللمقيائن هن IA بنا بعضها يشير لحوار داخلي ليجابي

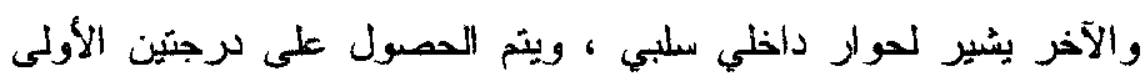

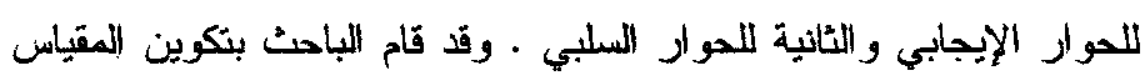
من خلا استعر اض النتراث المنشور. إجر اءات إعطاء الذرجات على مقياس الحوار النداخلي : 
طلب من كل مفحوص شارك في البحث أن يكتب جملتين من جمل الحوار اللواردة في المقياس، على أن تكون هذه الجمل هي الأكثر

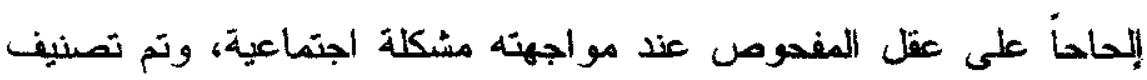
جمل الحوار المختارة في ثلاثة فئات هي :

1- نمط الحوار الداخلي الإيجابي الخالص Positive Internal Dialogue (PID Type) الإيجابية.

Mixed Internal بم الحوار الاخلي الخليط او السلبي المقاوم Dialogue (MID Type)

$$
\text { إيجابية وأخرى سلبية . }
$$

Negative Internal ب- بمط الحوار الداخلي السلبي الخالص Dialogue (NID Type)

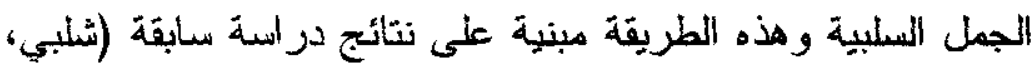

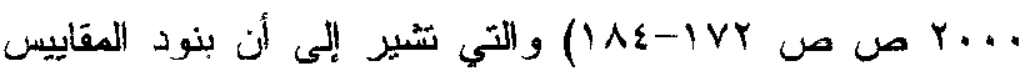

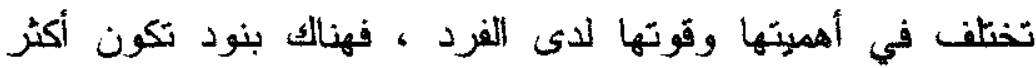

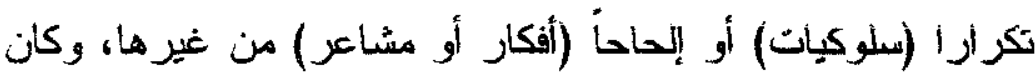
من الضروزي أن نختبز هذه الطربقة المقترحة. وقد ظهرت معاملات ثبات مرتفعة للغاية (19, •) عند الستخدام

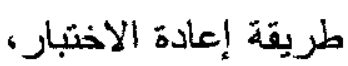
وبالنسبة اللصدق فقد أظهر التحليل العاملي وجود ثلاثة عوامل 
1- الإيجابي. ب- السلبي المقاوم (الخليط). السبلبي

المستسلم.

وبذلك بتفق مع افتز اضات الباحث في وجود ثلائة عوامل هي

الإيجابي و السلبي و النخليط

التصميم البحثي

تم تصميم هذا البحث على أساس وجود نيلاثة متغير أت مستقلة هي : 1- الانفعالية (عدم الاتزان الاثفعالي) ب- الانبساط . س- الحولر - الداخلي

و المتغيرات التابعة هي :

1- بنود مقياس (بندان) أسلوب المواجهة (التأني - الاندفاعية) .

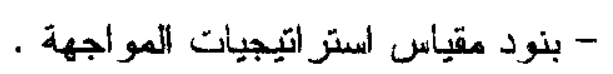

إجزاءات جمي البيانات :

تم تطبيق المقاييس المستخدمة في الدراسة الحالية في جلسات

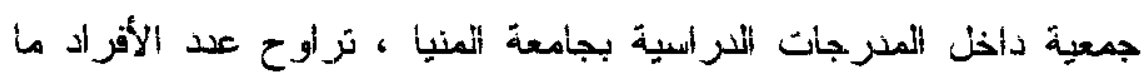

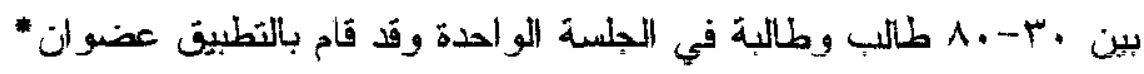

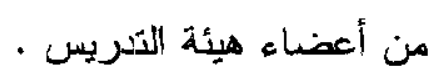

التحليلات الإحصائية :

" يشكر الباحث الزميل د. النابغة فتحي لمساعدته الباحث في تطبيق استمارة البحث . 


\section{r9}

تم وضع خطة للتحليل الإحصائي شملت عدة أساليب لاختبار فروض الدر أسة.

خطة التحليل الإحصائي : 1- تحليل عاملي لمقياس الانفعالية والانبساط.

Y- "كا" اللمقارنة بين المرتفعين و المنخفضين في عاملي

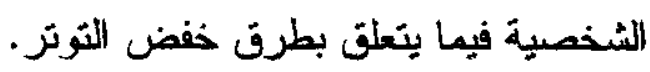

r- تطليل النباين المتعدد MA NOVA ونلك لدراسة أثز المتغير ات المستقلة (مرتفعي ومنخفضي الانفعالية والانبساط)

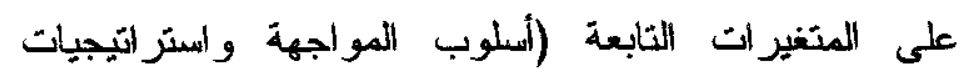

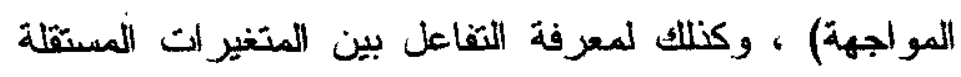

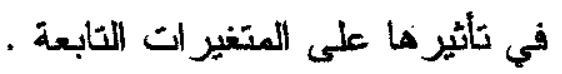




\section{ry}

\section{نتائم الدراسة}

نعرض في هذا الجزء لنتائج التحليلات الإحصائية التي أجريت

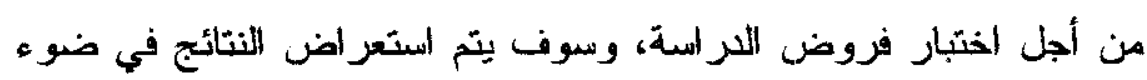
الفروض الأساسية .

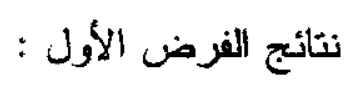

لاختبار صحة الفرض الأول الخاص بأن استخدام تعريفات محددة

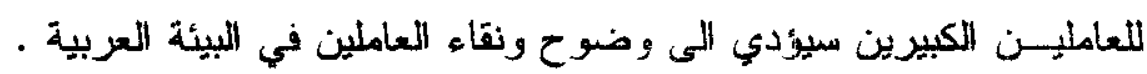

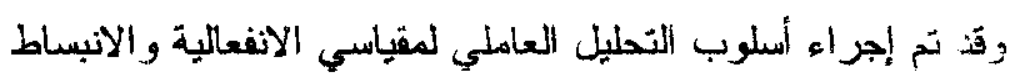
أولا : العلملان الكبيران :

تم حساب التحليل العاملي للعاملين الكبيرين (الانفعالية والانبساط)

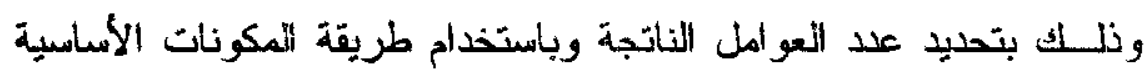

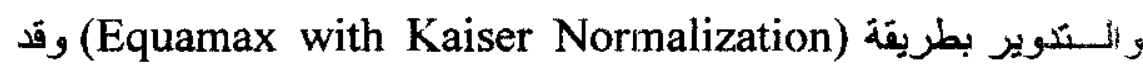
أظهرت النتائج وجود :عاملين كبيرين هما الانفعالية والانبساط. وكمســ نظهـــر النتائج بتعلق العامل الأول بعدم الاتزان الانفعالي

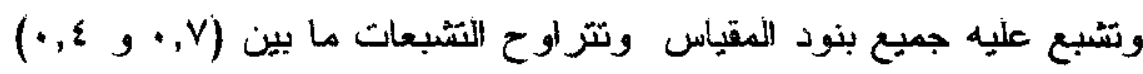

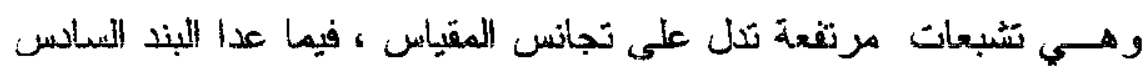
(تشبع VY, , ) وقد تم استبعاد البند عند إجر اء التحليلات الإحصائية التالية.

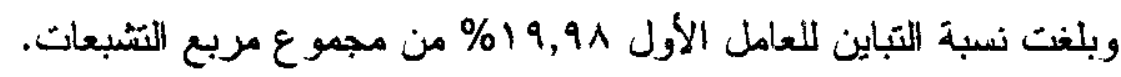


كما أظهرت النتائج وجود عامل ثاني يسهل تسميته بالانبساط فقد

تشبعت عليه جميع بنود المقياس وثر اوحت التشبعات ما بين (V0, • - -

$$
\text { ـ \& , · ) وهي تشبعات عالية. }
$$

وقد بلغت نسبة التباين للعامل الثاني r, Y ا \% وهي نسبة عالية لم

$$
\text { تظهر في مراسات عديدة. }
$$

وبفترض نتائج التحليل العاملي قوة العاملين الكبيرين في الشخصية

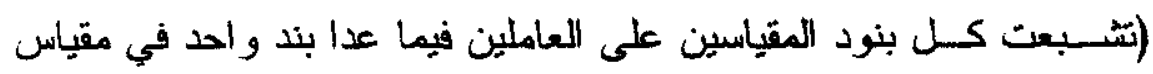

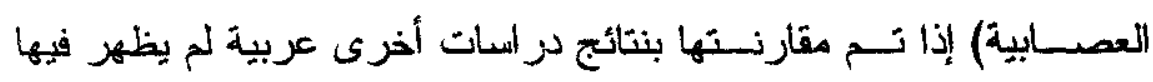

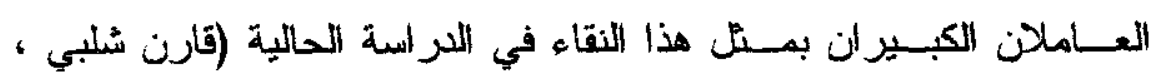

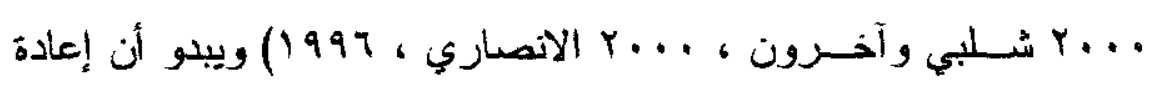

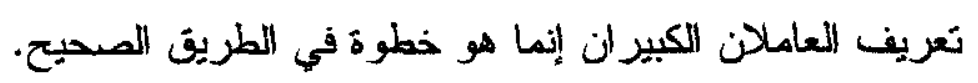
الفرض الثنانمي :

لاختــبار الفرض الثاني الخاص بوجود ثلانة عوامل واضحة في

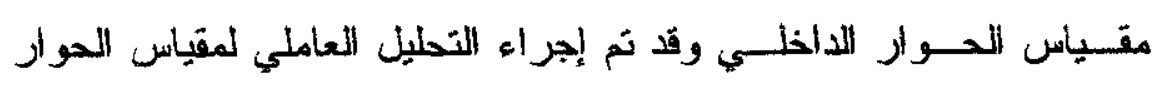

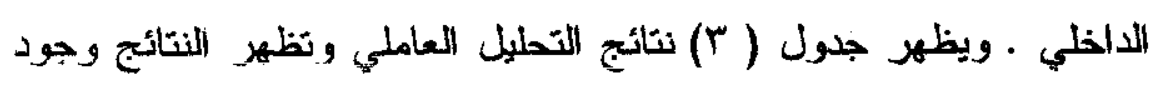

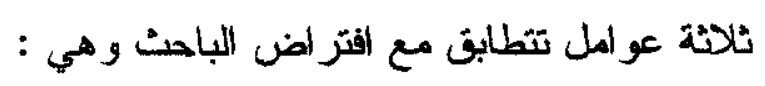

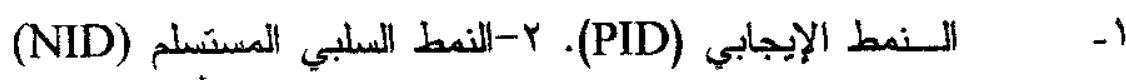

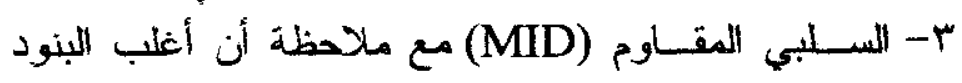
المتّبعة على هذا العامل هي بنود تشير الى الاكتئانب. 
جرل (r) نتائج التحطيل العلملي مقياس الافعلاية والاتبساط

\begin{tabular}{|c|c|c|c|}
\hline \multicolumn{2}{|c|}{ المعوأمل } & \multirow[t]{2}{*}{ مضمون النبند } & \multirow{2}{*}{ الاتفعيانلية } \\
\hline النئني & J, & & \\
\hline & $\cdot$, or & تقلب المزاج & 1 \\
\hline &., 79 & اللزرفزة لمشكلات بسيطة & Y \\
\hline & $\therefore, v$ & سهولة اللنرفزة & $r$ \\
\hline & $\cdot, 0 \mathrm{~V}$ & عصبية المز اج & 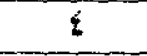 \\
\hline &., $9 r$ & اللتضايق من المشكلات الصغيرة & 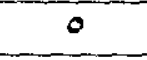 \\
\hline & $\therefore, Y V$ & القلق من أمور لا يصح فعلها & 7 \\
\hline & $\therefore, \leqslant 0$ & سُيل الهمب & $\bar{v}$ \\
\hline & 0,29 & هو اجهة الحدلث سيئة & $\Lambda$ \\
\hline &., $0 \mathrm{r}$ & الْمرور بخيرة عجلة & 9 \\
\hline &,$+ \varepsilon \varepsilon$ & جرح المنساعر & 3 \\
\hline & 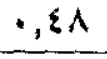 & الانهيار بسهورية & 11 \\
\hline & $\therefore \leqslant r$ & الخجل & ir \\
\hline & & & مالأنبئس \\
\hline$\therefore, 17$ & & كثرة الكلانم & 1 \\
\hline., 01 & & الاستمناع بأشخاص جدد & $Y$ \\
\hline$\therefore, 01$ & & ألمون في مركز المضوء & $r$ \\
\hline$\therefore \leqslant \Lambda$ & & أفضل التععلمل مي الناس & $\varepsilon$ \\
\hline., 09 & & لهي الصنقاء كثبروني & 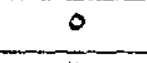 \\
\hline., 70 & & أبادر بالتعرف علي الأصدقاء & 7 \\
\hline$\therefore, 05$ & & $15 \mathrm{ij}$ & $\checkmark$ \\
\hline$\therefore .0 \mathrm{~V}$ & & أحب الاختلغم & 1 \\
\hline$\therefore$, Yo & & أبعت الحيورِية & 9 \\
\hline$\therefore, Y$ & & لحب الاندارة & 1. \\
\hline$\therefore, 01$ & & يز انيى الآخرون نشبيط & 11 \\
\hline$\therefore, 0 r$ & & أضحك بسهولية & IY \\
\hline$\therefore, \varepsilon \varepsilon$ & & عالماني دافنة & Ir \\
\hline., $0 \mathrm{~V}$ & & أحب الهزئ & $1 \varepsilon$ \\
\hline
\end{tabular}




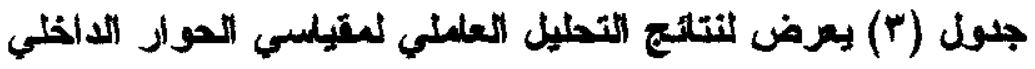

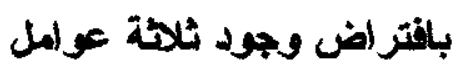

\begin{tabular}{|c|c|c|c|c|}
\hline \multicolumn{3}{|c|}{ Jilged } & \multirow[t]{2}{*}{ مضسعن اللبن } & \multirow{2}{*}{ رلبند } \\
\hline$r$ & $Y$ & 1 & & \\
\hline$\cdot .18-$ & $\because \cdots$ & $\cdot, \mathrm{V}$ & اللتنلب طى المشكلات & IV \\
\hline., 1, & $\cdot, \ldots$ & $\cdot, 7 \mathrm{~A}$ & المستقبل مشرق & $1 \varepsilon$ \\
\hline$\because, \cdot$ & $\cdots$ & $\cdot 7 \mathrm{~V}$ & أنا محظوظ & 10 \\
\hline., 14 & $\because \cdots$ &., 49 & ل S & 0 \\
\hline 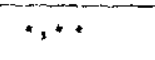 &,$\cdots$ &., 70 & أن ائئل & 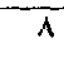 \\
\hline$\cdot, Y$. & $\cdot, 49$ & $\cdot, \leqslant \lambda$ & ربنا :هون السشكلات & $\bar{T}$ \\
\hline$\cdot, 47-$ & $\cdot, r 1$ &., 10 & كن ئزمني آحد & 11 \\
\hline$\cdot . \mathrm{Tr}$ & $\cdot, \overline{1 Y}$ &., 49 & التوفن عن التنكير في المشكلة & $\xi$ \\
\hline$\cdot, Y 7$ & $\cdot, T$ & $\cdot, \mathrm{KI}$ & آنا تععِس منذ طنولتي & 11 \\
\hline$\cdot, \cdots$ &., 79 & $\cdots, \cdots$ & المشكلحت لا تنتهي & $Y$ \\
\hline$\cdot, 11-$ &., 77 &., 10 & الناس شرلا & 9 \\
\hline., 10 &., 71 & $\because 14-$ & لماذا أنا بالذات & 17 \\
\hline •, rE & .01 & $\because \cdots$ & الخوف من العو ألتب & 11 \\
\hline$\cdot, r y$ & $\cdot, \$ 4$ & $\because, \cdots$ & المشكلة عويصة & 1 \\
\hline$\cdot, r \pi$ & $+\cdots$ &,+ 11 & الثل يعالَّبني & $\bar{Y}$ \\
\hline$\sqrt{n}$, & $\cdot, \overline{Y V}$ & $\cdot, \cdots$ & أنا سبب المثتكلات & 1. \\
\hline $.0 \mathrm{~V}$ &., $\mathrm{TV}$ & $\cdot, \cdots$ & آخطانتي وغباتي هما السببب & ir \\
\hline$\cdot, \leqslant \varepsilon$ & $\cdot Y$ &.,$Y 0-$ & آنا فاشل & $\bar{r}$ \\
\hline
\end{tabular}


وقد أظهرث وجود نلاثة عوامل (بعد التكوير بطريقة

هذه العوامل هي (Equamax with Kaiser)

1- العامل الأول : الحوار الإيجابي (الخالص)

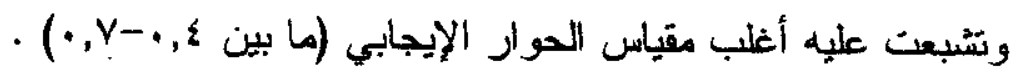
r- العامل الثاني : '"حوار السلبي (الخالص) المستسلم.

وتشبع عليه بنود ثتعلق بمواجهة مشكلات اجتماعية صعبة (أي أن

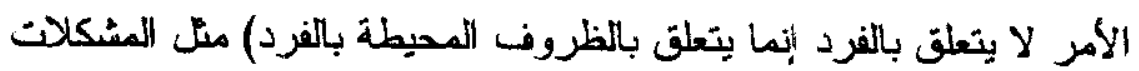

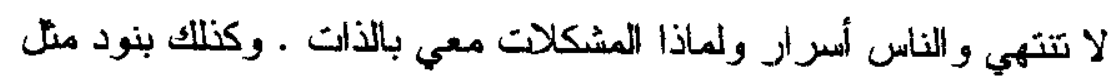
الخوف من العو اقب وأن المشكلة كبيزة وأن الله يعاقب الفرد.

ب- العـامل المثالث : الحوار السلبي المقاوم (أو الخليط) ويتشبع عليه بنود

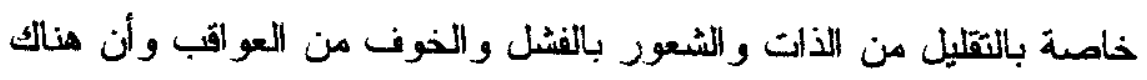

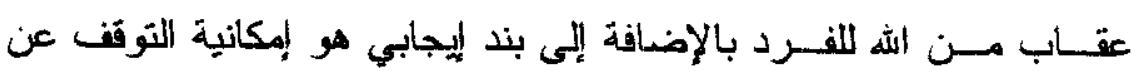

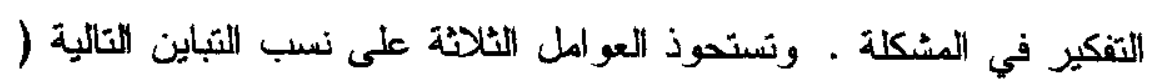

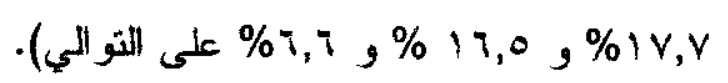

وتذعم هذه النتائج الفرض الثاني الخاص بوجود ثلانثة أنماط : أ أ- الأنمط الإيجابي.

ب-النمط الخليط (أو السلبي المقاوم).

ت-ألنمط السلبي .(السلبي المستسلم). 


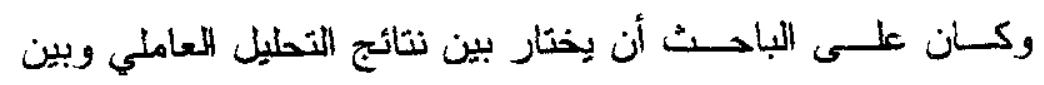

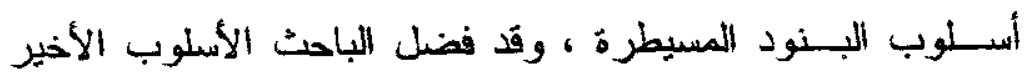

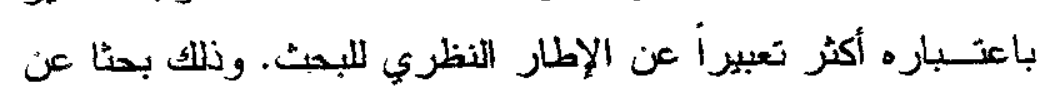

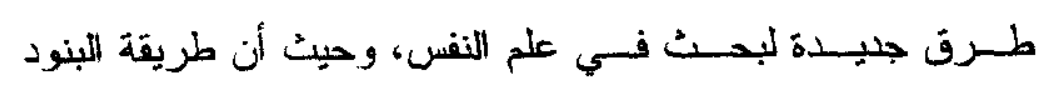

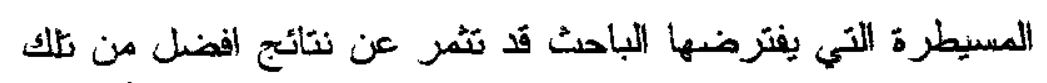

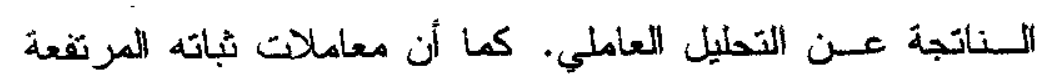
تجعله مفضلا عن استخدام نتائج التحليل العاملي. الفزض الثنتي :

لاختـبار الفرض الثاني الخاص بوجود فروف في استخدام طريق

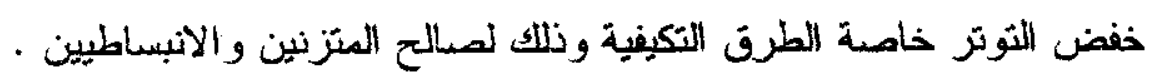
تدعـم النــتائج (جلول \&) صدق الفرض الثاني من أن المثزنين انفعالياً والمنبسطين يستخدمون طرق استرخاء نكيفية وصحيحة. أو لا : المقارنسـة بيسن المرتفعيسن والمنففضين على مقياس عدم الاتزان الانفعالثي : الأل

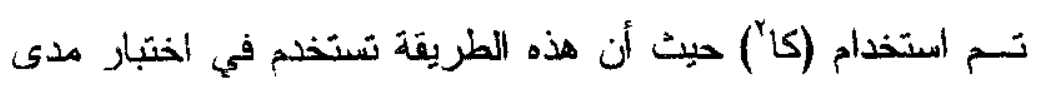

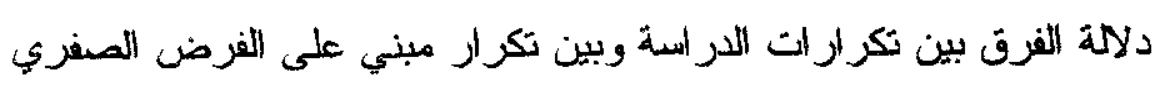

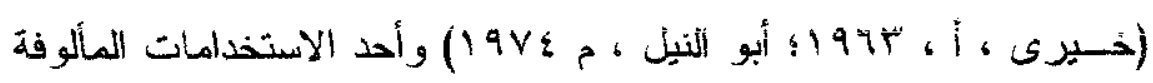

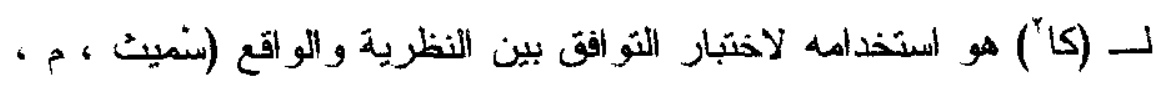




\section{$r \vee r$}

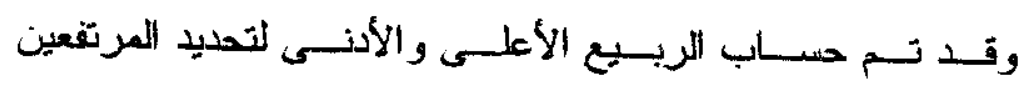

و المنخفضبين على اللسمة.

وتجيـب (كاب) عن الثشاؤل بأن المرتفعين و المنخفضين (في بعد عدم الاتزان الانفعالتي) بختلفوا في الطرن التي يستخدمونها لخفض التونز

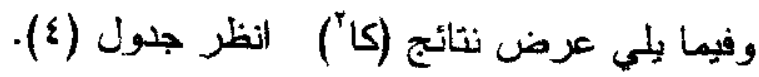
جدول (ع) يعرض لنتائج (كاب) لبحث الفروق بين مرتفي ومنخفض عدم

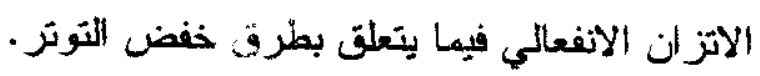

\begin{tabular}{|c|c|c|c|c|c|}
\hline | الثلالة واتجاهها & ('ts) & البند & الدلالة و اتجاهها & (14) & البند \\
\hline & $1, \varepsilon$ & كومدية & & $\cdot, \cdot 1$ & 1 - التركيز علم شه، ثابت \\
\hline " • متزن & $v, q$ & | & " • متزن & $\curlyvee, \wedge$ & r- تخيل منظر هادي \\
\hline متزن & $\uparrow, \varepsilon$ & |r | أترا في كتاب & " غير متزن & $0, \cdot r$ & r - ممارسة العادة العرية \\
\hline "• " عير متزن & $\wedge, \vee$ & |ri & "غير متزن & $r, Y$ & ؛ . تخيل صورة المحبوب \\
\hline |"•غير متزن & $r \varepsilon, 1$ & عا - انتشاجر الو أسب & & $\cdot, \varepsilon 0$ & هـ-- اتمدل على السرير \\
\hline & 1,0 & 10 - أتتاول ملحة مخرة: & & Drr & 1 - أجلس مع صديث \\
\hline "• غير متزن & $Y, Y$ & 17- أتتاول دواه مهثين & & 1,4 & V \\
\hline | " | غير متزن & $V, Y$ & | & & 1,1 & 1- أتخاول مأكو لات \\
\hline & $r, \wedge$ & 11 - إهزر وأتكت & &., $1 \leqslant$ & 9 - استمع الثموسيثم: \\
\hline & & & & $\begin{array}{l}\cdot, \lambda r) \cdot, \\
(, Y \xi) \\
r, A \xi)\end{array}$ & 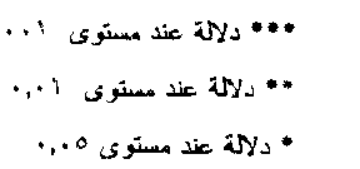 \\
\hline
\end{tabular}


تظهــر النستائج وجود فروق دالة في بعض البنود بين المرتفعين

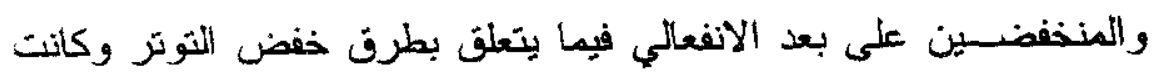

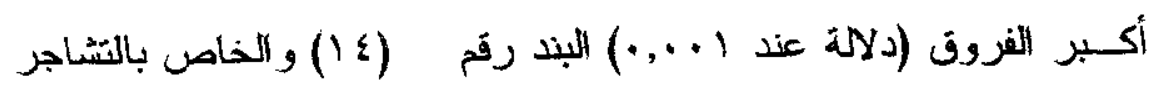

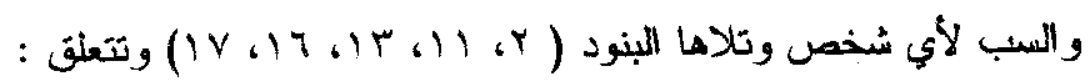

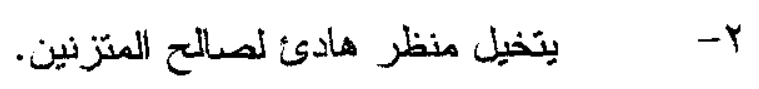

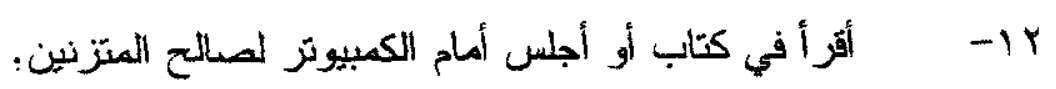
rا- أبكي أحيانا لصالح غير المتزنين. 19- أنتاول دو اء مهدي لصالح غير المتزنين. - IV أعيش في أحلام البقظة لصالح غير المتزنين. وفي المرنبة الثالثة (دلالة ه ., •) كانت البنود (؟،بr) وتتعلق r- ب أسترخاء بالعادة السرية. ع - أتخيل صورة من أحب لمسالح غير المتزنين. وتظهر النتائج أن المرتفعين في الانفعالية بستخدمون طرق غير

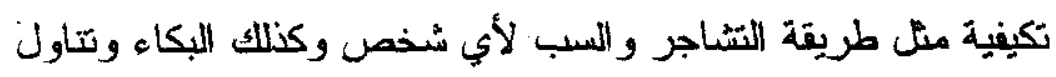

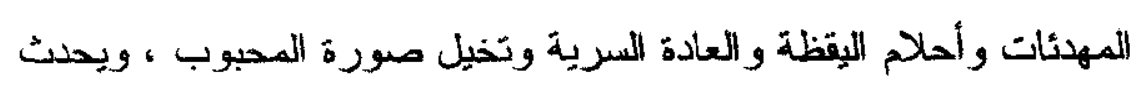

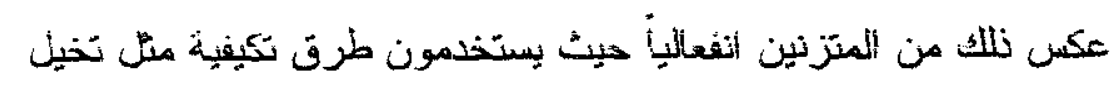
منظر هادئ أو أخذ حمام دافئ أو قر أهذ كتاب أو الجلوس أمار الكمبيونز أو قر اءة كتاب. 
وتظهر نتائيج النسب المئوية للعينة الكلية أن البنود التالية هي

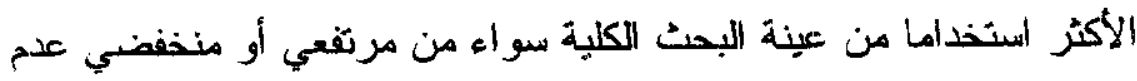

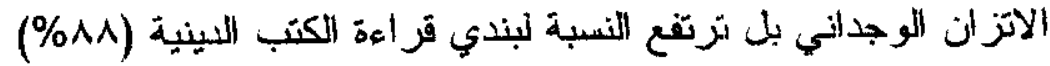
و البكاء (r^\%). باعنبار هما الأكثر استخداما.

$$
\begin{aligned}
& \text { - - - أتمد على السريز } \\
& \text { 1- أجلس مع صنيق }
\end{aligned}
$$

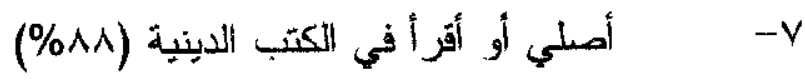

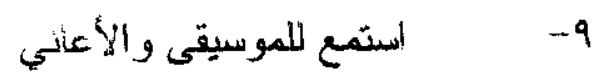

$$
\begin{aligned}
& \text { 1 أنداهد أفلام أو مسرحبانت }
\end{aligned}
$$

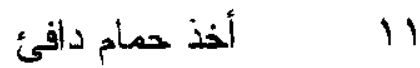

$$
\begin{aligned}
& \text { rا }
\end{aligned}
$$$$
\text { 11 ا- - هزار ونكت يستخدمه أكثر من ب\%. }
$$

ثانيا: : المقارنة بين المرتفعين و المنخفضين في الاتبساط فيما يتعلق بطرن

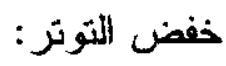

تم استخدام الأسلوب الإحصائي (كاب) ونلك للتعرف على الفروق

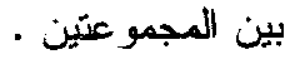




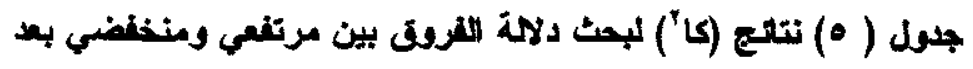
الأبساط فيا يتعن بطرق خاض التوتر

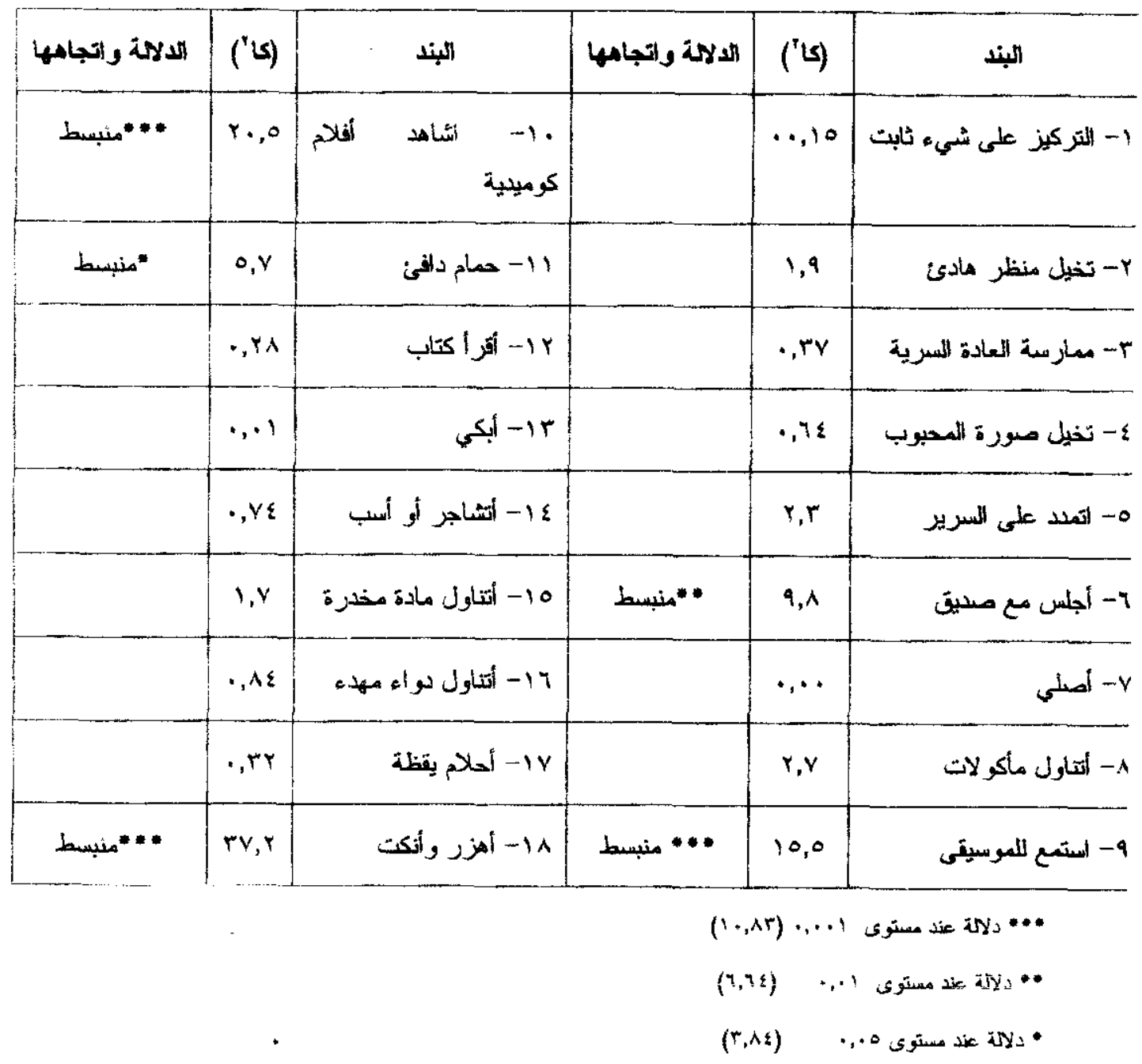

تظهر النتائج وجود فروق دالة مريفعة (دلالة ا +., • ) للبنود (9 (9

. 11 ، الصالح مريفعي الانبساط

وتثعلق هذه البنود بما يلي : 


\section{rVV}

$$
\text { - - مشاهدة الأفلام و المعرحيات للموسيقى والأغاني والثلفزيون. }
$$

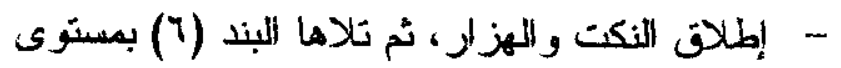
دلالة (1 ., •) ويتعلت بالجلوس مع صديق وفي النهاية

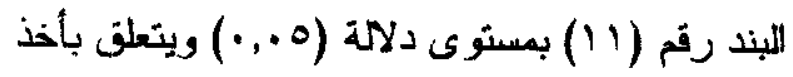

حمام دافئ وجميعها لصالح المنبسطين.

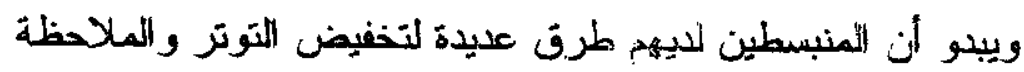

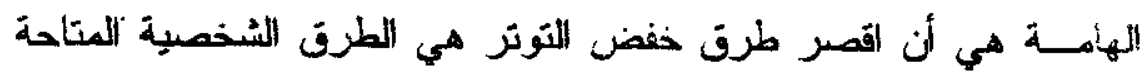

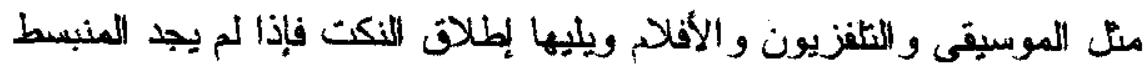

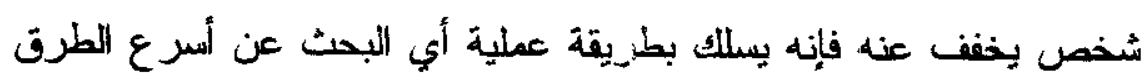
لخفض التوتز مثل الجلوس مع صديق.

وتظهر نتائج النسب المئوية للعينة الكلية أن البنود التالية :

؟- تخيل صورة المحبوب.0 - أنعد على السرير . ج- أجلس مع منديق.

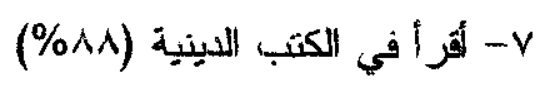

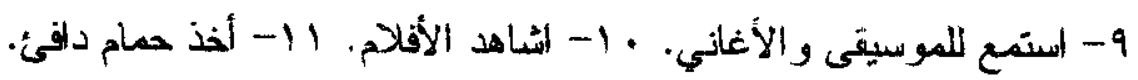

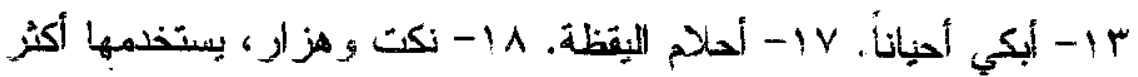
من • \% \% من مرتفعي ومنخفضي الانبساط على حذ سواء.

وتؤكـد النتائج السابقة صحة الفرض الثاني الخاص بوجود فروف

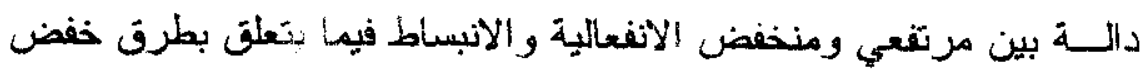


الــتوتر فقد استخدم المتزنين والمنبسطين أساليب أكثر نكيفية من مرنقعي

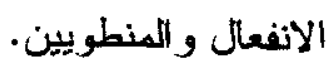

المرضان الزايع والخلمس :

وبالنسـبة للفروض الرابع والخامس فقد تم استخدام أسلوب تحليل

التبايسن المتعدد MANOVA لاختبار هذه اللفروض ونلك لبحث الفروق

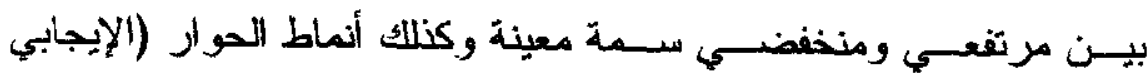

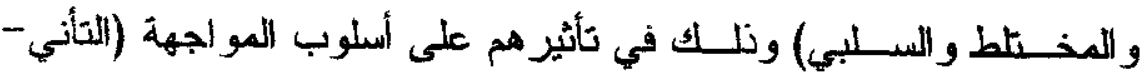

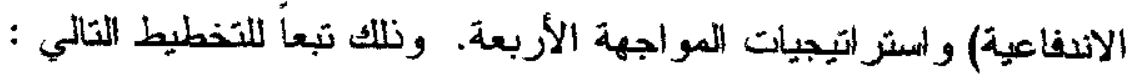


rvq

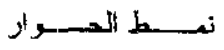

سلبي

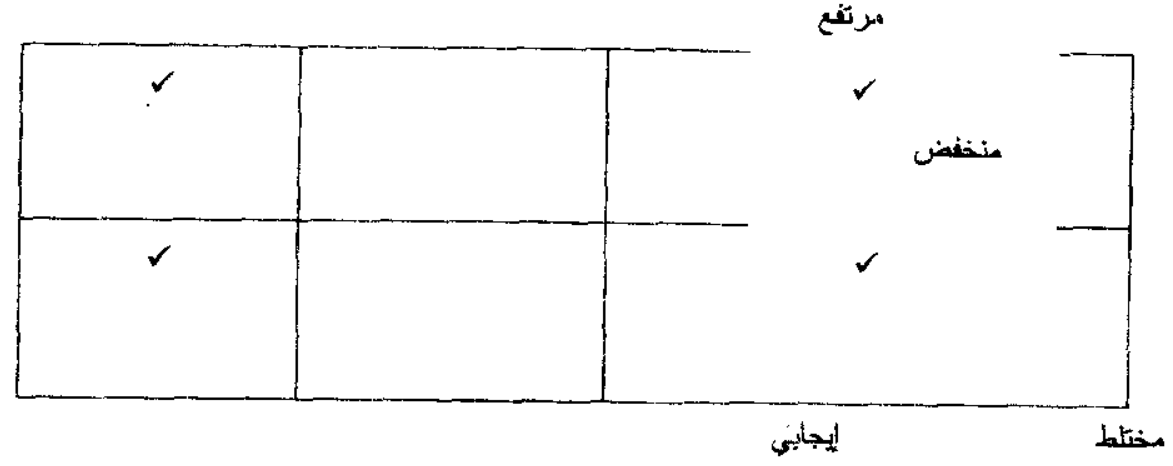

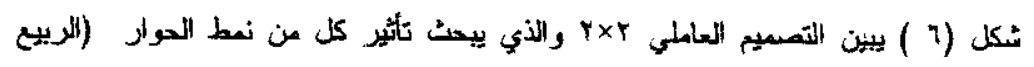

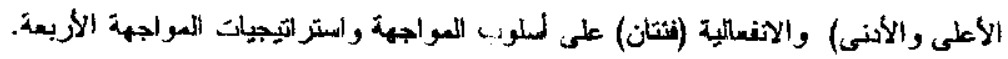

لمعامل الحورار

مختط

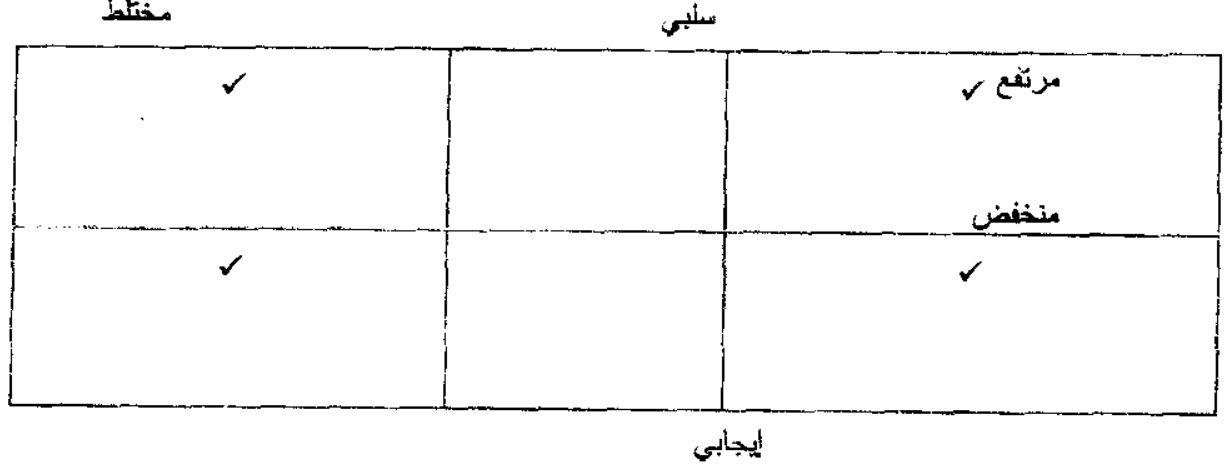

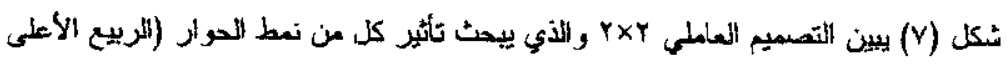

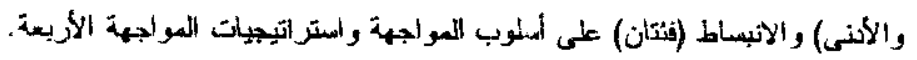


rí.

تحليل اللتباين المتعدد - اختبار ات آثار ما بين المجموعات

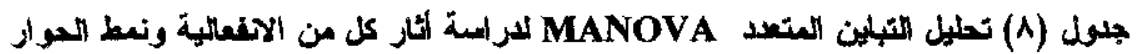

على كل من أسلايب المواجهة واستراتيجيات المواجهة.

\begin{tabular}{|c|c|c|c|c|c|c|c|}
\hline الدلآة & "قت". & لمثربطات برت & لمرجاتت & لمربعرت & المستغيراتة & & \\
\hline \multirow{2}{*}{$\because \cdots$} & $1 \leq, r r$ & rr,vi & $!$ & $r, A$ & \multirow{7}{*}{ 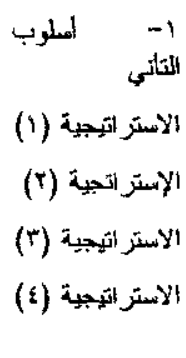 } & \multirow{7}{*}{\multicolumn{2}{|c|}{ الاثنعالية }} \\
\hline & $r, r \xi$ & 1,19 & 1 & 1.9 & & & \\
\hline$\cdot, 1 r v$ & $\cdot,+r$ & $\ldots Y$ & 1 & $\ldots y$ & & & \\
\hline$\cdot$, A $\vee$ & \multirow{4}{*}{$\begin{array}{l}r, s . \\
r, i o\end{array}$} & \multirow{4}{*}{$\begin{array}{l}q Y, q q \\
r, q r\end{array}$} & 1 & $Y, 99$ & & & \\
\hline,$\cdots$ & & & 1 & $Y, . Y$ & & & \\
\hline$*$ & & & & & & & \\
\hline$\cdot .1 \leq T$ & & & & & & & \\
\hline$\cdot, \cdots 9$ & $\sum, \lambda \xi$ & $\lambda_{1} \ldots$ & r & $18, .5$ & أسلوب & & نمط الحورلر \\
\hline & $\{,\{:$ & r. & r & $Y, Y E$ & & & \\
\hline$\cdot . .01 r$ &.,$\infty$ & $\bullet, \ldots$ & $Y$ & $\bullet, \wedge \Lambda$ & الأستر اتيجية (1) & & \\
\hline .929 & $\{, A !$ & צ, & $r$ & $9, r$ & الإستر اتجية (T) & & \\
\hline$* \cdots, \cdots q$ & $Y, \xi \leqslant$ & $Y, r$. & $Y$ & 2,09 & الاستر اتتيجية (T) & & \\
\hline$\cdot, \times 14$ & & & & & الأستر اتيجية (ع) & & \\
\hline צדירים & $\cdot, \leqslant Y$ &,$+ \vee \wedge$ & r & 1,00 & أسلوبب & بين & الثفاعل \\
\hline$\cdot, 7 \times 4$ & $\cdot, \ldots$ &.,$r Y$ & $r$ &., $7 \varepsilon$ & & & \\
\hline$\because, t \leq$ & $\varepsilon, r \Delta$ & $\because, 8 \alpha$ & Y & vil9 & الإسترَ اتيجيه (1) & & \\
\hline ** & $\cdot, 27$ &.,$\varepsilon$ & $r$ &, 149 & الإستر أتجية (Y) & & \\
\hline S & $\cdot . \leqslant \leq$ & & $Y$ & - XY & الاستز اثيجية (r) & & \\
\hline . $T \leqslant \wedge$ & & & & & الاستر أتيجية (؛) & & \\
\hline
\end{tabular}

* دالة عند م.,.

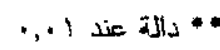


كما أظهرث نتائج تطليل الثباين المتعدد و MANOVA أن هناك فروق دالة بين المتزنين وغير المتزنين انفعالياً في استخدام الستراتيجية

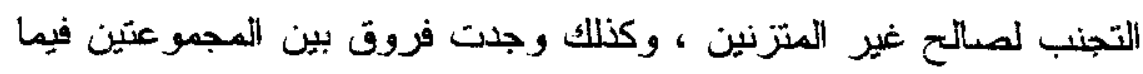

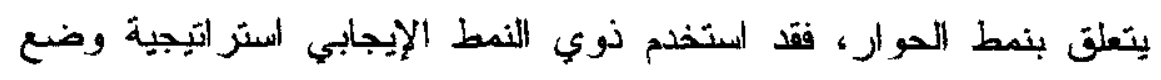

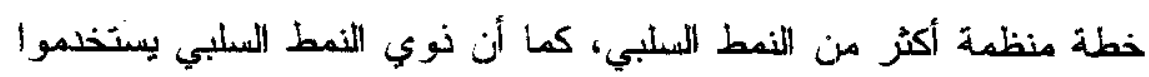

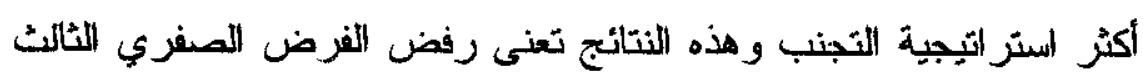

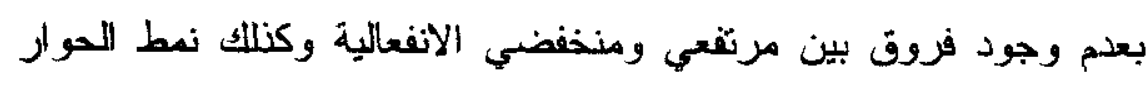

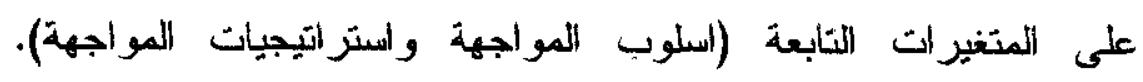
وتتشابه نتائج غير المتزنين وذوي النمط الأول (السلبي) في الستخدامهم لاستر اتيجية التجنب.

وفيما يتعلق بالتفاعل بين سمة عدم الاتزان ونمط الحوار بين

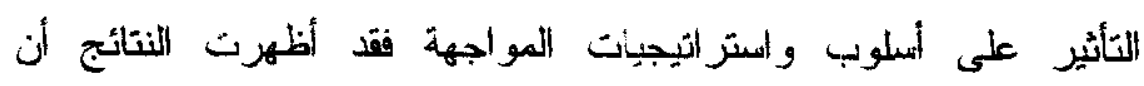
التخص المثزن وذو الحوار الإيجابي يختار الاستراثيجية الثانية(التركيز

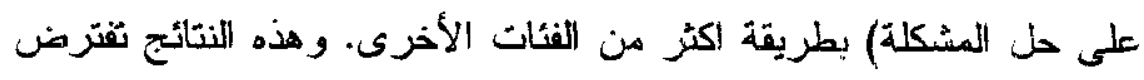

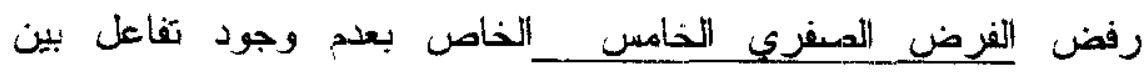

$$
\text { المتغيرات المسنقلة (الانفعالثية ونمط الحوأر) }
$$

تطليل المثباين المنتعد - اختبار ات تأثيرات ما بين المجموعات 
rAY
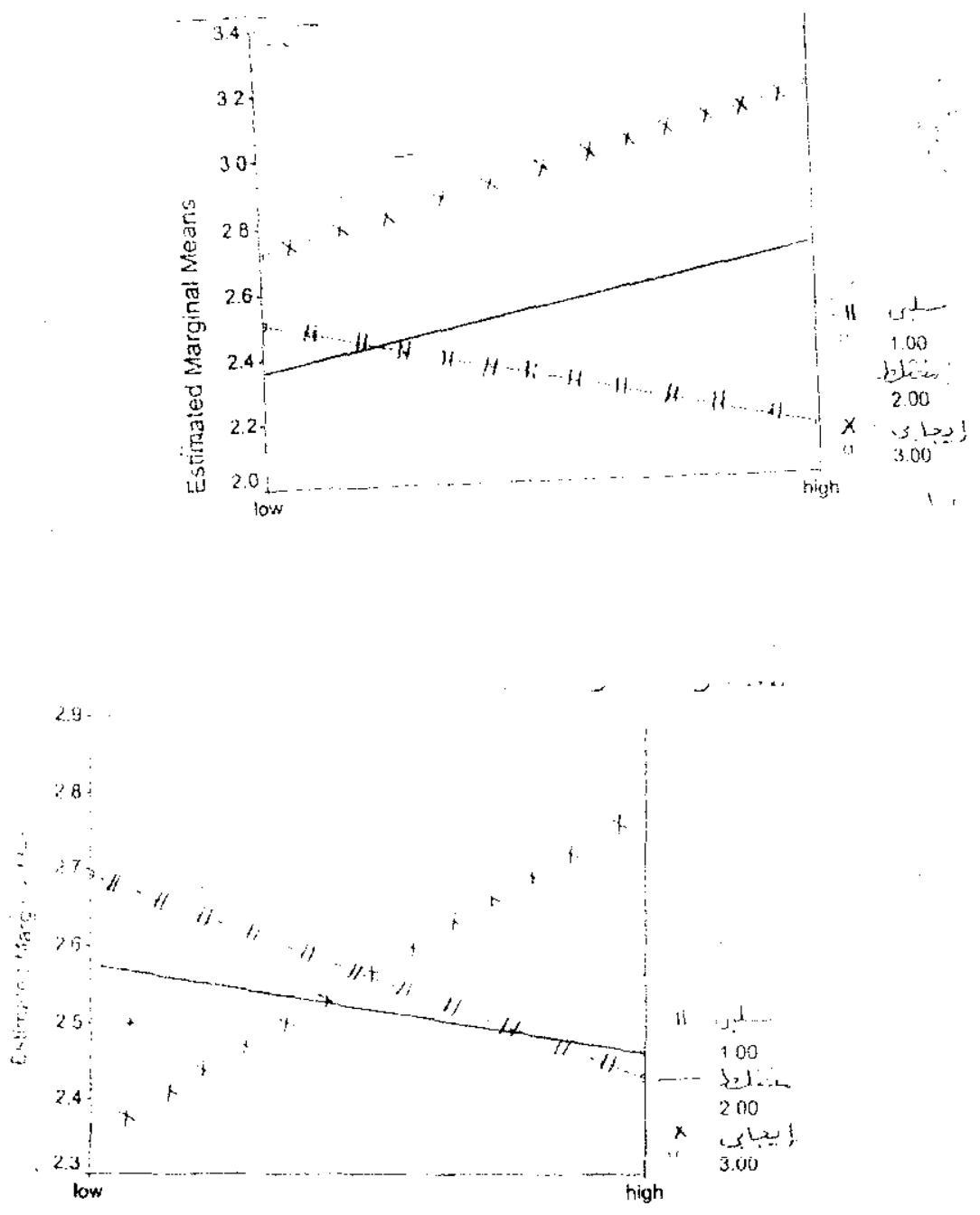

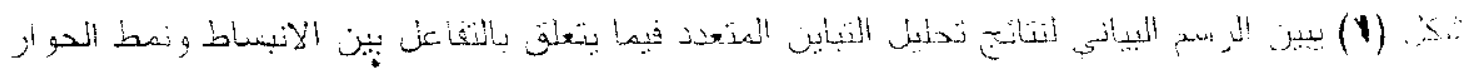

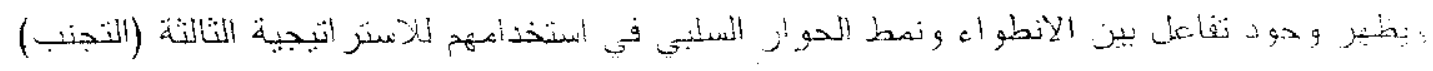

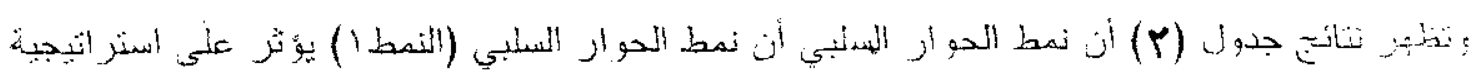

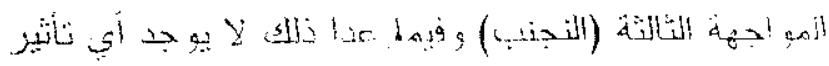


جلول (9) تطيل التباين المتعد MANOVA لاراسة آثار كل من الانبساط

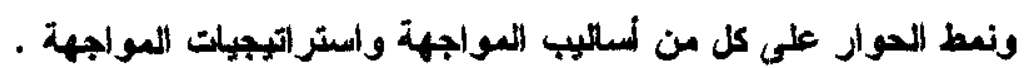

\begin{tabular}{|c|c|c|c|c|c|c|}
\hline 14 & "مَّ" & المتوسطيعت مريع & لرجات & 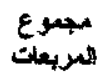 & 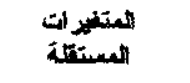 & \\
\hline., $1 \mathrm{rV}$ & $T_{1} \cdot \wedge$ & $r, \lambda r$ & $r$ & $r, y_{0}$ & 1- اسلوب التأني & \multirow{5}{*}{ نسط الحولر } \\
\hline$\ldots n$ & $Y, \wedge)$ & r r & $r$ & E,To & الاستر اتيجية (1) & \\
\hline$\cdot, \wedge \vee V$ &., 15 &., $1 Y$ & r & $\cdot, r r$ & الاسشتراتجية (r) & \\
\hline$* \cdots, \ldots$ & $v, q \wedge$ & 8,93 & $r$ & 10,94 & الاستز اتيجيل (r) & \\
\hline$\cdot,+$ Vo & $r, 7$ & T.EY & 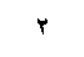 & $\{, \lambda \varepsilon$ & الاستر اتيجية (ع) & \\
\hline., $1 \leqslant 0$ & Y.1T & $r, 9 Y$ & , & $r, 4 r$ & ا- أبلوب الثاتي & \multirow[t]{5}{*}{ الالنبساط } \\
\hline$\because Y y \varepsilon$ & $r, r$ & $Y, 17$ & 1 & Y Y & الأستر لتيجية (1) & \\
\hline$\cdot, Y \leftleftarrows$ & $1, \mathrm{rA}$ & $1, Y 1$ & 1 & $1, Y Y^{\circ}$ & الاستر اتتحرة (Y) & \\
\hline$\cdot, r u v$ & $1, Y E$ & i,r & 1 & $1, r r$ & الأستز التيجية (r) & \\
\hline$\cdot, \varepsilon \ldots$ & $\cdot, V_{1}$ & $\cdot .14$ & 1 & יוי, & الاستر اتتحجية (i) & \\
\hline$\cdot, Y \leqslant Y$ &.,$\times 4$ &., $0 \leqslant$ & r & $1 . .1$ & 1 - أسلوب التأنى & \multirow{5}{*}{ 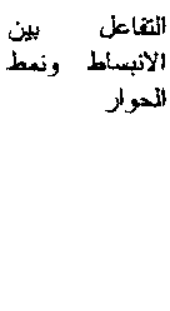 } \\
\hline$\cdot ., 7 r r$ & $\cdot .24$ & $\cdot$. TA & r &.,$\times 7$ & الاستر اتتيجية (1) & \\
\hline$\cdot, 7+7$ &,$+ \infty$ & 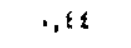 & r & $\cdot, \wedge \Lambda$ & الاستراتجية (r) & \\
\hline$\because$ & $\xi, 70$ & $\{, t r$ & $r$ & $9, Y_{4}$ & الأستر اتيّية (r) & \\
\hline .org & , $7 \varepsilon$ & $\therefore$ & $r$ & 1,19 & الانستر اتثيجية (s) & \\
\hline
\end{tabular}

* دالة عند 0.,

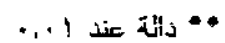


وتظهر نتائج جبول (9) أن نمط الحوار السلبي أن نمط الحوار

السلبي (النمطا) يؤثر على استراتيجية المواجهة الثالثة (التجنب) وفيما

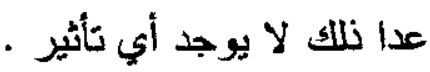

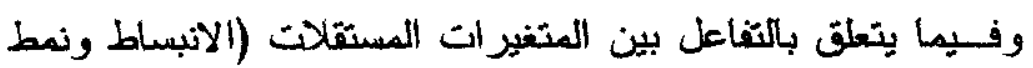

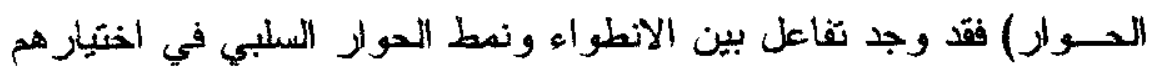
بالاستراتيجية الثالثة (التجنب) وفيما عدا نلك لا توجد أي علاهات تثاعل.

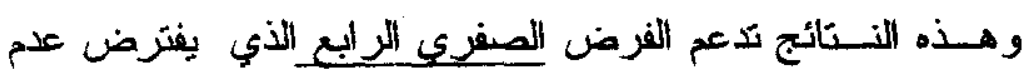
وجود فروف بين المرتفعين والمنففضين في المتغيرين المستقلين (الانبساط

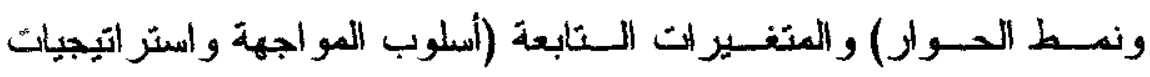

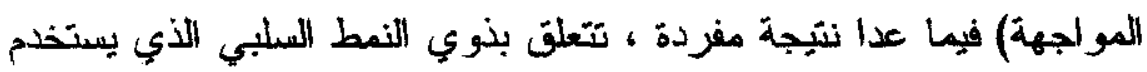
( بدلالة أكتر ) الستر اتيجية التجنب.

والنـائج تدعم رفض الفرض الخامس والسادي الخاص بالثفاعل

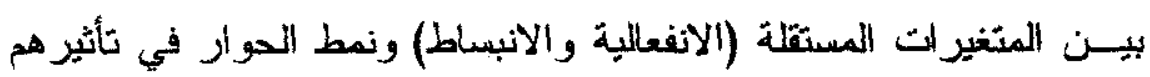

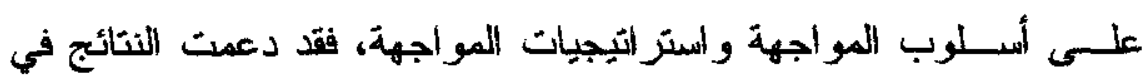

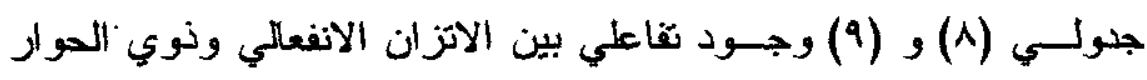

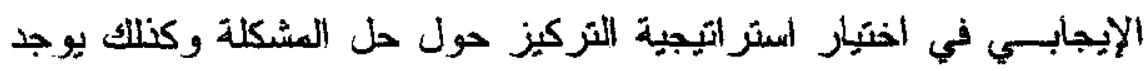

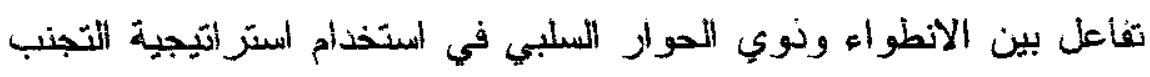

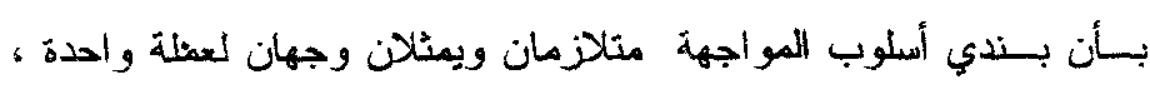
ويشير ذلاك إلى رفض الفرض السابع. 


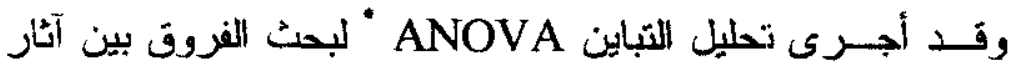

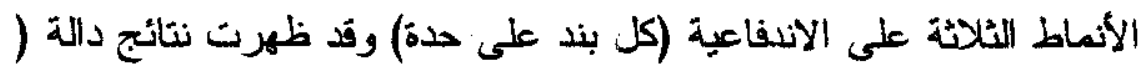

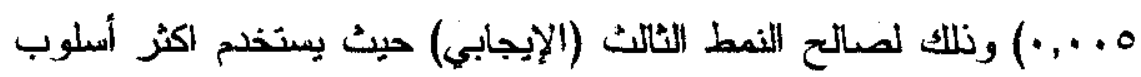

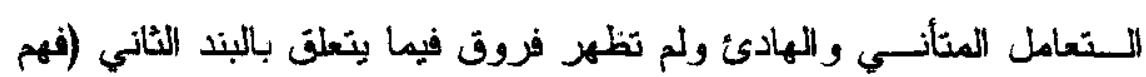
تفاصيل المشكلة) ويتعارض نلك مع فرض الباحث. 


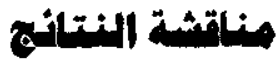

أولا : العاملان الكبيران في الثخصية :

أظهــرت نتائج التحلي العاملي لمقياس الانفعالية والانبساط ظهور

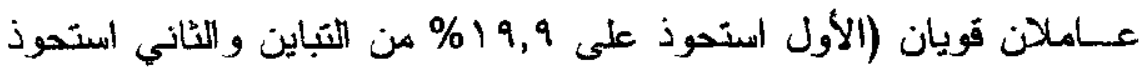

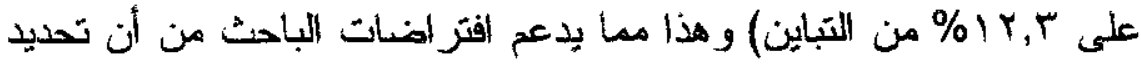

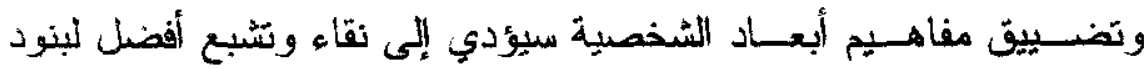
المقياس وقد تشبعت كل بنود المقياسين على العاملين (أكثر من عا...) فيها عدا بند واحد من مقياس الانفعالية .

ويبيو أن ذلك أفضل من التعريفات التشاملة التي تقل فيها التشبعات

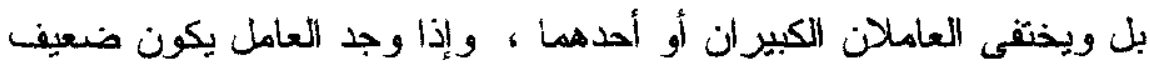

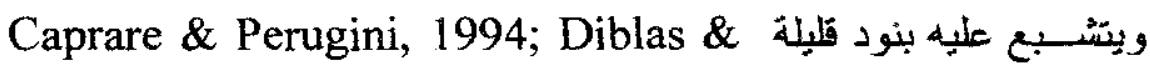
Forzi, 1998;1999 Digman, 1979; Cheung et al., 1992; Somer, \& Goldberg; 1999) (Y.... ، (1)

وتدعم هذه النثائج ضرورة أن بهتم علماء النفس بأبعاد الشخصية

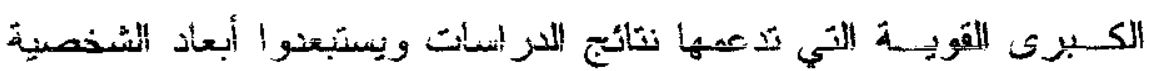
الضعيفة والتي بختلفو ا بشأنها.

ويسبدو أن تعـريف عدم الاتزان الانفعالي (المقتز ح)؛ في الدراسة

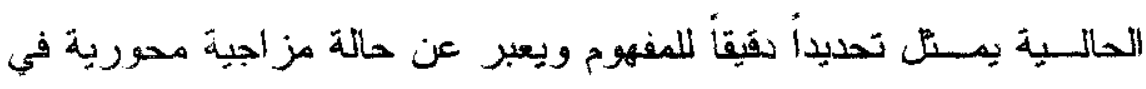
تكوين الشخصية. 


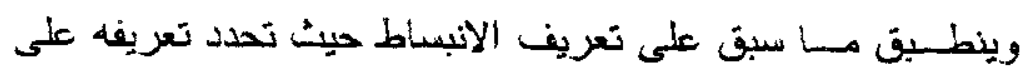

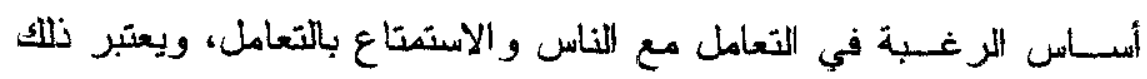
تضييق وتحديد للمفهو باعتباره النقيض لمفهوم الانطو اء.

وبالنسبة للفرضي الأول الخاص بتحديد نعريفات العاملان الكبير ان

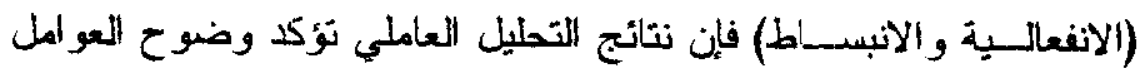

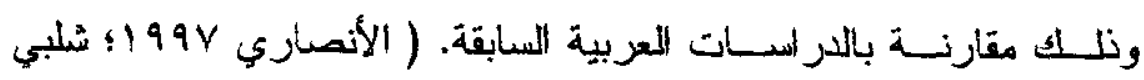

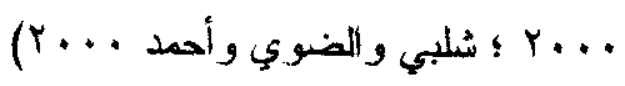

$$
\begin{aligned}
& \text { ثاثيا : العوار الإخلي) : }
\end{aligned}
$$

تعتبر الدراسة الحالية إحياء لمفهوم الحوار الداخلي باعتباره مكون

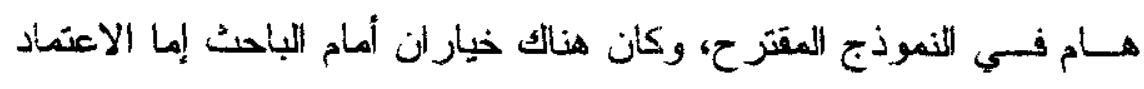

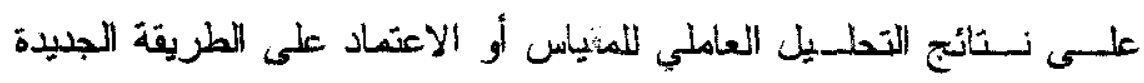

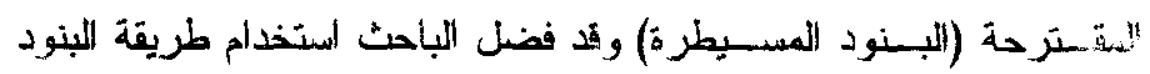

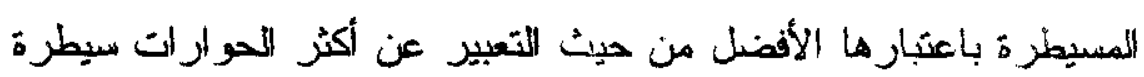

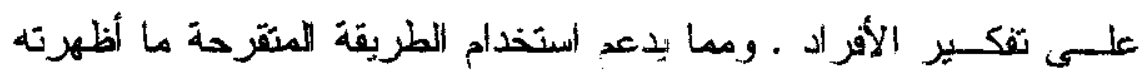

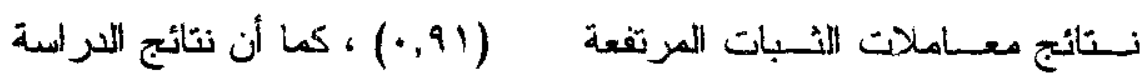

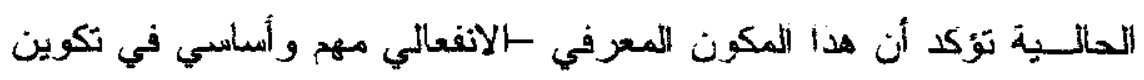

$$
\text { الشخصية واته يسبق أسياليب و الستر التيجيات المو اجهة. }
$$

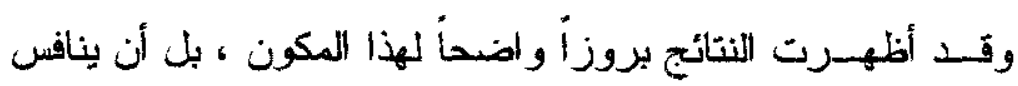

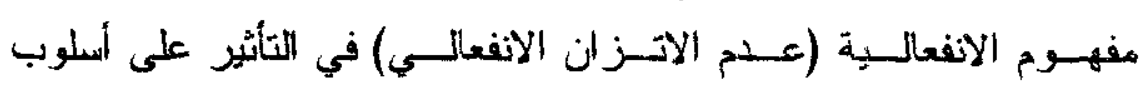

$$
\text { وأستر التيجيات المو الجهة. }
$$




\section{YAN}

بالنسبة للفرض اللثانيـ الخاص بأهمية مفهوم الحوار الأخلي وقد

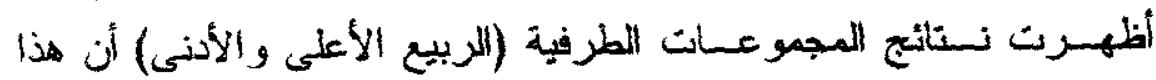

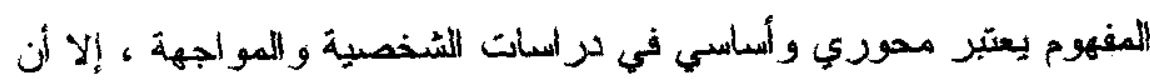

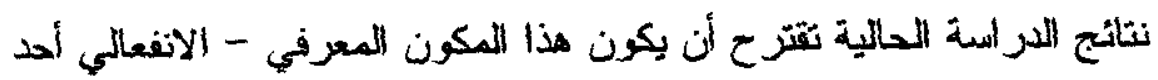
أبعاد الشخصية وليس ضنمن مكون مفهوم استر اتيجيات المواجهة.

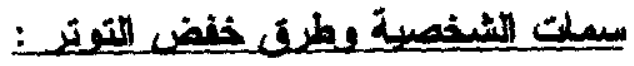

أظهـرث نستائج الدراســة أن الأشسخاص غير المتزنين الفعالياً

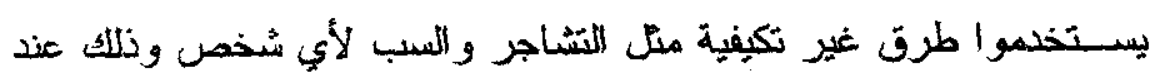

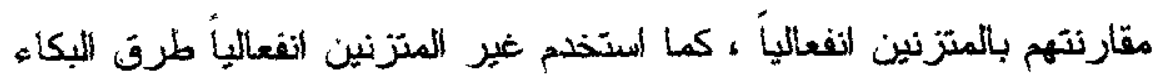

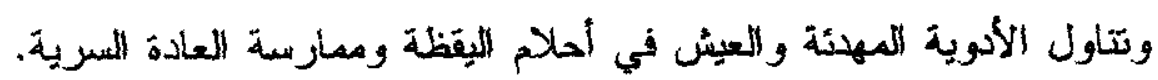

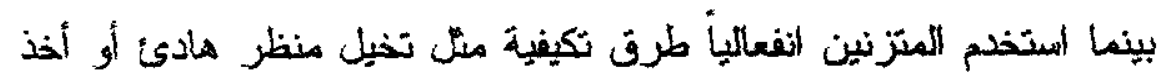

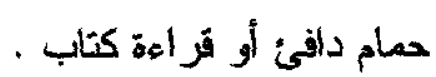

ونستفق هـــه النتيجة مع نتائج البحوث السابقة من أن العصابين

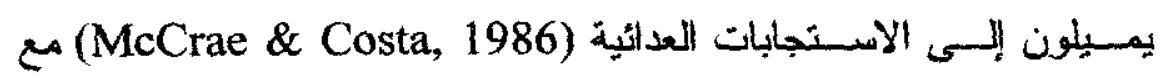

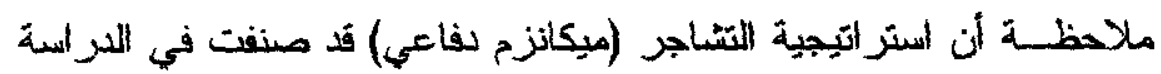

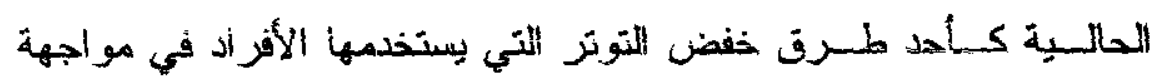

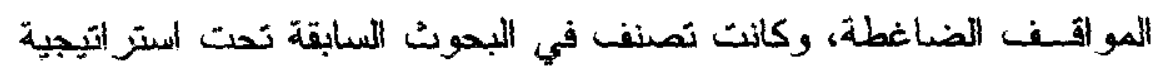

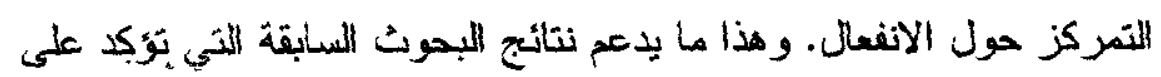

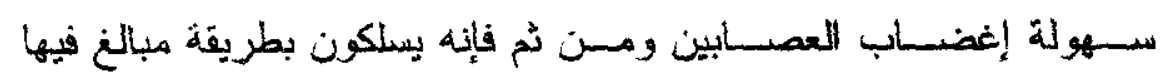
لمشكلات الحياة اليومية، (Clark, 1993; Watson, et al., 1994). 
ويــنق نلــك من نتائج الدراسات السابقة التي تؤكد على ارتباط

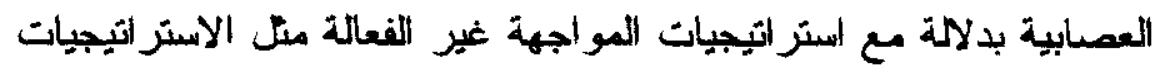

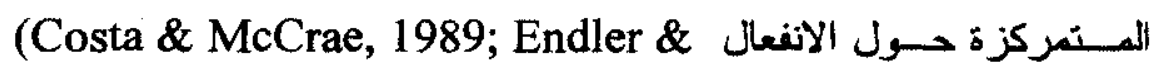

Parker, 1990)

ويـرجع ذلــك إلى ميل العصابين إلى التقديرات السلبية للأحداث البيئية و إدر اكهج للمنبهات المحايدة بطريقة سلبية أكثر مما بفعل الآخرون .(Costa \& McCrae, 1990; Watson \& Clark, 1984) وفــيما يتعلق بالانبساط فقد أظهر الانبساطيون طرق خفض توتر

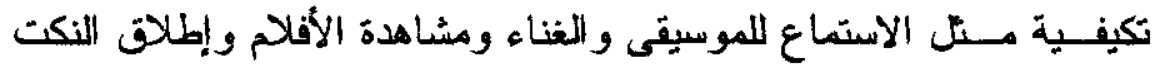

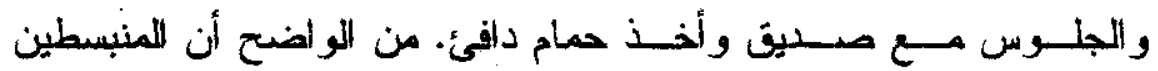

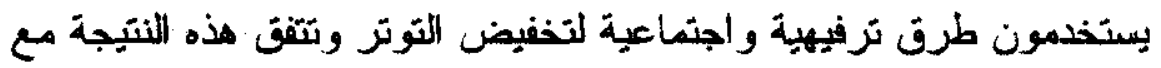
نتائج الدراسات العابقة التي تؤكد على استخدام الانبساطيون استراتيجيات

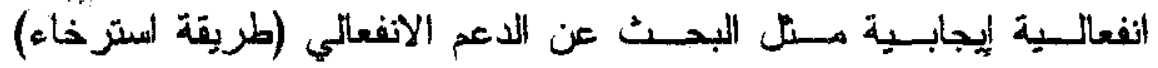
(Hooker et al., 1994; McCrae \& Costa, 1986) "بالمواجهـة الناضـــة" وهي استخدام - أكثر - لاستر اتيجيات منطقية

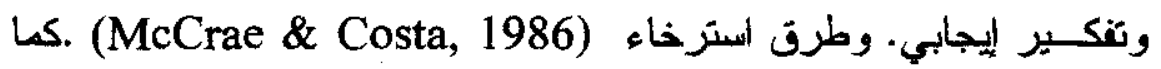
يمسيل الانبساطيون الى المُاعر الإيجابية ميل الدفء (علاقات اجنماعية)

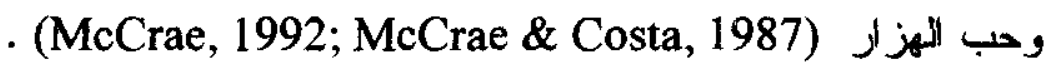

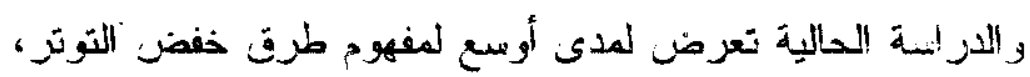

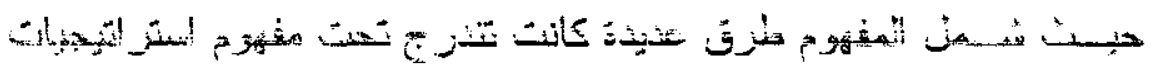

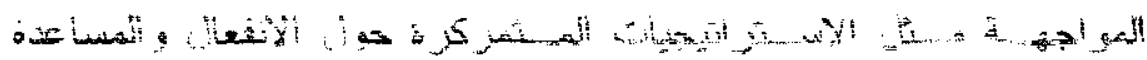

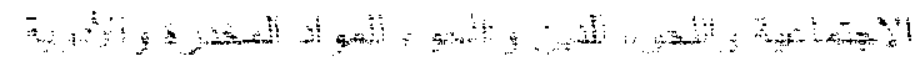




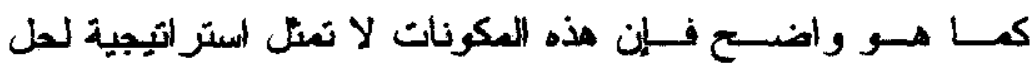

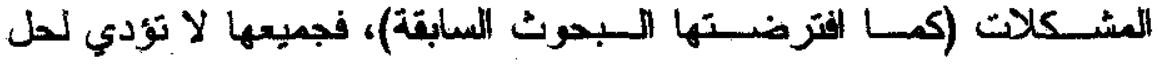
المشكلة، إنما هي فتط طرق يستخدها الفرد لتخفيض التوبتر .

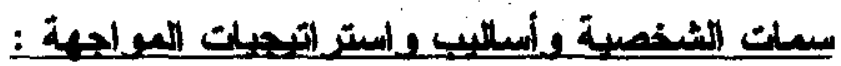

أظهرت النتائج أن المبزنين انفعالياً يتعاملوا مع المواقف الضاغط

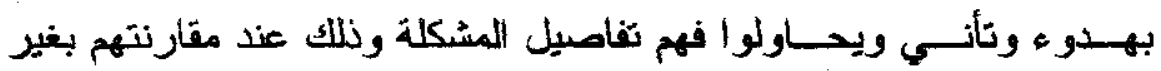

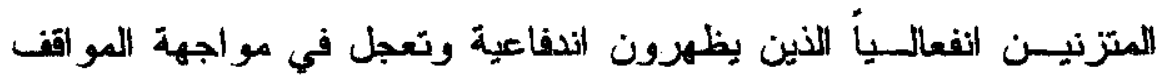

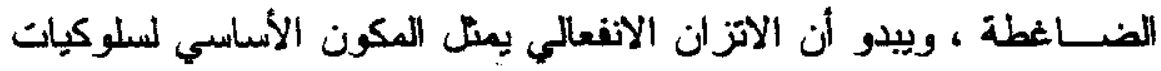

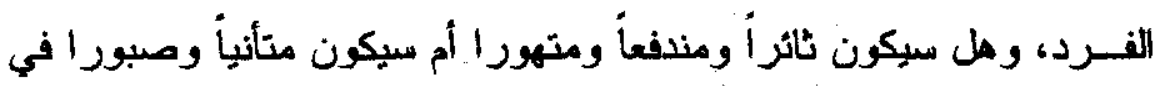

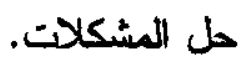

ويستفق ذلــك مب نتائج الإيراسات العابقة حيث ارتبطت العصابية

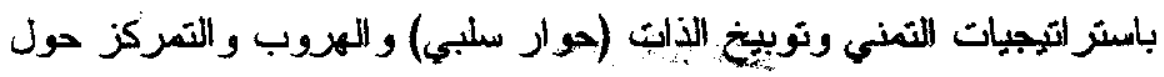
الانفعال. الال

. Rim, 1986; Smith et al., 1989; Vickers et al., 1989)

كمـــ تظهـر النتائج أن الانغعاليين يستخدمون استر التيجية التجنب

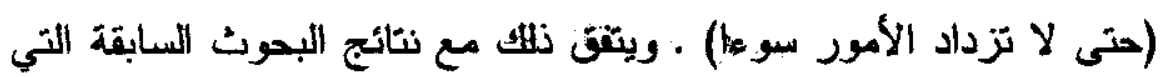

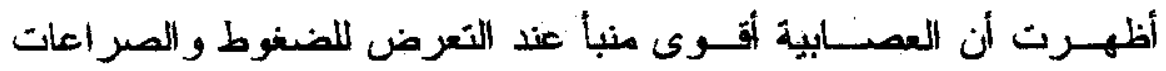

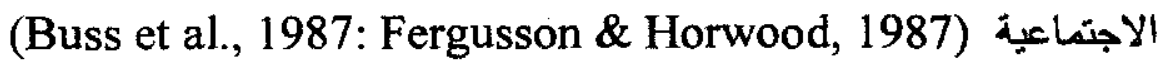

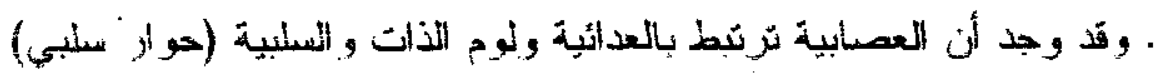

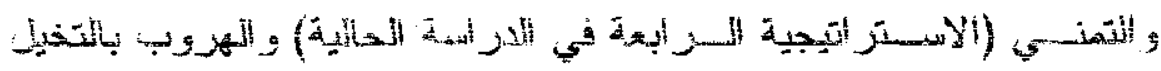

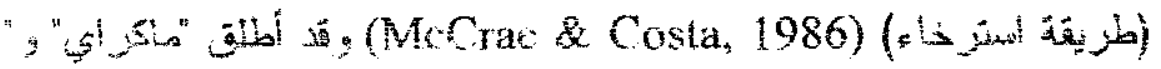


كوستا" اسم "المواجهة العصابية" على هذا النوع من الاستجابة وكما نلاحظ

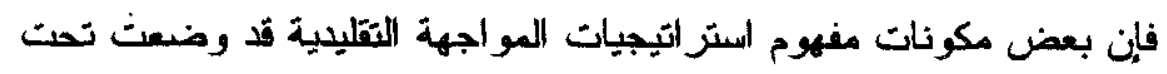

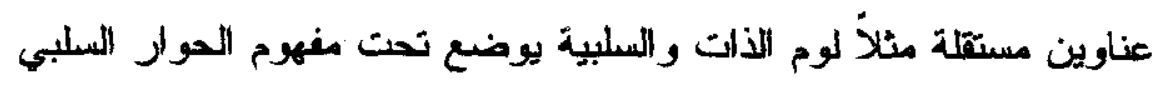

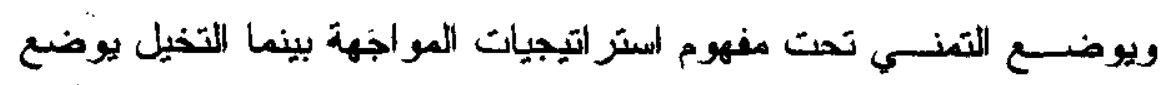
تحت طرن خفض التوتر .

وفـيما بــتعلق بسمة الاثبساط فقد أظهرت النتائج أن لا فرت بين

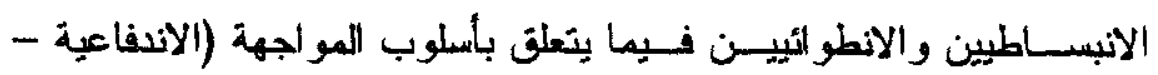

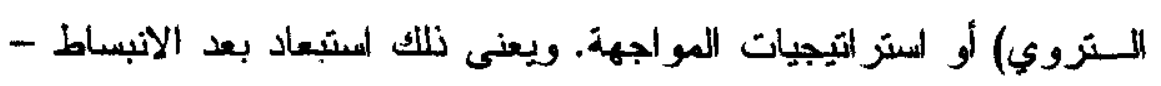

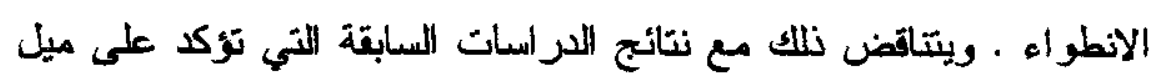

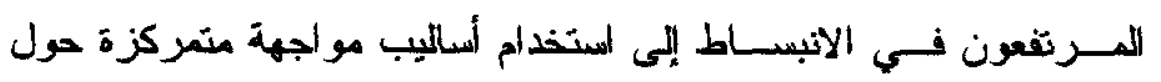

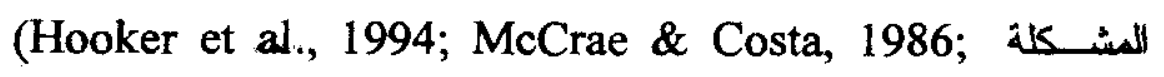
كما أظهرت الار اسات السابقة

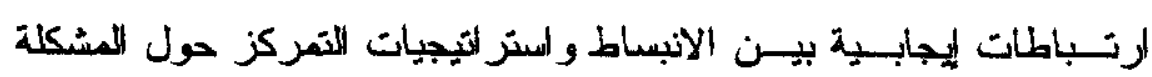

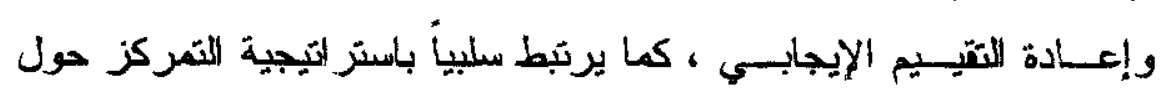

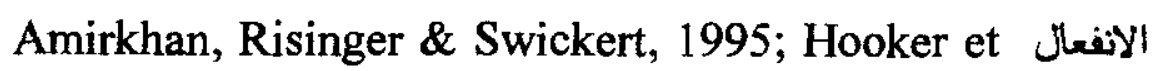
. al., 1994; Rim, 1987; Vickers, et al., 1989)

ويسبدو أن اختلاف النتائج يرجع التى اختلاف التعريفات الإجرائية

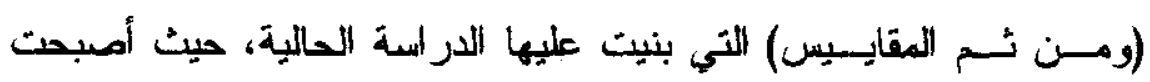

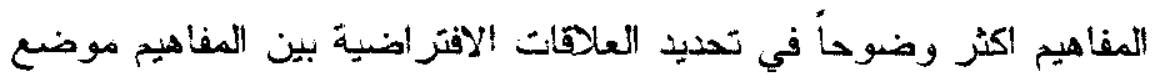

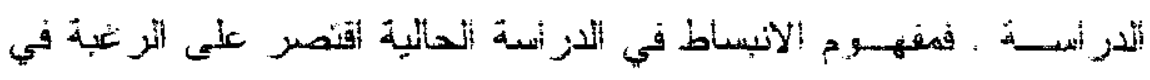


إقامة علاقات اجتماعية والاستمتاع بذلك ويختف ذلك عن المغهوم اللقليدي كلانبساط. (انظر نعريف المفاهيم).

كما أن مفهوم استر اتيجيات المواجهة قد تم تصنيفه في أربعة فئات

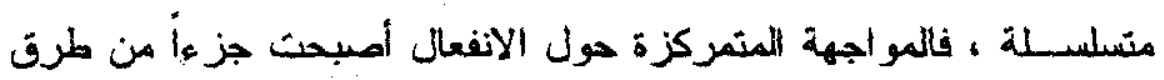

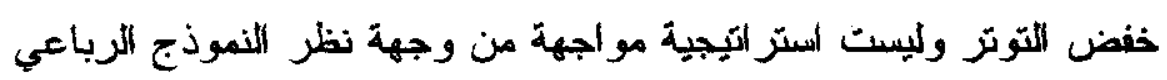

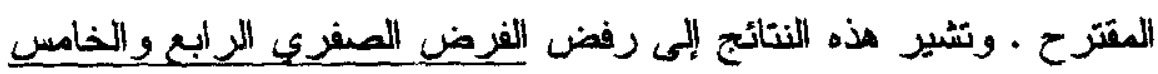

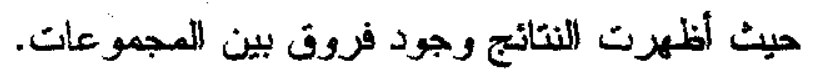

وفـيما بــنعلق بالتفاعل بين المتغيرين المستقلين (الانفعالية ونمط

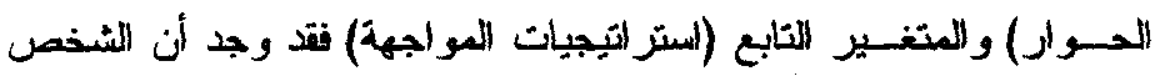

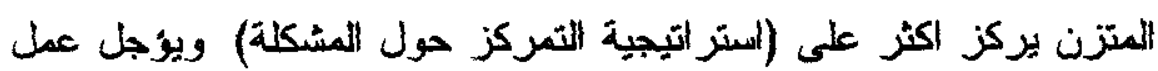

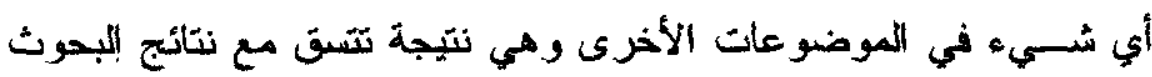
السابقة.

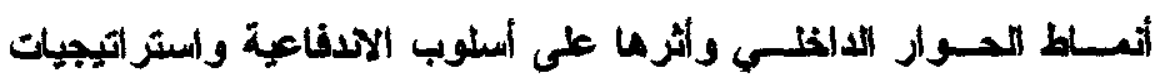
: المواجهة

وتظهر النتائج أن النمط الإيجابي الخالص (r) و السلبي المقاوم (

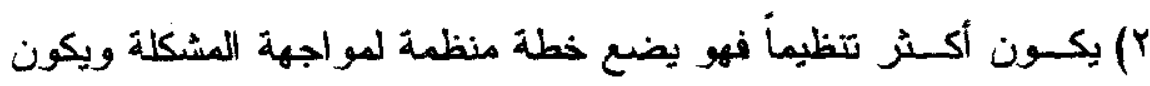
متأنسياً علـى العكس من النهط السلبي الذي يخشى المو اجهة (الستر التيجية

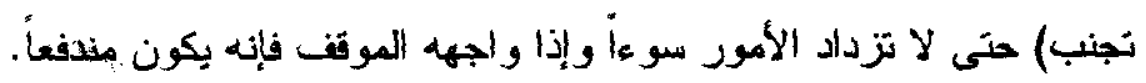
كما أظهرت النتائج وجود فروقي بين النمط (السلبي) و (الإبجابي)

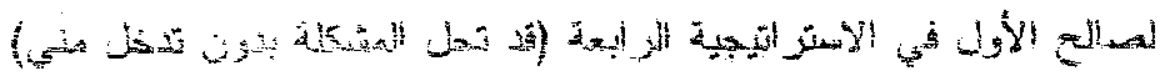

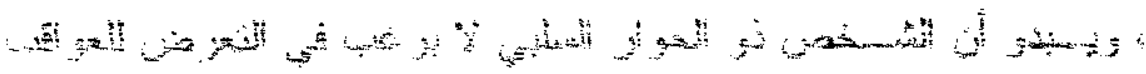


السـلبية للمشكلات ويتمنى (استر اتيجية التمني) أن نحل بأي وسيلة ، ولا يرغب في فعل سلوك قد يؤدي لنتائج سلبية.

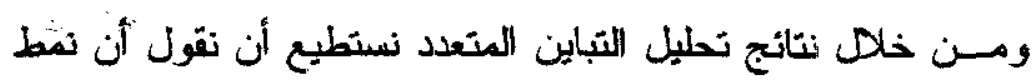

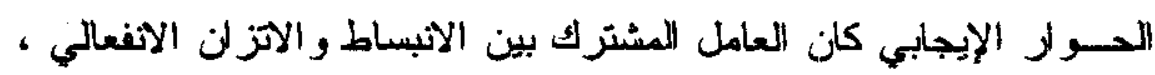

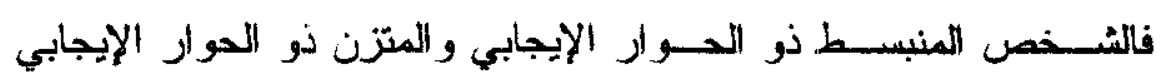
يستخدمان استر اتيجية واحدة هي التركيز على حل المشكلة.

و مهـــه النتائج تدعم افتر اضـات الباحث الحالي من ضرورة الفصل

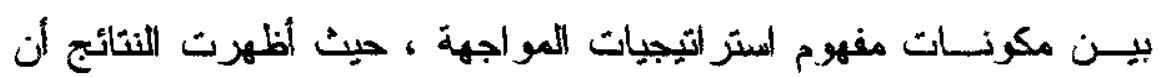

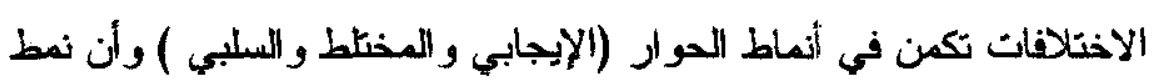

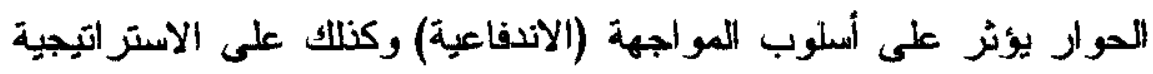
المستخدمة.

وفـيما بــنعلق بعلاقات التفاعل بين المتغيرات المستقلة (الأثبعاط

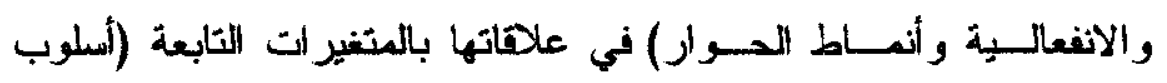

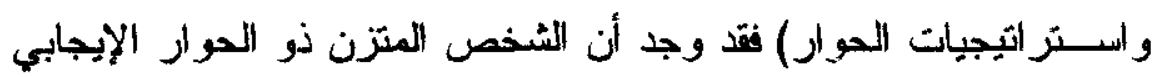

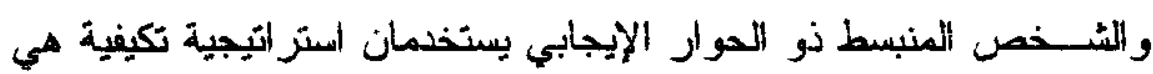
التركيز على حل المثكلة .

وهـــه النــائج تدعم رفض الفرض الخامس الخاص بعدم وجود

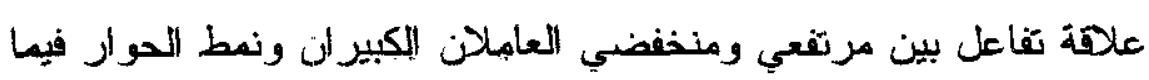

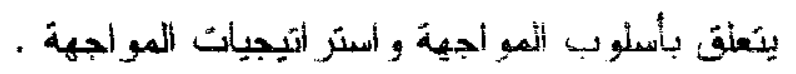


بالنسبة للفرض الثالث الصفريخ (علم وجود فروق بين المتغيرين

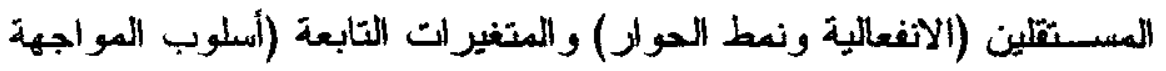

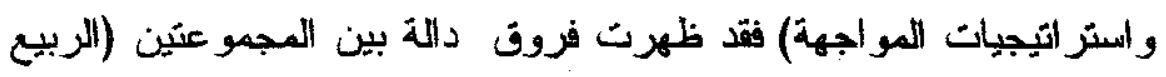

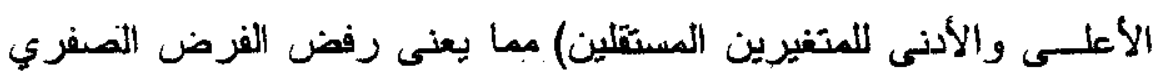
والتأكيد على وجود فروق بين المجوعات.

تأتسي أهمـية هذه النتائج من أنها ندرس علاقة سمات الشخصبية بينود مفردة في أساليب واستراتيجيات المواجهة مع أن البنود المفردة نادراً

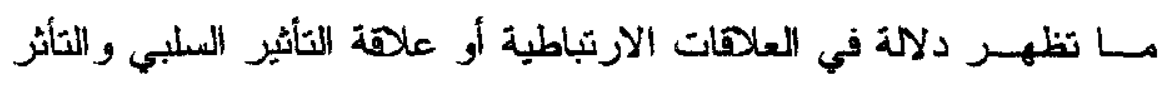

(العلاقات السبيبة)

وبالنســـة للفرض المفري المرابع الخاص بعدم وجود فروق بين المتغيرين المستملين (الانبساط ونمط الحوار) و المتغيرات التابعة (أسلوب المباب

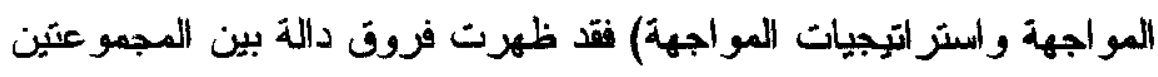

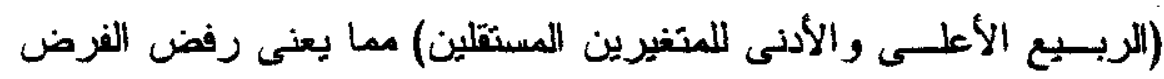
الصفري ، و الثأكيد على وجود فروق بين المجمو عات.

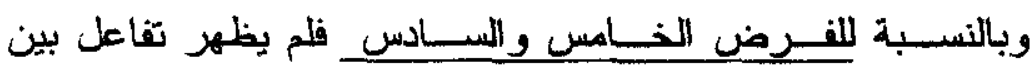

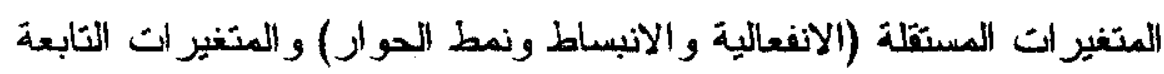

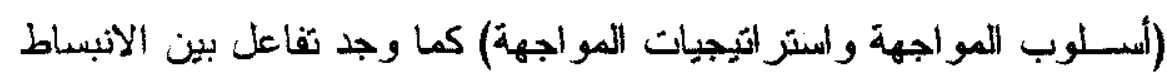
والحوار الإيجابي حيث يفضل من بجمع بينهم أستخدام اسئر ائيجية التصركز

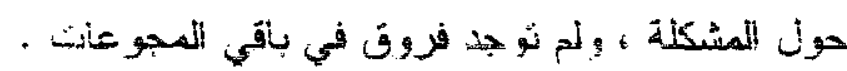


وبالنسبة للفرص الساد فقد أظهرت النتائج رفض الفرض السابع

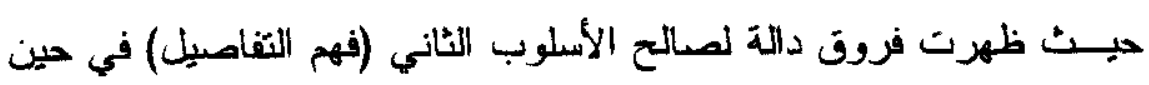

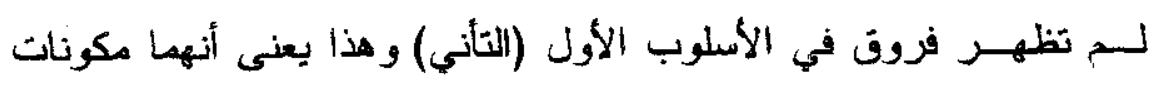
منفصلان.

وبالنســبة للطريقة المقترحة "البنود المسنطرة" فقد أظهرت النتائج

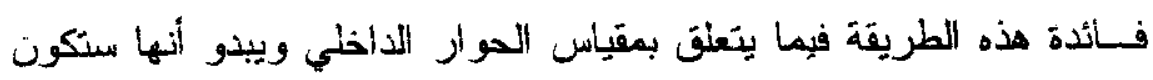
ناجحة ومناسبة في مقاييس الحالات الانفعالية و الوجدانية أيضا.

هناك عدة ملاحظات مهمة تتعلق بنتائج الار اسة :

1- أن التزكيز على البعدين القويين (الانفعالية والانبساط) يكون أفضل

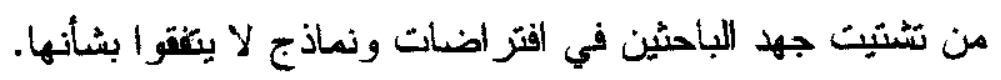
r- أن تحديد وتقييد تعريغات سمات النخصية بِاعد على بناء مقاييس

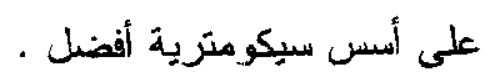

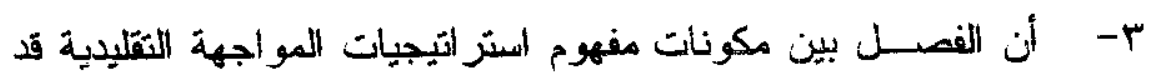

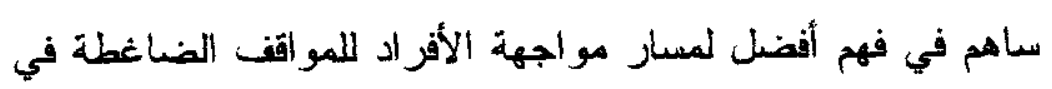
حياتهم ، حيث أبرز أهمية بعض المفاهيم منل مفهوم أنماط الحوار . ع- بـبدو أن أسلودب التصحيح المقترح (البنود المسيطرة) يقدم إضافة

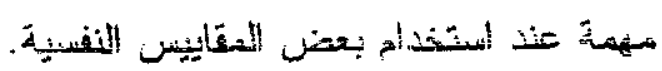


0 - ينبغي أستيعاد أسلوب التحليل العاملي عند التعامل من مقاييس تبني

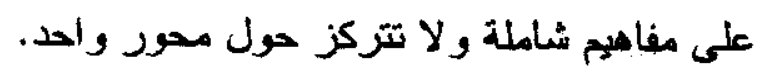

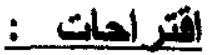

1 يقـتر ح الباحث استخدام مقياسي الانفعالية والانبساط في المجال

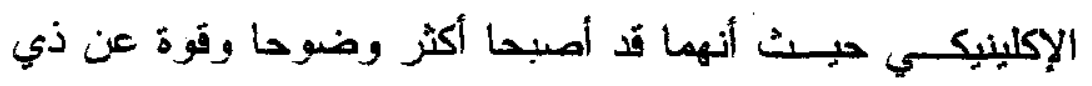

قبل.

r- بجــب التزكيز على مفهوم الحوار الداخلي باعتباره مفهوما محوريا

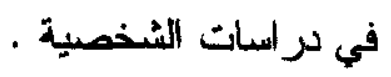

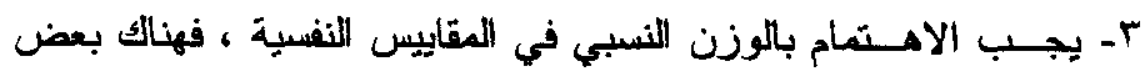

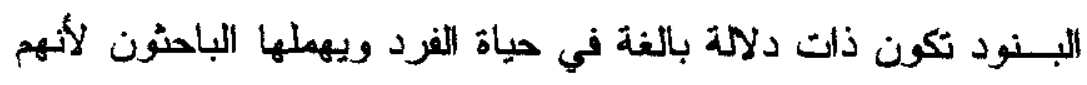
يهتمون بالدرجة الكلية للمقياس فقط ويههلون أهمية البنود المفردة. 


\section{المراجع}

-

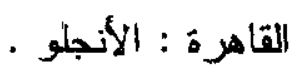

أبو حطب ، ف وصادق ، أ (1997) مناهج البحث وطرق التحليل

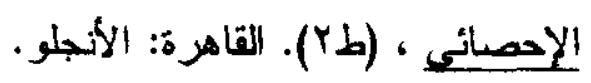

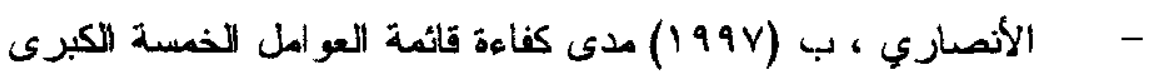

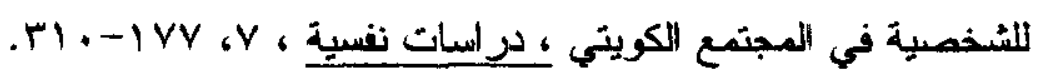

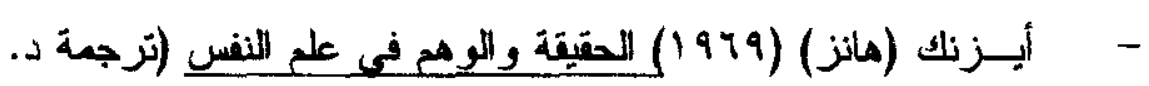
قري حني ورؤوف نظمي)، القاهرة : دار المعارف.

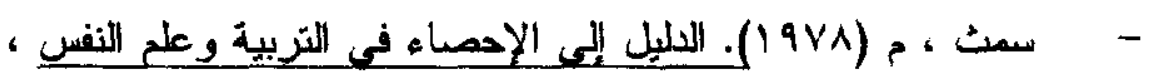

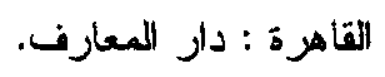

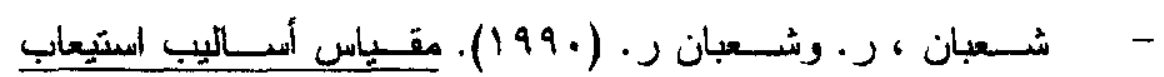

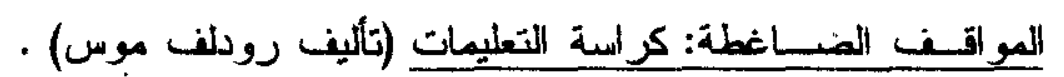
القيوم : مكثبة أم القرى.

- سكري ، م (1999). التقاول والتشاؤم وعلاقتهما بأساليب مواجهة

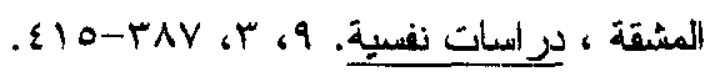

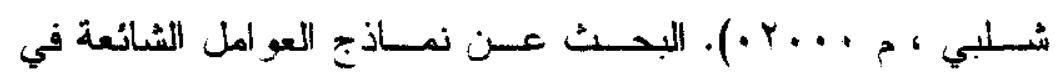

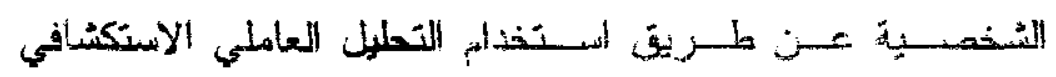

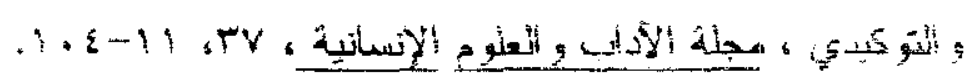


- - شـلبي ، م (1991) النسـبية النفسية. القاهرة : دار الثقافة للنشر واللوزيع.

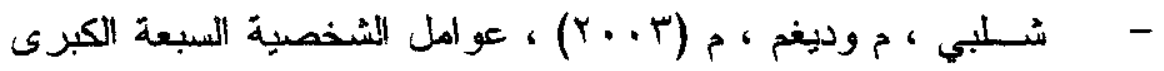

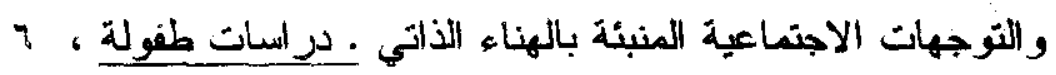

$$
\text { .V.-09، }
$$

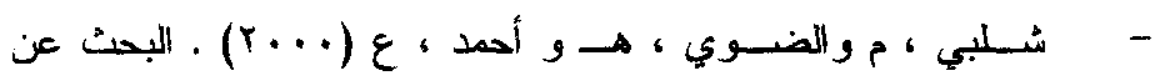

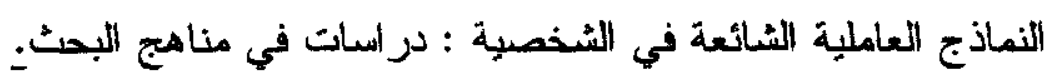

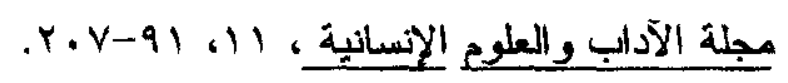

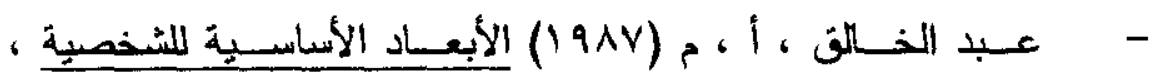
الإسكندرية : دار المعرفة الجامعية. - عـبد الخالف ، أ. (.919) استخبارات الشخصية ، القاهرة : دار المعارف. عـبد الخالق أ ، الأنصاري ، ب (1997) العوامل الخمسة الكبرى

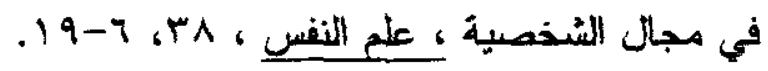

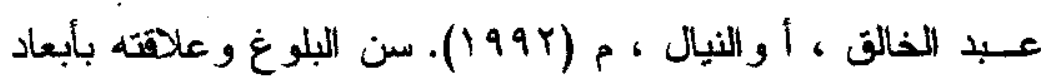

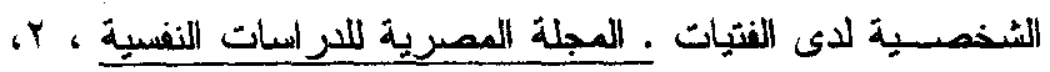

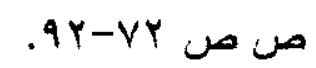

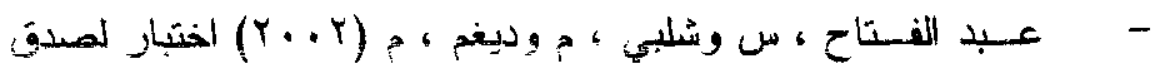

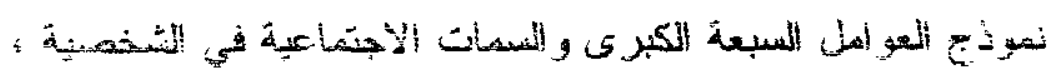

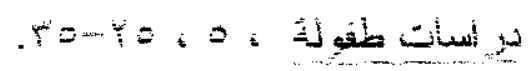




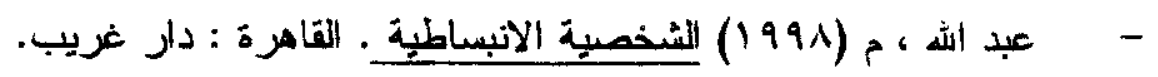

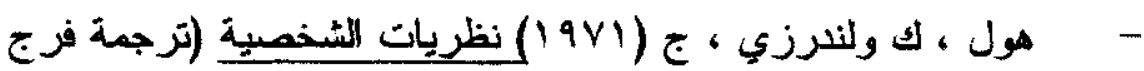

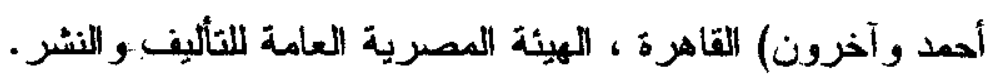

Adelson, J. (1969). Personality. Annual Review of Psychology, 20,217-252.

Aldwin, C. Folkman, s., Schaefer, C., Coyne, J. C., \& Lazaus, R.s (1980). Ways of Coping : A Process Measure. Paper presented at the 88th annual Convention of the American Psychological Associaltion, Montreal, Quebec. (Cited in suls et al., 1996).

Aldwin, C.M., \& Revenson, T.A. (1987). Does Coping help ? A reexamination of the relation between coping and mental health. Journal of Personality \& Social Psychology, 53, 337-348.

Allport, G.W., \& Odbert, H.S. (1936). Trait-names : A psycho- lexical study. Psychological Monographs, 47 ( I, whole No. 211).

Almagor, M., \& Ben-Porath, Y, (1989). The twofactor model of self- reported mood : Acrosscultural replication. Journal of Personality Assessinent, 53, 10-21.

Amirkhan, \& H. (1900). Afactor analytically dirnef measure of roping : the oping 
strategy indicator. Journal of Personality \& Social Psychology, 59, 1066-1074.

Amirkhan, J. H., Risinger, R.T., Swickert, R.J. (1995) Extraversion : A hidden Personality factor in coping? Journal Personality , 63, 189-212.

Bakan, D. (1966). The Duality of Human Existence. Chicago : Rand McNally.

Benet- Maritinez , V., \& Waller, N. G. (1997). Further evidence for cross- cultural generality of the Big Seven Factor Model : Indigenous and imported spanish personality constructs. Journal of Personality, 65, 567598.

Benet - Martinez, V., \& Waller N.G. (1995). The Big Seven Factor Model of personality description ; Evidence for its cross-cultural generality in a spanish sample. Journal of Personality \& Social Psychology, 69, 4, 401718.

Billings, A. G., \& Moos, R.H. (1981). The role of coping responses and social resources in attenuating the stress of life events. Journal of Behavioral \& Medicine, 4, 139-157. 
Bolger, N. (1990). Coping as personality process : A prospective study, Journal of Personality \& Social Psychology, 59, 525-537.

Bolger, N., \& Shilling, E. (1991). Personality and the problems of everyday life : the role of neuroticism in ewposute and reactivity to daily stressors. Journal of Personality, 59, 355-386.

Borgatta, E. F. (1964). The structure of personality characteristics. Behavioral Science, 9, 8-17.

Botwin, M. D. \& Buss, D.M. (1989). Structure of report data : is the five factor model of personality recaptured ? Journal of Personality \&Social Psychology, 56, 9881001.

Breslau, N., Davis, G.C. \& Andreski, p. (1995). Risk factors for PTSD- related traumatic events : A prospective andlysis . American Journal of Psychiatry, 152, 529-535.

Buss, D.M., Gomes, M., Higgins, D.S \& Lauterbach, K. (1987). Tactics of manipulation . Journal of Personality \& social Psychology, 52, 1219-1229.

Caprara, G.V., \& Perugini, M. (1994), Personality described by adjectives: Ceneralsability of 
the Big Five to the Italian lexical context, European Journal of Personality, 8, 357-369.

Carlson, R. (1984). What's social aabout social psychology ? where's the person in personality research? Journal of Personality \& Social Psychology, 47, 6, 1304-1309.

Carlson, R. 91975), Personality, Annual Review of Psychology, 26, 393-413.

Carver, C.S. (1997). You want to measure coping but your protocl's to long: Consider the brief cope . International Journal of Behovioral Medicine, 4, 92-100.

Carver, C.S., Scheier, M,F., \& weintraub, J. K. (1989). Assessing coping srategies : A theoretically based approach. Journal of Personality \& Social Psychology, 56, 267283.

Cattelle, R. B. (1946). The Description \& Measurement of Personality. Yonkers-onHudson, NY: world Book.

Cattell, B.B. (1945). The principal trait clusters for describing personality, Psychological Bulletin, 42, 129-161.

Cattell, R.B, \& Coan, R.W. (1957), Child personality stucture as revealed in teacher's 
rating, Journal of Clinical Psychology, 13, 315-327.

Chang, $\mathrm{E}(1996)$. Cultural differences in optimism, Pessimism and coping : Predictors of subsequent adjustment in Asian American and Caucasian American college students, Journal of Counseling Psychology, 43, 113123.

Cheung, P.C., Conger, A.J., Hau, J. T., Lew, W., \& Lau,s. (1992), Development of the MultiTrait Personality Inventory (MTPT) : Comparison among four Chinese populations. Journal of Personality Assessment, 59, 528-551.

Clark, L.A. (1993). Schedule for Nonadaptive and Adaptive Personality (SNAP): Manual for administration, Scoring, and Interpretation, Minneapolis : University of Minnesota Press

Clark, L.A., \& Watson, D. (1991). Tripartite model of anxiety and depression : Psychometric evidence and taxonomic implications. Journal of Abnormal Psychology, 100, 316336.

Clark, L.A., watson, D., \& Mineka, s. (1994). Temperament, personality, and the mood and 
anxiety disorders. Journal of Abnormal Psychology, 103, $103-116$.

Cohen, F., \& Lazarus, R.s. (1979). Coping wit the stresses of illness, In G.C. Stone, F. Cohen, \& N. E. Adler (Eds.), Health Psychology, San Francisco : Jossey- Bass.

Compas, B.F. Forsythe , C.J., \& Wagner , B.M. (1988). Consistency and variability in causal attributions and coping with stress. Cognitive Therapy \& Research, 12, 305-320.

Costa , P. T., Jr., \& McCrae, R.R. (1989). Personality, stress, and coping : Some lessons from a decade of research. In K.S. Markides \& C.L. cooper (Eds.), Aging, Stress, Social Support and Health, N.Y : Wiley.

Costa, P.T., Somerfield, M.R., \& McCrae, R.R. (1996). Personality and coping : Areconceptu-alization. In M. Zeidner \& N. S Endler (Eds.) Handbook of Coping : Theory, Research, applicantions. Oxford, England : Wiley.

Coyne, J.C., \& Gottlieb, B.tl. (1996) the mismeasure of coping by checklist. Journal of Personality, $64,959-991$ 
Coyne, J.C., \& Racioppo, M.w. (2000) Never the twain shall meet ? closing the gap between coping reseatrch and clinical intervention research American Psychologist, 55, 655664.

DiBlaas, L., \& Forzi, M. (1999). Refining a descriptive structure of personality attributes in the Italian language : the abridged Big three circumplex structure, Journal of Personality \& Social Psychology, 76, 451481.

Digman, S.M. (1997). Higher order factors of the - Big Five. Journal of Personality \& Social Psychology, 73, 124-156.

Digman, J. M. (1990). Personality structure :

Emergence of the five- factor model. Annual

Review of Psychology, 41', 417-440.

Digman, J. M., \& Inouye, J. (1986). Further specification. Of five robust factors of personality. Journal of personality \& Social Psychology, 50, 116-123.

Duke, M., \& Nowicki, S. (1986). Abnormal Psychology: A New Look, N.Y. : Holt

Eckenrode, J. (Ed). (1991), The Social Context of Coping. NY: Plenum. 
Endler, N.S., \& Parker, J. D. (1990). Multidimensional assessment of coping : A critical evaluation. Journal of Personality \& Social Psychology, 58, 844-854.

Epstein, s., \& Katz, L. (1992). Coping ability, stress, productive load, and symptoms, Journal of Personality \& Social Psychology, 62, 813-825.

Eysenck, H. J. (1992). Four ways five factor are not basic. Personality \& Individual Differnces, 6, 667-673.

Eysenck, H.J., \& Eysenck, S.B.G. (1975). Manual of the Eysenck Personality Questionnaire. San Diego: Educational \& Industrial Testing Service.

Eysenck, H. J., \& Eysenck, S.B.G. (1968). Manual for the Eysenck Personality Inventory. San diego : Educaltional \& Industrial Testing Service.

Fennell, M.J.V., \& compbell, E.A. (1984). The cognitive questionnaire : specific thinking errors in depression, British Journal of Clinical Psychology, 23, 81-92.

Fergusson, D.M., \& Horwood, [..], (1987) Vunerability to life events exposure. Parhologed Medicine 17,739-749. 
Fisk, D.W. (1949). Consistency of the factorial structures of personality ratings from different sources. Journal of Abnormal \& Social Psychology, 44, 329-344.

Fleishman, J.A. (1984). Personality characteristis and coping patterns, Journal of Health \& Social Behavior, 25, 229-244.

Fokman, S., \& Lazarus, R.S. (1985). If it changes it must be a process : study of emotion and coping during three stages of a college examination. Journal of Personality\& Social Psychology, 48. 150-170.

Folkman, S., \& lazarus, R.S. (1980). An analysis of coping in a middle aged community sample. Journal of Health \& Social behavvior, 21, 219-239.

Folkman, s., Lazarus, R.S., Dunkel -schetter, c., Delongis, A., Gruen, R.J. (1986). Dynamics of a stressful encounter : Cognitive appraisal, coping, and encoounter outcomes, Journal of Personality \& social Psychology, 50, 9921003.

Folkman, s., \& Moskowitz. J. (2004). Coping : Pitfalls and promise. Annual Review of Psychology, 55, 745-774. 
Gignac, M.M., \& Gottlieb, B.H. (1996). Caregivers' appraisals of efficacy in coping with dementia. Psychology of Aging, 11, 2, 214-225.

Glass, C.R., \& Arnkoff, D.B. (1994). Validity issues in self- statement measures of social phobia and social anxiety . Behavior Research \& therapy, 32, 255-267.

Glass, C.R. \& Arnkoff, D.B. (1998). Questionnaire methods of cognitive self- statement assessment. Journal of Consulting \& Clinical Pssychology, 65, 911-927.

Gosling, S., Rentfrow, P., \& Swann, W.L.(jr) ( 2003). A very brief measure of the big five personality, Journal of Research in Personality, 37, 504-528.

Gough, H.G. (1987) California Psychological Inventory, Palo Alto, CA : Consulting Psychologists Press,

Gunthert, k., Cohen, L., \& Armeli, S. (1999). The role of neuroticism in daily stress and coping. Journal of Personality \& Social Psychology, 77, 1087-1100.

Haan, N, (1977). Coping and Defending: Frocesses of self environment Organization. NY: Academic Pres: 
Haan, N. (1963). Proposed model of ego functioning : coping and defense mechanisms in relationship to IQ change, Psychological Monographs, 77 (8, whole No. 571).

Hart, k. E. (1991). Coping with anger-provoking situations : adolescent coping in relation to anger reactivity. Journal of Adolescent Research, 6, 357-370.

Headey, b., \&Wearing, A . (1989). Personality, life events, and subjective well-being : toward a dynamic equilibrium model . Journal of Personality \& Social Psychology, 57, 731739.

Helson, R., \& Mitchell, V. (1978). Personality, Annual Review of Psychology, 29, 555-585.

Helgeson, V.F. (1994), Relation of agency and communion to well-being : Evidence and potential explanations . Psychological bulletin, 116, 312-428.

Hogan, R (1986). Hogan Personality Inventory Manual._Minneapolis : National Computer Systems.

Hollon, S.D., \& kendall, P.C. (1980). Cognitive self-statements indepression : Development of an Automatic Thoughts Ouestonnaire, Cognitive Therapy \& Research $4, \$ 83-395$. 
Hooker, K., Frazier, L.D., \& Monahan,D.J. (1994).

Personality and coping among caregivers of spouse with dementia. The Gerontologist, 34, 386-392.

Ingram, R.E. kendall, P.C., Sieqle, G., Guarino, J., \& McLaughlin, S.C. (1995). Psychometric properties of the Positive Automatic thoughts Questionnaire, Psychological Assessment, 7, 485-507.

John, O.P., Goldberg, 1.R., \& Angleitner, A. (1984). Better than the alphabet : taxonomies of personality - descriptive terms in English, Dutch, and German, In H.C.J. Bonarims, G.Hek, \& N.Smid (Eds.), Personality Psychology in Europe. Lisse, The Netherlands : Swets \& Zeithlinger.

Katigbak, M.S., Chutch, T., \& Akamine, T.X. (1996). Cross-cultural generalizabiltiy of personality dimensions : relating indigenous and imported dimensions in two cultures. Journal of Personality \& Social Psychology, 70, 99-114.

kendall, P.C. (2000). Differentiating Anxious and depressive self-statement : combined factor structure of the Anxious self-statements questionnaire and the automatic thoughts 
Questionnaire -Revised. Cognitive Therapy \& Research, 24, 327-345.

Kendall, P.C. (1982). Behavioral assessment and methodology, in C.M. franks; G.T.Wilson; P.C. kendall \& K.D. Brownell (Eds.), Annual Review of Behavior Therapy: Theory \& Practice, N.Y. McGraw-Hill.

Kenrick, D.T., \& Funder, D.C.(1988). Profiting from controversy: lessons from the personsituation debate, American Psychologist 43, 23-34.

Lazarus, R.S. (1966). Psychological Stress and the Coping Process. NY : McGraw-Hill.

Lazarus, R.S., \& Folkmaan, S. (1984). Stress, Appraisal and Coping . N Y : Springer.

Livneh, H, Livneh, C. (1996) A multidimensional approach to the study of the structure of coping with stress, Journal of Psychology, 30,5

Lorr, M. (1986). Interpersonal style Inventory Manual . Los Angeles : Western Psychological Services.

Mandel, N.M., \& Shrauger, J.S (1980). The effects of self-evaluative statements on hetrosocial approach in shy and non-shy males. Coytue Therapy Research, 360.381 . 
Monicas, P. \& Secord, P. (1983). Implication for psychology of the new philosophy of science. American Psychologist, 38, 399-413.

Marmor, J. (1981). Systems thinking in psychiatry, American Journal of Psychiatry, 140-833845

Maner, J.D., \& Gaschke, Y. N. (1988). The experience and meta-experience of mood. Journal of Personality \& Social Psychology, 55, 1092-1111.

McCrae, R.R. (Ed.). (1992). The Five-Factor Model : Issues and applications. Journal of Personality, 670 (2).

McCrae, R.R. (1984). Situational determinants of coping responses : loss, threat, and challenge. Journal of Personality \& Social Psychology, 46, 919-928.

McCrae, R.R., \& Costa, P.T., Jr, (1987). Validation of the Five -Factor Model of personolity across instruments and observers. Journal of Personality \& Social Psychology, $54,81-90$.

McCrae, R.R., \& Costa, P.T., Jr. (1986). Personality coping, and coping effectiveness in an adult sample Journal of Personality 54, 385405 
McCrae, R., Costa, P., Martin, T. Orgole, V., Rukaavishnikove, a., Senin, I., Hrebickova , M., Urbanek, T. (2004). Consensual validation of personality traits across cultures. Journal of Research in Personality $38,179-201$

Matlin, J.A., Wethington, E., \& Kessler, R.X.(1990). Situational determinantes of coping and coping effectiveness. Journal of Health \& Social Behavior 31, 103-122

Meyer, G.J., \& shack, J.R. (1989). The structural convergence of mood and personality : Evidence for old and new directions. Journal of Personality \& Social Psychology, 57, 691-706.

Moos, R.H. (1992). Coping Response Inventory Manual. Palo Alto, CA : center for Health care Evaluation, Department of Veteran Affairs \& Stanford University Medical Centers.

Norman, W.T. (1963). Toward an adequate taxonomy of personality attributes: Replicated factor structure in peer nomination personality ratings. Journal of Abnormal \& Social Psychology, 66, 574583. 
Norman, W.T., \& Goldberg,, L.R. (1966). Raters. Ratees, and randomness in personality structure. Journal of Personality \& Social Psychology, 4, 681-691.

Magley, V.J. (2002). Coping with sexual Harassment; Reconceptualizing women's resistance Journal of Personality \& Social Psychology, 83, 930-946.

Ntoumanis, M., \& Biddle, S.H. (1998). The relationship of coping and its perceived effectives to positive and negative effect in sport. Personality \& Individual Differences, 24, 773-788.

O'Brien, T.B., \& Delongis, A. (1996). The interactional context of problem, emotion, and relationship- focused coping : the role of the Big five personality factors. Journal of Personality, 64, 4, 773-813

Ormel, J., \& Wohlforth, T. (1991). How neuroticism, Long- term difficulties and life situation change influence psychological distress : A longitudinal model. Journal of Personality \& Social Psychology, 60, 744755.

Parker, J.A., Endler, N.S., \& Babdy, R.M. (1993). If it changes it might be unstable : Examining 
the factor structure of the ways of coping questionnair, Psychological Assessment, 5, 361-368.

Paker, J. \& Endler, N. (1992). Coping with coping assessment : A critical review. European Journal of Personality, 6, 321-345.

Parkes, K.R. (1986). Coping in stressful episodes: the role of the individual differences, environmental factors, and situational characteristics. Journal of Personality \& Social Psychology, 51, 1277-1292.

Peabody, D., \& Goldberg, L.R. (1989). Some determinants of factor structures from personality -trait descriptors. Journal of Personality \& Social Psychology, 57, 552567.

Pearlin, L.I., \& Schooler, C. (1978). The structure of coping. Journal of Health \& Social Behavior, 19, 2-21.

Phares, E.J., \& Lamiell, J.T. (1977). Personality. Annual Review of Psychology, 28, 113-140.

Pracek, J.T., Smith, R.E., Espe, K., \& Raffety, B.(1994). Limited correspondence between daily coping reports and retrospective coping recall. Psychological Assessment, 6, 41:49. 
Ratsep, T., Kallasmaa, T., Pulver, A., \&GrossPaju, K. (2000). Personality as a predictor of coping efforts in patients with multiple sclerosis. Multiple Sclerosis, 6, 397-402.

Revenson, T.A. (1981). Coping with loneliness : the impact of causal attributions. Personality and social Psychology Bulletin, 7, 565-571.

Rim, Y. (1987). A comparative study of two to anomies of coping, personality, and sex. Personality and Individual Differences, 8, 521-526.

Rim, Y. (1986). Ways of coping, personality, age, sex and family structural variables. Personality \& Individual Differences, 7, 113116.

Sanford, N. (1982). Social psychology : its place in personalogy. American Psychologist, 37, 896-903.

Scheier, M.f., Carver, C.S., \&Bridges, M.W. (1994). Distinguishing optimism from neuroticism: A reevaluation of the life orientation Test. Journal of Personality \& Social Psychology, 67, 1063-1078.

Schwartz, R.M., \& Gottman, J.M. (1976). Toward a task analysis of assertive behavior, Journal 
of Consulting \& Clinical Psychology, 44, 910-920.

Schwartz, J.E., Neale, J., Marco, C., Shiffman, S.S., \& Stone, A.A. (1999). Does trait coping exist? Amomentary assessment approach to the evaluation of traits. Journal of Personality \& Social Psychology, 77, 360-369.

Schwarzer, R., \& Schwarzer, C. (1996). Acritical survey of coping instrument, In M. zeidner \& N.S. Endler (Eds). Handbook of coping : theory, Research, Application's .Oxford, England : Wiley.

Schwartz, J.E., \& Stone A.A. (1993). Coping with daily work problems: contributions of problem content, appraisals, and person factors. Work \& Stress, 7, 47-62.

Skinner, E.A., Edge, K,. Altman, J., \& Sherwoord, H. (2003) Searching for the structure of coping : A review and critique of category systems for classifying ways of coping. Psychological Bulletin, 129, 216-269.

Somer, O., \& Goldbery, L.R. (1999). The structure of Turkish trait-descriptive adjective, Journal of Personality \& Social Psychobgy, 76 , $431-450$. 
Somerfield, M.R., \& McCrae, R.R. (2000). Stress and coping research : Methodological challenges, theoretical advances, and clinical application, American Psychologist, 55, 6, 620-625.

Stanton, A.L., Donoff-Burg, S., Cameron, C.L., \& Ellis, A.B. (1994). Coping through emotional approach : Problems of conceptualization and confounding. Journal of Personality \& Social Psychology, 66, 350-362.

Stanton, A.L., kirk, S.B., Comeron, C.L., \& Danoff-Burg, S. (2000). Coping through emotional approach : Scale construction and validation. Journal of Personality \& Social Psychology, 78, 1150-1169.

Stone, A.A., \& Kennedy-Moore, E. (1992). Comentary to part three : Assessing situational coping : Conceptual and methodological con side rations. In H.S. Friedman (Ed.), Hostility, Coping, and Health. Washington : American Psychological Association.

Stone, A.A., \& kennedy - Moore, E. (1992). Assessing situational coping: conceptual and empirical considerations. In H.S. Friedman (Ed) Hostility Coping and Health, 
washington, D C : American Psychological Association.

Stone, A.A., \& Neale, J.M. (1984). New measure of daily coping: Development and preliminary results. Journal of Personality \& Social Psychology, 46, 892-906.

Stone, A.A., Schwartz, J.E., Neale, J.M., shiffman, S., Marco, C A, (1998). A comparison of coping assessed by ecological momentary assessment and retrospective recall. Journal of Personality \& Social Psychology, 74, 1670-1680.

Suls, J., David, J.P., \& Harvey, J.H. (1996). Personality and coping : three generations of research. Journal of Personality 64, 4, 711735.

Tamres, K., Denise, J., \& Helgeson, S. (2002). Sex differences in coping behavior : Ametaanalytic review and an examination of relative coping, Personality \& Social Psychology Review, 6, 1-18

Tellegen, A. (1993). Folk concepts and psychological concepts of personality and personality disorder. Psychological Inquiry, $4,122-130$. 
Tellegen , A. (1985). Structures of mood and personality and their relevance to assessing anxiety, with an emphasis on self-report. In A.H. Tuma \& J.D. Maser (Eds.), Anxiety and Anxiety Disorder. Hillsdale, $\mathrm{N} \mathrm{J}$ : Erlbaum.

Tellegen, a., Grove, W.M,. \& waller, N. G. (1991). Inventory of personel Characteristics 7 (IPC-7). Unpublished materials, Univ. of Minnesota.

Tennen, H., \& Affleck, G. (1996). Daily processes in coping with chronic pain : Methods and analytic strategies In M. Zeidner \& N.S. Endler (Eds). Handbook Of Coping: Theory, Research, Applications . Oxford, England : Wiley.

Tennen, H., Affleck, G., Armeli, S. \& Carney, M. A. (2000). A daily process approach to coping. Linking theory research and practice, American Psychologist, 55, 626-636.

Terry, D.J (1994). Determinants of coping : the role of stable and situational factors, Journal of personality \& Social Psychology, 66, 895-910.

Tupes, E.C., \& Christal, R.E. (1992). Recurrent personality factors based on trait ratings. Journal of Personality , 60, 225-251 
Vaillant, G.E. (1994). Ego mechanisms of defense and personality psychopathology, Journal of Abnormal Psychology, 103, 44-50.

Vickers, R.R., Jr., kolar, D.W., Hervig, L.K. (1989). Personality correlates of Coping with Military Basic Training (rep. No. 89-3). San Diego : Naval Health Research Center.

Vitalino, P.P., Russo, J., Carr, J.E., Maiuro, R.D., \& Becker, J. (1985). The ways of coping checklist ; Revision and psychometric properties. Multivariate Behavioral Research, 20, 3-26.

Watson, D. (1988). The vicissitudes of mood measurement ; Effects of varying descriptors, time frames, and response formats on measures of positive and Negative Affect. Journal of personality \& Social Psychology, $55,128-141$.

Watson, D., \& Clark, L.A. (1993). Behavioral disinhibition versus constraint: A dispositional perspective, In D.M. weagner \& J.W. Penne baker (eds.) Handbook of Mental Control. N.Y. : Prentice - Hall.

Watson, D., \&Clark, L.A. (1992). On traits and temperament ; General and specific factors of enotional experience and their relation to the 
five-factor model. Journal of personality 60 , 441-476

Watson, D., \& Clark, L.A. (1984). Negative affectivity : the disposition to experience aversive emotional states. Psychological Bulletin, 96, 465-490.

Watson, D., Clark, L.A., \& Harkness, A.R. (1994). Structures of personality and their releance to psycho pathology, Journal of Abnormal Psychology, 103, 18-31.

Watson, D., Clark, L.A., McIntyre, C.W., \& Hamaker, S. (1992). Affect, personality, and social activity, Journal of Personality \& Social Psychology, 63, 1011-1025.

Watson, D., \& Hubbard, B. (1996). Adaptational style and dispositional structure : coping in the context of the five-factor model. Journal of Personality 64, 737-774.

Watson, D., \& Tellegen, A. (1985). Toward a consensual structure of mood, Psychological bulletin, 98, 219-235.

Wethington, E., \& Kessler, R.C. (1991) Situations and processes in coping, In J. Eckenrode (Ed), the Social Context of Coping. N Y: plemm 
Wiggins, J.S., \& Trapnell, P.D (1996) Adyadic interactional perspective on the Five - Factor Model. In J.S. Wiggins (Ed.). The FiveFactor Model of Personality: Theoretical Perspectives. N Y : Guilford.

Zantra, A.J., Sheets, V.L., \& Sandler, I.N. (1996) An examination of the construct validity of coping dispositions for a sample of recently divorced mothers. Psychological Assessment, 8, 256-264.

Zeidner, M., \& Saklofske, D. (1996). Adaptive and maladaptive coping. In M. Zeidner N.S. Endler, Handbook of Coping. N Y : Wiley.

Zuckerman, M., \& Gagne, M.(2003). The COPE revised: Proposing a 5-factor model of coping strategies, Journal of Research in Personality, 37, 169-204. 
ملق (1) تصنيف بنود أمم أربعة مقاييس على بعد العصابية

\begin{tabular}{|c|c|c|c|c|c|}
\hline \multirow[b]{2}{*}{ 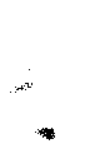 } & IPC-7 & & & & \\
\hline & $\sigma$ & & $\bar{T}$ & $\sigma$ & تقلب المزاج \\
\hline$*$ & $\bar{r}$ & & & $\bar{c}$ & التعاسة \\
\hline 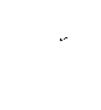 & & $\checkmark$ & $\bar{v}$ & 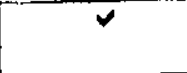 & القلق \\
\hline 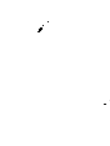 & $\bar{v}$ & $\checkmark$ & $r$ & $r$ & النزفزة \\
\hline \multirow[t]{5}{*}{ " } & 5 & $\bar{v}$ & & 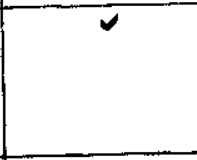 & الحساسية تجرح \\
\hline & & & & $\checkmark$ & الز هقان \\
\hline & & & $\checkmark$ & $\checkmark$ & التشاؤ \\
\hline & & & & 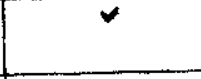 & اضطر اب النوم \\
\hline & & & & $\checkmark$ & الإرهاق \\
\hline \multirow{3}{*}{-} & & & & $v$ & الحباة مملة \\
\hline & & & & $\checkmark$ & تمنى الموت \\
\hline & & & & $\checkmark$ & تلق شديد \\
\hline \multirow[t]{2}{*}{. } & & & & $\sigma$ & الاضطر اب النفسي \\
\hline & & & & $\checkmark$ & الشعوز بالوحدة \\
\hline \multirow{2}{*}{ r } & & & $v$ & & الخون الشديد \\
\hline & & $\checkmark$ & & & الكآبة \\
\hline \multirow{3}{*}{, } & & $\sigma$ & 5 & & الخجل \\
\hline & $w^{2}$ & $\sigma$ & & & 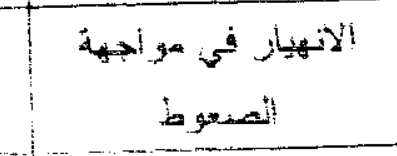 \\
\hline & & & & & لإذهنب \\
\hline
\end{tabular}




\begin{tabular}{|c|c|c|c|c|}
\hline$\overline{\mathrm{IPC}-7}$ & $\begin{array}{l}\text { NEO } \\
\text { FFl-R }\end{array}$ & BFI & $\mathrm{EPQ}$ & \\
\hline & $\checkmark$ & & & العجز وتلة الحيلة \\
\hline & 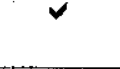 & & & الضحكك بسهرلة \\
\hline & $\checkmark$ & & & الابتهاج \\
\hline & $\checkmark$ & & & سرعة مرور الوتَت \\
\hline 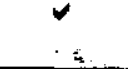 & & & & علاقات دافتة \\
\hline$r$ & & & & كتم الأسراد \\
\hline 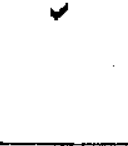 & & & & تلقائي لا بفكر في \\
\hline & $\checkmark$ & & & الانشغال بالآخرين \\
\hline
\end{tabular}


ملحن (Y) تطيل المقاييس الأربعة فيما يتعلق بالانبساط

\begin{tabular}{|c|c|c|c|c|c|}
\hline \multirow[b]{3}{*}{ 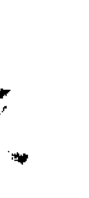 } & IPC-7 & $\mathrm{NEO}$ & PF 1 & $\mathrm{EPQ}$ & \\
\hline & & & & $\checkmark$ & هو ايات كثيرة \\
\hline & $\checkmark$ & $\checkmark$ & $\checkmark$ & $\bar{v}$ & كثرة الكلام \\
\hline \multirow[b]{2}{*}{ 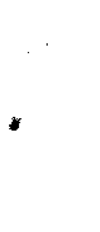 } & $\checkmark$ & $\checkmark$ & $\checkmark$ & $\checkmark$ & نشيط وحيوي \\
\hline & $\checkmark$ & & & $\checkmark$ & $\begin{array}{c}\text { المشاركة في الأنشطة } \\
\text { الاجتماعية }\end{array}$ \\
\hline \multirow{2}{*}{. } & $\checkmark$ & $\checkmark$ & & $\checkmark$ & تفضيل مقابلة \\
\hline & & & & $\checkmark$ & مداقات كثيرة \\
\hline \multirow{2}{*}{ 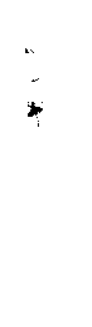 } & . & & & $\checkmark$ & غير مهموم \\
\hline & & & & $\checkmark$ & بالتعرف على أمبادرة \\
\hline * & $\checkmark$ & $\checkmark$ & $\checkmark$ & $\checkmark$ & خفة الظلل \\
\hline $\begin{array}{l}\boldsymbol{P} \\
:\end{array}$ & & & & $\checkmark$ & السرعة في \\
\hline 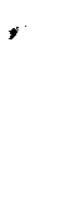 & & & & $\checkmark$ & الانشغالل بأكير \\
\hline 3 & . & & $\checkmark$ & & 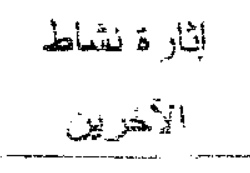 \\
\hline
\end{tabular}




\begin{tabular}{|c|c|c|c|c|}
\hline IPC-7 & NEO & PF1 & EPQ & \\
\hline & & $\checkmark$ & & مؤكد \\
\hline & $\checkmark$ & & & الفرح \\
\hline & $\checkmark$ & & & تفاول \\
\hline$\checkmark$ & & & & الشعور بالذنب \\
\hline$\checkmark$ & & & & المز الأكار \\
\hline$\checkmark$ & & & & غر ابة الأطو أر \\
\hline & & $\checkmark$ & & الاسترخاء \\
\hline
\end{tabular}

